\title{
American Thoracic Society/European Respiratory Society: Standards in Diagnostik und Therapie bei Patienten mit Alpha-1-Antitrypsin-Mangel
}

\author{
American Thoracic Society/European Respiratory Society Statement: \\ Standards for the Diagnosis and Management of Individuals \\ with Alpha-1 Antitrypsin Deficiency
}

Planungs- und

Exekutiv-Kommittee:

J. K. Stoller, G. L. Snider (Co-Chairs),

M. L. Brantly, R. J. Fallat,

R. A. Stockley

Lungenerkrankungen:

G. M. Turino, N. Konietzko (Co-Chairs),

A. Dirksen, E. Eden,

R. J. Fallat, M. Luisetti,

J. Stolk, C. Strange

Inhalt

\section{Zusammenfassung}

Einleitung

Ziele, Organisation des Projektes und Zeitplan

Zusammenfassung der wichtigsten Empfehlungen der Arbeitsgruppe

zur Diagnose und Behandlung des Alpha-1-Antitrypsin-Mangel

Klinische Erkennung des Alpha-1-Antitrypsin-Mangels . . . . . . . 38

Genetische Testung auf Alpha-1-Antitrypsin-Mangel . . . . . . . . 38

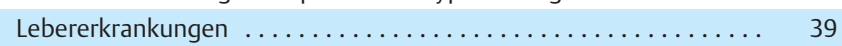

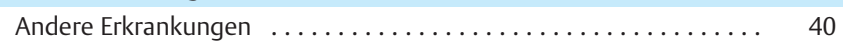

Wirksamkeit der Substitutionstherapie . . . . . . . . . . . . 40

Allgemeines Management bei obstruktiver Atemwegserkrankung .. 40

Literatur ............................... 41

Lungenerkrankung
Erstellung dieses Dokuments $\ldots \ldots \ldots \ldots \ldots \ldots \ldots \ldots \ldots . \ldots \ldots \ldots$

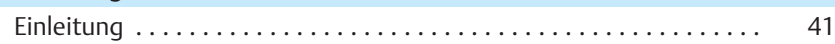

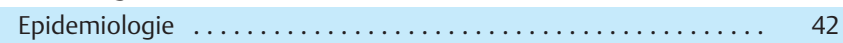

Pathophysiologie des Alpha-1-Antitrypsin-Mangels .......... 42

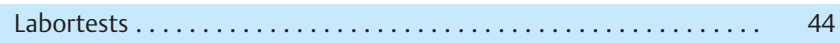

Erkennung von Individuen mit Alpha-1-Antitrypsin-Mangel ...... 45

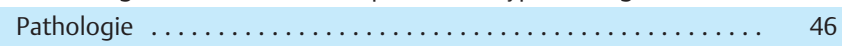

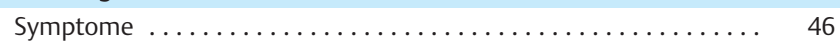

Klinische Befunde ........................... 47

Lungenfunktionsuntersuchungen................. 47

Bildgebende Verfahren (einschließlich Computertomographie und

Ventilations-Perfusionstherapie) $\ldots \ldots \ldots \ldots \ldots \ldots \ldots \ldots \ldots . \ldots \ldots$

Verlaufsparameter: $\mathrm{FEV}_{1}$, Desmosine Computertomographie ..... 49

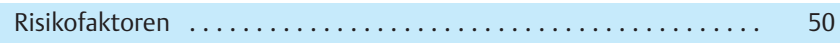

\begin{tabular}{|c|c|}
\hline Inhalt & Seite \\
\hline Krankheitsverlauf & 51 \\
\hline $\begin{array}{l}\text { Risiken der MZ- und SZ-Phenotypen für die Entwicklung von Lungen- } \\
\text { emphysem und COPD } \ldots \ldots \ldots \ldots \ldots \ldots \ldots \ldots \ldots \ldots \ldots \ldots \ldots \ldots\end{array}$ & 53 \\
\hline Prognose $\ldots \ldots \ldots \ldots \ldots \ldots \ldots \ldots \ldots \ldots \ldots \ldots \ldots \ldots \ldots$ & 55 \\
\hline Prävention von Lungenerkrankung $\ldots \ldots \ldots \ldots \ldots \ldots \ldots$ & 55 \\
\hline Allgemeine medizinische Behandlung $\ldots \ldots \ldots \ldots \ldots \ldots \ldots$ & 56 \\
\hline Substitutionstherapie $\ldots \ldots \ldots \ldots \ldots \ldots \ldots \ldots \ldots \ldots \ldots \ldots \ldots \ldots \ldots$ & 56 \\
\hline Operative Maßnahmen $\ldots \ldots \ldots \ldots \ldots \ldots \ldots \ldots \ldots \ldots \ldots$ & 58 \\
\hline Spezielle Situationen $\ldots \ldots \ldots \ldots \ldots \ldots \ldots \ldots \ldots \ldots \ldots \ldots \ldots \ldots \ldots \ldots$ & 59 \\
\hline $\begin{array}{l}\text { Zukünftige Richtung in der Forschung bei Alpha-1-Antitrypsin- } \\
\text { Mangel }\end{array}$ & 59 \\
\hline Spezieller Forschungsbedarf bei Alpha-1-Antitrypsin-Mangel $\ldots . .$. & 61 \\
\hline Literatur $\ldots \ldots \ldots \ldots$ & 62 \\
\hline
\end{tabular}

Zur Zusammensetzung der Arbeitsgruppe siehe Tabelle am Ende der Arbeit. Dieses Statement wurde gemeinsam von einer Arbeitsgruppe der ATS/ERS entwickelt. Die Veröffentlichung dieses Statements wurde zum Teil unterstützt durch die Alpha-1-Foundation und durch Aventis Behring, LLC. Weitere Unterstützung erfolgte durch die American Thoracic Society, die European Respiratory Socienty, das American College of Chest Physicians und die American Association for Respiratory Care.

Mitglieder des ad hoc Statement Komitees haben jegliche direkte kommerziellen Verbindungen (finanzielle Verbindungen oder gesetzliche Verpflichtungen) offengelegt, die mit der Vorbereitung dieses Statements verbunden sind. Die Information kann am ATS Headquarter eingesehen werden.

Darüber hinaus wurde ähnlich wie bei Lungenkrankheiten eine Arbeitsgruppe eingesetzt zum Thema „Leber und andere Erkrankungen“ und eine Arbeitsgruppe zum Thema „Genetische Testung auf Alpha-1-Antitrypsin-Mangel: ethische, legale, psychologische, soziale und ökonomische Aspekte“. Beide wurden nicht für die Übersetzung ins Deutsche vorgesehen. Der interessierte Leser sei aber auf die beiden profunden Publikationen hingewiesen.

Anmerkung

Dieses gemeinsame Statement der American Thoracic Society und der European Respiratory Society wurde vom ATS Board of Directors im Dezember 2002 und vom Executive Committee der ERS im Februar 2003 gebilligt.

Originalpublikation

American Thoracic Society/European Respiratory Society: Standards for the Diagnosis and Management of Individuals with Alpha-1-Antitrypsin Deficiency. Am J Respir Crit Care Med 2003; 168: 818 - 900,. Übersetzer: Prof. Dr. med. Nikolaus Konietzko, Essen

Korrespondenzadresse

Prof. Dr. med. Nikolaus Konietzko · Spillheide 78 · 45239 Essen ·E-mail: Nikolaus.Konietzko@t-online.de

Bibliografie

Pneumologie 2005; 59: 36-68 @ Georg Thieme Verlag KG Stuttgart · New York

DOI $10.1055 / \mathrm{s}-2004-830176$

ISSN 0934-8387 


\section{Zusammenfassung}

\section{Einleitung}

Seit dem ersten Statement der American Thoracic Society zur Diagnose und Therapie des schweren Alpha-1-Antitrypsin-Mangels im Jahre 1989 [1] und den ursprünglichen Standards der Canadian Thoracic Society aus dem Jahre 1992 [2], (welche 2001 neu überarbeitet wurden), [3], konnten wichtige Fortschritte im Verständnis der zellulären und molekularen Biologie des Alpha1-Antitrypsin-Mangels und bei Diagnose, Verlauf und Behandlung von Patienten mit Alpha-1-Antitrypsin-Mangel erzielt werden. Diese neuen Erkenntnisse zusammen mit der Fertigstellung zweier großer europäischer und nordamerikanischer Longitudinal-Studien und einer kleinen randomisierten, kontrollierten Studie zur Substitution mit Alpha-1-Antitrypsin haben uns wichtige, neue Einsichten vermittelt, die für die klinische Behandlung von Individuen mit schwerem Alpha-1-AntitrypsinMangel bedeutsam sind.

Im Zusammenhang mit diesen neuen Entwicklungen wurde die Notwendigkeit gesehen, die Empfehlungen zur optimalen Behandlung des Alpha-1-Antitrypsin-Mangels zu überarbeiten; dabei sollte unser derzeitiges Wissen von Diagnose und Behandlung für den praktizierenden Kliniker zusammengefasst und die entscheidenden offenen Fragen zur weiteren Erforschung der Erkrankung herausgearbeitet werden. Mit dieser Intention erfolgte 1998 die Gründung einer Arbeitsgruppe zur Entwicklung eines neuen Standarddokumentes zur Diagnose und Behandlung von Individuen mit schwerem Alpha-1-Antitrypsin-Mangel unter Führung der American Thoracic Society und der European Respiratory Society und zusätzlicher Unterstützung der Alpha-1-Foundation, des American College of Chest Physicians und der American Association for Respiratory Care. Aufgrund einer vertraglichen Vereinbarung wurden vom „Office of Patient Care Services“ des „Veterans Administration Technology Assessment Program" alle Unterlagen zur Vorbereitung eines Evidenz basierten Dokumentes herausgesucht und die Autoren bei der Literatursuche unterstützt.

Um mit den laufenden Standards zur Entwicklung einer Evidenz basierten Empfehlung zur optimalen Behandlung Schritt zu halten, unternahm die Arbeitsgruppe eine systematische Suche der laufenden Literatur zum Thema „Alpha-1-Antitrypsin-Mangel“. Es wurde große Mühe darauf verwendet, die wissenschaftliche Evidenz für die jeweilige Stellungnahme darzulegen, aber auch Bereiche aufzuzeigen, bei denen es keine oder wenig Evidenz gab. Bei Fehlen jeglicher Evidenz wurden unter den Mitgliedern der Arbeitsgruppe die Empfehlungen im Konsens erstellt.

Die vorliegende Zusammenfassung beschreibt in Kürze die Organisation der Arbeitsgruppe, die Vorbereitung des Berichts und die wichtigsten klinischen Empfehlungen. In den drei folgenden Abschnitten werden die kompletten, systematischen Berichte der drei Autorengruppen zu den Themen „Lungenerkrankungen“, „Leber und andere Erkrankungen“ und „Genetische Testung auf Alpha-1-Antitrypsin-Mangel: ethische, legale, psychologische, soziale und ökonomische Aspekte“ widergegeben. Für die vorliegende Übersetzung ins Deutsche wurde nur das Thema „Lungenkrankheiten“ ausgewählt.
Ziele, Organisation des Projektes und Zeitplan

Ziel der Arbeitsgruppe Alpha-1-Antitrypsin-Mangel war es, für Ärzte und interessierte Laien die gegenwärtige, wohl durchdachte Ansicht einer großen internationalen Expertengruppe zur aktuellen Diagnostik und Behandlung von Personen mit Alpha1-Antitrypsin-Mangel vorzubereiten und darzustellen. Dabei wurde in Form eines systematischen Überblicks ein Evidenz basierter Ansatz angewendet. Die Arbeitsgruppe berücksichtigte bei der Evaluation alle klinischen Aspekte dieser Multiorganerkrankung unter Einschluss der Manifestationen von Lunge, Leber und anderer Organe. Des weiteren wurden die Implikationen ethischer, legaler, sozialer, psychologischer und ökonomischer Art im Zusammenhang mit der genetischen Testung des Alpha1-Antitrypsin-Mangels thematisiert.

Eine Planungsgruppe wurde im Herbst 1997 zusammengerufen, nachdem die Unterstützung und Finanzierung durch größere Sponsoren - die American Thoracic Society, die European Respiratory Society und die Alpha-1-Foundation - feststand. Zusätzliche Unterstützung kam von der Alpha-1-Foundation, dem American College of Chest Physicians und der American Association for Respiratory Care. Mit ihrer Hilfe konnte das Planungskomitee die Mitglieder der Arbeitsgruppe auswählen und das Projekt weiterführen.

Wie in Abb. 1 dargestellt, bestand die Arbeitsgruppe Alpha-1-Antitrypsin-Mangel aus einem Exekutive Kommitee, drei unterschiedlichen Autorengruppen mit internationalen Experten und einem Lenkungsausschuss, der zusammengesetzt war aus dem Exekutive Kommitee und den Vorsitzenden der jeweiligen Autorengruppen. Die Vorbereitung der systematischen Literatursuche wurde unterstützt von Mitgliedern des „Health Care Technology Assessment Program“ des „Department of Veterans Affairs“, die laufend die Literatur ergänzten und die bei dem Projekt die Federführung auch in Sachen Literatursuche und bei der Methodik der „evidence-based medicine“ die Federführung übernahmen. Die American Thoracic Society leistete administrative Hilfe.

Die Zusammensetzung der Arbeitsgruppe wurde im September 1998 festgelegt, zu diesem Zeitpunkt begannen die Autorengruppen auch die Literatursuche und die Erstellung der Dokumente, die dann anschließend vom Lenkungsausschuss durchgesehen wurden. Der Lenkungsausschuss organisierte mehrere Telefonkonferenzen und fünf „face-to-face“-Treffen zwischen Herbst 1998 und Herbst 2001, zur Überprüfung der erarbeiteten Dokumente.

Die Dokumente der einzelnen Autorengruppen waren im Herbst 2001 abgeschlossen, wurden zur endgültigen Stellungnahme dem Exekutivkomitee vorgelegt und anschließend an die fördernden Organisation weitergegeben.

Die Gutachten waren im Juni 2002 abgeschlossen und die revidierten Dokumente wurden im Herbst 2002 zur endgültigen Genehmigung eingereicht. Diese Genehmigung wurde durch das American Thoracic Society im Dezember 2002 erteilt, zu diesem Zeitpunkt wurde eine zusätzliche Literatursuche erstellt und eine letzte Aktualisierung des Dokumentes erreicht. 


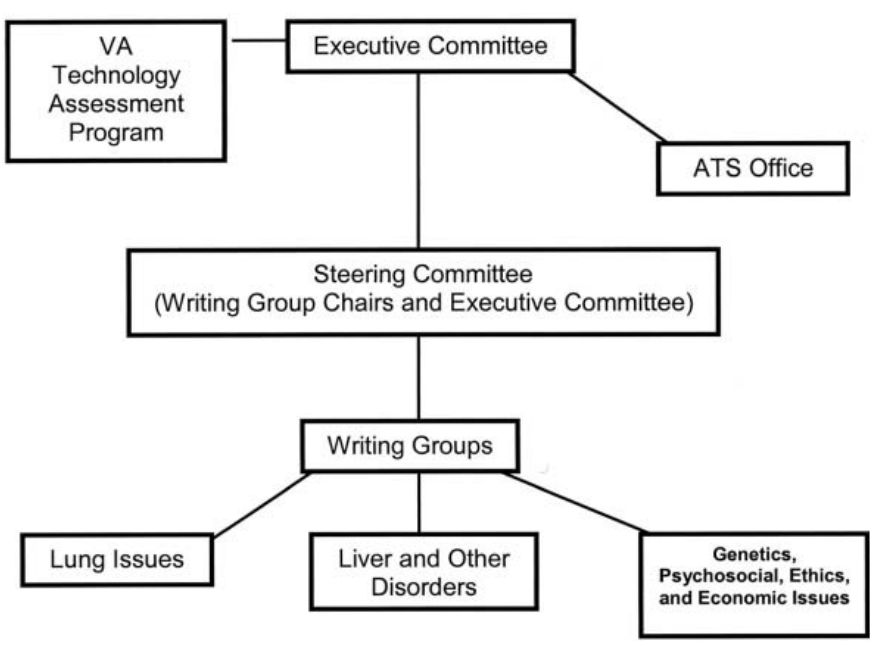

Abb. 1 Struktur der „Alpha-1-Antitrypsin Deficiency Task Group“.

Während das Exekutivkommitee bemüht war, Überlappungen zwischen den drei Dokumenten zu vermeiden, führte das erklärte Ziel der Arbeitsgruppen, jedes der drei Dokumente in sich abgeschlossen mit eigenem Schwerpunkt, eigenem Literaturverzeichnis und zusätzlichen Tabellen und Abbildungen zu erstellen, unweigerlich zu einigen Überschneidungen.

Schließlich war der Arbeitsgruppe klar, dass angesichts weiterer Fortschritte in der Forschung und damit auch der Weiterentwicklung unseres derzeitigen Wissensstands zum Thema Alpha1-Antitrypsin-Mangel und seiner optimalen Behandlung eine regelmäßige Überarbeitung und Aktualisierung der Empfehlungen unumgänglich sind.

Zusammenfassung der wichtigsten Empfehlungen der Arbeitsgruppe zur Diagnostik und Behandlung des Alpha-1-Antitrypsin-Mangels

\section{Klinische Erkennung des Alpha-1-Antitrypsin-Mangels}

Nach den vorliegenden Erkenntnissen muss man annehmen, dass der PI*ZZ AAT-Mangel häufig durch Kliniker in ungenügendem Ausmaß erkannt oder fehldiagnostiziert wird. Die folgenden Hinweise sollten beim Arzt den Verdacht erwecken, dass sein Patient einen Alpha-1-Antitrypsin-Mangel haben könnte:

- Früh-Manifestation eines Emphysems (Alter von 45 Jahren oder jünger)

- Lungenemphysem in Abwesenheit von bekannten Risikofaktoren (Rauchen, berufliche Staubexposition, etc.)

- Emphysem mit vorwiegend basaler Lungenüberblähung

- Anderweitig nicht erklärbare Lebererkrankung

- Nekrotisierende Panniculitis

- Anti-proteinase 3-positive Vaskulitis (C-ANCA = anti-neutrophile zytoplasmatische Antikörper-positive Vaskulitis)

- Familienanamnese mit einer der folgenden Erkrankungen: Lungenemphysem, Bronchiektasen, Lebererkrankung oder Panniculitis

- Bronchiektasen ohne erkennbare Ursache (siehe unten).
Es sei bemerkt, dass die Arbeitsgruppe sich der widersprüchlichen Aussagen von Studien über den Zusammenhang von Bronchiektasen und Alpha-1-Antitrypsin-Mangel wohl bewusst war und dass deswegen die Empfehlung, bei Patienten mit Bronchiektasen ohne erkennbare Ursache auf Alpha-1-AntitrypsinMangel zu testen, ebenso akzeptiert wie abgelehnt werden kann.

\section{Genetische Testung auf Alpha-1-Antitrypsin-Mangel}

Wohl wissend, dass die Diagnose eines Alpha-1-AntitrypsinMangels bei der betroffenen Person nicht unproblematisch ist (z.B. die psychologische Belastung oder die genetische Diskriminierung bei Versicherungen), empfiehlt die Arbeitsgruppe dem Kliniker, die Risiken abzuwägen und sie mit den zu testenden Personen zu besprechen (Serumspiegel oder Phenotyp). Bei der Beurteilung der Nachdrücklichkeit ihrer Empfehlungen zur Testung auf Alpha-1-Antitrypsin-Mangel kam die Arbeitsgruppe zu der Erkenntnis, dass die Testung auf Alpha-1-Antitrypsin-Mangel zu vier verschiedenen klinischen Zwecken durchgeführt werden kann: (1) zur diagnostischen Testung (z. B. um symptomatische oder anderweitig betroffene Individuen zu herauszufinden), (2) zur prädispositionellen Testung (z.B. um asymptomatische Personen, die ein erhöhtes Risiko eines Alpha-1-AntitrypsinMangels haben, zu identifizieren), (3) die Feststellung des Trägerstatus zu eugenischen Zwecken bei Kinderwunsch und (4) allgemeines Screening.

Die Empfehlungen zur genetischen Testung in speziellen Situationen wurden mit Typ A bis Typ D gewichtet (siehe Tab.1). Jeder dieser Empfehlungstypen basierte auf dem Grad der Evidenz für die betreffenden Umstände der Testung (z. B. die Genpenetranz beim Alpha-1-Antitrypsin-Mangel, die Prävalenz des Alpha-1-Antitrypsin-Mangels in einer Population, die klinische Bedeutung der Früherkennung, die Genauigkeit genetischer Tests, die Wirksamkeit der Behandlung, die psychologischen und sozialen Auswirkungen und die ökonomische Kosten) und der Gewichtung der Für und Wider-Argumente durch die Arbeitsgruppe. Nach dieser Graduierung lauten die Empfehlungen für die vier Arten der genetischen Testung wie folgt:

\section{Diagnostische Testung}

Eine Typ A-Empfehlung zur diagnostischen Testung wurde unter folgenden Voraussetzungen ausgesprochen:

- Symptomatische Erwachsene mit Lungenemphysem, chronisch obstruktiver Lungenerkrankung (COPD) oder Asthma mit - trotz intensiver Therapie mit Bronchodilatantien - ungenügend reversibler Atemwegsobstruktion. (Bei einer Bevölkerung mit deutlich niedrigerer Prävalenz des Alpha-1-Antitrypsin-Mangels als in Nordamerika oder Nordeuropa ist eine Typ B-Empfehlung zur diagnostischen Testung auszusprechen).

- Personen mit Lebererkrankungen unklarer Genese, einschließlich Neugeborener, Kinder und Erwachsener, besonderes älterer Erwachsener.

- Asymptomatische Personen mit persistierender Atemwegsobstruktion in der Lungenfunktion und identifizierbaren Risikofaktoren (z.B. Zigarettenrauchen, berufliche Exposition).

- Erwachsene mit nekrotisierender Panniculitis. 
Tab. 1 Klassifikation der Empfehlungen zum genetischen Testen

\section{Typ Empfehlung}

\begin{tabular}{|ll} 
A & genetische Testung wird empfohlen. \\
\hline$B$ & $\begin{array}{l}\text { genetische Testung sollte erörtert werden und kann mit guten } \\
\text { Gründen akzeptiert oder abgelehnt werden. }\end{array}$ \\
C & $\begin{array}{l}\text { genetische Testung wird nicht empfohlen (d. h. es sollte nicht zur } \\
\text { Testung geraten werden). }\end{array}$ \\
\hline$D \quad \begin{array}{l}\text { es wird empfohlen, die genetische Testung nicht durchzuführen } \\
\text { (d.h. es sollte von der Testung abgeraten werden). }\end{array}$
\end{tabular}

Die Art der Empfehlung wurde von der Arbeitsgruppe nach subjektiver Wichtung aller Gesichtspunkte, die für oder gegen eine genetische Testung sprechen, erstellt. Das Gewicht, welches jedem Punkt zugewiesen wird, hängt ab vom Evidenz-Grad jedes einzelnen Punktes. Dementsprechend basiert die Empfehlung zur genetischen Testung sowohl auf dem Evidenz-Grad jedes Punktes als auch auf dem Konsens der Experten darüber, wie stark jeder Punkt für oder gegen eine genetische Testung spricht.

Die Klassifizierung der Empfehlungen sollte nicht verwechselt werden mit den Schemata zur Graduierung der Evidenz-Qualität, welche, wie in anderen, hier nicht aufgeführten Dokumenten ebenfalls die Buchstaben-Bezeichnung benutzt (Tab. 1a).

Tab. 1a Evidenz-Grade

Grad Beschreibung

\begin{tabular}{|c|c|}
\hline 1 & $\begin{array}{l}\text { Evidenz, die aus wenigstens einer richtig angelegten, randomisierten } \\
\text { und kontrollierten Studie stammt. }\end{array}$ \\
\hline II-1 & $\begin{array}{l}\text { Evidenz, die aus gut angelegten und kontrollierten Studien ohne } \\
\text { Randomisierung stammt. }\end{array}$ \\
\hline $11-2$ & $\begin{array}{l}\text { Evidenz, die aus gut angelegten Kohorten- oder Fallkontrollstudien } \\
\text { stammt, vorzugsweise aus mehreren Zentren oder mehreren } \\
\text { Forschergruppen. }\end{array}$ \\
\hline $11-3$ & $\begin{array}{l}\text { Evidenz, die aus Studien aus verschiedenen Zeitabschnitten mit oder } \\
\text { ohne Intervention stammt. Eindeutige Ergebnisse bei unkontrollierten } \\
\text { Versuchen (so wie beispielsweise die Einführung der Penicillin-Behand- } \\
\text { lung in den } 40 \mathrm{er} \text { Jahren des } 20 \text {. Jahrhunderts) könnten zur gleichen } \\
\text { Evidenz führen. }\end{array}$ \\
\hline III & $\begin{array}{l}\text { Meinungen angesehener Autoritäten, auf klinischer Erfahrung basie- } \\
\text { rend, beschreibende Studien und Fallberichte. }\end{array}$ \\
\hline
\end{tabular}

Nach der U.S. Preventive Service Task Force [1].

Bekanntlich gibt es auch andere Wichtungen, um Evidenz-Grade festzulegen (z. B. WHO/NHLBI GOLD Reports; siehe http://www.goldcopd.com/workshop/ intro.html).

Eine Typ B-Empfehlung zur diagnostischen Testung wurde in der folgenden Situation empfohlen:

- Erwachsene mit Bronchiektasen ohne eindeutige Ursache.

- Heranwachsende mit persistierender Atemwegsobstruktion.

- Asymptomatische Personen mit persistierender Atemwegsobstruktion, aber ohne Risikofaktoren.

- Erwachsene mit C-ANCA-positiver (anti-proteinase 3-positive) Vasculitis.

Eine Typ C-Empfehlung zur diagnostischen Testung wurde ausgesprochen bei:

- Erwachsenen mit Asthma, bei denen die Atemwegsobstruktion vollständig reversibel ist.

\section{Prädispositionale Testung}

Eine Typ A-Empfehlung wurde ausgesprochen für:

- Zwillingsgeschwister von Personen mit Alpha-1-AntitrypsinMangel

Eine Typ B-Empfehlung wurde ausgesprochen für:

- Personen mit einer Häufung von COPD oder Lebererkrankung in der Familienanamnese, bei der nicht bekannt ist, ob sie mit einem Alpha-1-Antitrypsin-Mangel in Zusammenhang steht.

- Entfernte Verwandte einer Person mit einem homozygoten Alpha-1-Antitrypsin-Mangel.

- Nachkommen oder Eltern eines Betroffenen mit homozygoten Alpha-1-Antitrypsin-Mangel.

- Zwillinge, Nachkommen, Eltern oder entfernte Verwandte einer Person mit einem heterozygoten Alpha-1-AntitrypsinMangel.

Eine Typ D-Empfehlung wurde ausgesprochen für:

- Prädispositionale fetale Testung.

\section{Bestimmung des Trägerstatus bei eugenischer Beratung und Kinderwunsch}

Eine Typ B-Empfehlung wurde vorgeschlagen für:

- Personen mit einem hohen Risiko einer Erkrankung auf dem Boden eines Alpha-1-Antitrypsin-Mangels

- Partner von Personen mit homozygoten oder heterozygoten Alpha-1-Antitrypsin-Mangelträgern, auch wenn sie selbst kein Risiko eines Alpha-1-Antitrypsin-Mangels haben.

\section{Allgemeines Screening}

Eine Typ D-Empfehlung wurde vorgeschlagen für:

- Allgemeines Screening von Neugeborenen, Heranwachsenden und Erwachsenen.

D.h., ein allgemeines Screening wird derzeit nicht empfohlen. Eine Ausnahme zum allgemeinen Screening (Typ B-Empfehlung) könnte möglicherweise bei Ländern gemacht werden, die drei Bedingungen erfüllen:

1. die Prävalenz des Alpha-1-Antitrypsin-Mangels ist hoch (ungefähr $1 / 1500$ oder mehr),

2. Rauchen ist häufig und

3. adäquate Beratungsdienste sind verfügbar.

Eine Typ C-Empfehlung wurde ausgesprochen für:

- Allgemeines Screening von Rauchern mit normaler Spirometrie.

\section{Lebererkrankung}

Die Arbeitsgruppe kommt zu folgenden Ergebnissen und Empfehlungen für Personen mit Alpha-1-Antitrypsin-Mangel beim Auftreten von Lebererkrankung:

- Die Erkrankung der Leber ist bedingt durch eine Ansammlung von polymerisiertem Alpha-1-Antitrypsin, dieses bildet charakteristische, PAS-positive Einschlüsse bei Patienten mit Zund einigen anderen Allelen (z.B. $S_{\text {iivama, }}, M_{\text {malton }}$ ). Diese Einschlusskörperchen finden sich innerhalb der Leberzellen und können nicht sezerniert werden. Andere Mangel-Allele (z.B. die Nullvarianten oder $S$ ) prädisponieren nicht zur Erkrankung der Leber. 
- Der „Goldstandard“ zur Diagnostik des Alpha-1-AntitrypsinMangels ist die Serumphänotypisierung durch isoelektrische Fokussierung, welche in einem erfahrenen Labor durchgeführt werden sollte. Eine Leberbiopsie ist zur Diagnostik des Alpha-1-Antitrypsin-Mangels nicht indiziert. Die Leberbiopsie sollte nur zur Stadiierung bei Personen mit eindeutiger klinischer Lebererkrankung vorgenommen werden. Umgekehrt sollte der zufällige Befund von PAS-positiven Einschlusskörperchen in der Leberbiopsie den Verdacht auf einen Z-Allel oder anderen seltenen Alpha-1-Antitrypsin-Mangel, verbunden mit intrahepatischen Einschlusskörperchen, lenken.

- Die meisten Patienten mit einem PI*ZZ Alpha-1-AntitrypsinMangel sind in der Kindheit klinisch gesund, haben aber in den ersten Lebensjahren pathologische Leberenzyme im Serum. Der PI*ZZ-Phenotyp ist eine häufige Ursache der neonatalen Cholestase. Trotz spontaner Besserung bei der Mehrzahl der Betroffenen stellt der Alpha-1-Antitrypsin-Mangel eine häufige Indikation zur Lebertransplantation in der Kindheit dar. Die Leberzirrhose kann bei Individuen mit PI*ZZ Alpha1-Antitrypsin-Mangel in jedem Alter klinisch manifest werden, am häufigsten wird sie bei älteren Nierauchern beobachtet, die, ohne ein schweres Lungenemphysem zu entwickeln, länger leben und dadurch erst , ihre Leberzirrhose erleben“.

- Mit Ausnahme des niedrigen Plasma-Alpha-1-AntitrypsinSpiegels unterscheiden sich weder Laborwerte noch klinischer Befund der Betroffenen von denen bei Leberzirrhose anderer Ätiologie.

- Männer mit PI*ZZ Alpha-1-Antitrypsin-Mangel haben ein größeres Risiko eine Leberzirrhose zu entwickeln, es gibt jedoch keine eindeutigen Hinweise, dass weitere Risikofaktoren wie Virushepatitis oder Alkoholabusus eine Rolle spielen.

- Bei Personen mit heterozygoten Z-Allel ist das Risiko, eine Leberzirrhose zu entwickeln, sehr viel niedriger. Hierbei kann ein toxischer Leberschaden (Alkohol, Virus, insbesondere Hepatitis C) ein zusätzliches Risiko sein.

- Bei heterozygoten Patienten mit aktiver Lebererkrankung oder Vaskulitis ist der Alpha-1-Antitrypsin-Spiegel im Plasma häufig normal; die Diagnose bei Personen mit möglichem heterozygoten $\mathrm{PI}^{*} \mathrm{Z}$ muss daher mittels isoelektrischer Fokussierung gestellt werden.

- Eine spezifische Therapie der Lebererkrankung bei Patienten mit ausgeprägtem Alpha-1-Antitrypsin-Mangel gibt es derzeit nicht, außer der Lebertransplantation; die intravenöse Substitutionstherapie mit $\alpha_{1}$-Antiprotease bringt verständlicherweise keine Vorteile für die Lebererkrankung.

- Obwohl es keine eindeutige Evidenz für eine optimale Strategie zur Nachsorge und Prävention gibt, empfiehlt die Arbeitsgruppe, dass das klinische Management von Personen mit Alpha-1-Antitrypsin-Mangel und Lebererkrankung folgendermaßen gestaltet werden sollte: Hepatitis A- und B-Impfung, regelmäßige klinische Untersuchung mit Leberfunktionstests und Ultraschall. Bei älteren Personen (d.h. 50 Jahre oder älter) mit dekompensierter Leberzirrhose auf dem Boden eines Alpha-1-Antitrypsin-Mangels und einem erhöhten Risiko eines Leberzellkarzinoms werden regelmäßige Computertomogramme zur Darstellung der Leber empfohlen. Andere Tests, wie z.B. Bestimmung des $\alpha$-Fetoproteins, sind für die Früherkennung eines Leberzellkarzinoms nicht sensitiv genug.
- Bei älteren Personen mit Alpha-1-Antitrypsin-Mangel, die keine Lebersymptome haben, empfiehlt sich die regelmäßige Untersuchung mit einfachen Leberfunktionstests.

\section{Andere Erkrankungen}

Neben dem Lungenemphysem und den chronischen Lebererkrankungen besteht nach heutigem Wissen eine Beziehung zwischen Alpha-1-Antitrypsin-Mangel einerseits und nekrotisierender Panniculitis und C-ANCA-positiver Vaskulitis (d.h. Wegener's Granulomatose) andererseits. Eine Assoziation mit anderen Gefäßerkrankungen (z.B. intrakraniales Aneurysma, Bauchaortenaneurysma), Pankreatitis oder Zöliakie kann nicht angenommen werden.

\section{Wirksamkeit der Substitutionstherapie}

- In der Erkenntnis, dass die Wirksamkeit der Substitutionstherapie sich auf übereinstimmende Beobachtungsstudien stützt, aber nicht auf randomisierte, kontrollierte klinische Studien, empfiehlt die Arbeitsgruppe die intravenöse Substitutionstherapie bei Patienten mit nachgewiesener Atemwegsobstruktion infolge eines AAT-Mangels. Die Evidenz, dass die Substitutionstherapie von Nutzen ist (d.h. den Abfall der FEV verlangsamt und die Mortalität reduziert) ist eindeutiger bei Patienten mit mittelschwer ausgeprägter Atemwegsobstruktion (d.h. FEV $135-60 \%$ des Sollwertes) als bei Patienten mit schwerer Atemwegsobstruktion. Die Substitutionstherapie wird derzeit nicht für Personen empfohlen, die kein Lungenemphysem haben. Der Nutzen einer Substitutionstherapie für Patienten mit schwerer $\left(\mathrm{FEV}_{1} \leq 35 \%\right.$ des Sollwertes) oder leichter $\left(\mathrm{FEV}_{1} \geq 50-60 \%\right.$ des Sollwertes) Atemwegsobstruktion ist weniger eindeutig nachgewiesen.

- Der Nutzen einer Substitutionstherapie bei Patienten nach Lungentransplantation bei AAT-Mangel ist nicht eindeutig belegt. Eindeutige Empfehlungen sind deswegen nicht möglich. Es gibt jedoch Beobachtungen, dass sich bei Patienten nach Lungentransplantation während Entzündungen der Lunge freie Elastaseaktivität in der epithelialen Flüssigkeit findet, z.B. während einer akuten Abstoßungsreaktion oder bei pulmonalen Infekten. In Zusammenschau aller verfügbaren Daten zu diesem Thema spricht sich die Arbeitsgruppe dafür aus, die Substitutionstherapie bei lungentransplantierten Patienten während solcher Episoden durchzuführen.

\section{Allgemeines Management bei obstrulktiver Atemwegserkrankung}

Das optimale Management von Individuen mit AAT-Mangel sollte in der stabilen Phase viele der Interventionen beinhalten, die für Patienten mit Lungenemphysem ohne AAT-Mangel empfohlen werden, einschließlich:

- Inhalation von Bronchodilatatoren.

- Präventionen inform der Influenza- und Pneumococcus-Impfung.

- Sauerstofflangzeittherapie, sofern die Indikation nach den üblichen Kriterien gegeben ist, auch während Flugreisen. 
- Pulmonale Rehabilitation für Patienten mit funktioneller Beeinträchtigung.

- In Betrachtziehen der Lungentransplantation bei ausgewählten Personen mit schwerer Funktionsstörung und Atemwegsobstruktion.

- Während einer akuten Exazerbation der COPD sollte das Management die übliche Therapie, wie sie auch bei Patienten mit normalem AAT-Spiegel durchgeführt wird, beinhalten (z.B. Stoßtherapie mit systemischen Corticosteroiden, maschinelle Beatmung, wenn indiziert). Da die Lunge des Patienten mit AAT-Mangel jedoch bei jeder akuten Infektion durch eine erhöhte Elastase-Belastung bedroht ist, empfiehlt die Arbeitsgruppe eine frühzeitige antibiotische Therapie bei allen eitrigen Exazerbationen.

Die Evidenz zur Wirksamkeit der operativen Lungenvolumenreduktion (eventuell mit Resektion der Unterlappen) bei Patienten mit AAT-Mangel ist begrenzt. Sie besagt, dass eine Verbesserung von Dyspnoe, Lungenfunktion und Funktionsstatus möglich ist. Es gibt jedoch keine eindeutigen Selektionskriterien für den idealen Kandidaten, außerdem ist der Nutzen einer operativen Lungenvolumenreduktion bei Patienten mit AAT-Mangel offensichtlich von kürzerer Dauer als bei Patienten mit COPD ohne AAT-Mangel.

\section{Literatur}

${ }^{1}$ American Thoracic Society. Guidelines for the approach to the patient with severe hereditary alpha1-antitrypsin deficiency. Am Rev Respir Dis 1989; 140: $1494-1497$

${ }^{2}$ Ad hoc Committee on Alpha ${ }_{1}$-Antitrypsin Replacement Therapie, Standards Committee of the Canadian Thoracic Society. Current status of alpha ${ }_{1}$-antitrypsin replacement therapy: recommendations for the management of patients with severe hereditary deficiency. CMAJ 1992; 146: 841 - 844

${ }^{3}$ Abboud RT, Ford GT, Chapman KR et al. Alpha ${ }_{1}$-antitrypsin deficiency: a position statement of the Canadian Thoracic Society. Can Respir J 2001; 8: $81-88$

\section{Lungenerkrankung}

\section{Erstellung dieses Dokumentes}

Dieses Dokument wurde von einem internationalen Komitee mit Repräsentanten der American Thoracic Society, der European Respiratory Society und des American College of Chest Physicians erstellt. Es will ein autoritativer Führer für Ärzte und andere Personen, die im Gesundheitswesen arbeiten, sein und unser derzeitiges Verständnis des Alpha-1-Antitrypsin- (AAT-) Mangels mit den vorhandenen Möglichkeiten in Diagnostik und Therapie darlegen.

Die Literatursuche beinhaltete Veröffentlichungen seit 1963. Zur Information über die klinische Manifestation einschließlich der radiologischen Charakteristika, Risikofaktoren und Therapie wurden Studien mit den größten Patientenzahlen ausgewählt. Die Evidenz für klinische Charakteristika, Risikofaktoren und therapeutische Empfehlungen wurde der Qualität entsprechend nach den „U. S. Preventive Service Task Force (siehe Tab.1)“ gewichtet [1].

\section{Einleitung}

Der AAT-Mangel ist eine erst vor kurzem entdeckte erbliche Veranlagung, erstmals im Jahre 1963 beschrieben [2]. Dank einer intensiven Forschung in den vergangenen 40 Jahren konnten detaillierte Kenntnisse zu strukturellen und genetischen Veränderungen, Pathophysiologie des Lungenemphysems und der Lebererkrankung sowie Ansatzpunkte zur Therapie des Mangelzustandes und Behandlung der damit zusammenhängenden Erkrankung gewonnen werden.

Der schwere Mangel dieses Proteins in Serum und Gewebe, die Lunge eingeschlossen, ist das Ergebnis der Vererbung von zwei Protease-Inhibitor-Mangel-Allelen des AAT-Gens; dieses ist auf dem Chromosomsegment 14q31-32.3 lokalisiert [3,4]. Unter den Mangel-Allelen ist PI*Z am häufigsten. In seiner homozygoten Form (PI*ZZ) hat dieser Defekt niedrige AAT-Serum Konzentration zur Folge, gewöhnlich unter $50 \mathrm{mg} / \mathrm{dl}$ (weniger als $11 \mu \mathrm{M}$ ) [5]. Das Lungenemphysem vom panazinären Typ ist das häufigste klinische Korrelat dieses Mangelzustandes und der Hauptgrund für Invalidität und Tod [6]. Die zweithäufigste klinische Komplikation ist die Lebererkrankung, die sich gewöhnlich im Kindesalter als Cholestase, die bis zur Adoleszenz spontan rückläufig ist, manifestiert [7,8]. Neuste Ergebnisse deuten jedoch darauf hin, dass Leberzirrhose und Leberkarzinom bei ungefähr 30 - 40\% der Patienten mit ATT-Mangel im Alter von über 50 Jahren vorkommen und bei Nichtrauchern mit PI*ZZ-Phenotyp eine wesentliche Todesursache darstellen [9-11].

AAT ist der wichtigste Protease-Inhibitor im Serum. Es zirkuliert normalerweise im Serum in Konzentration von 120-200 mg/dl und wurde wegen seiner Eigenschaft, Trypsin zu hemmen, so benannt. Seine hauptsächliche biologische Rolle besteht jedoch darin, neutrophile Elastase (NE) zu hemmen, ein Enzym, das Elastin, aber auch Basalmembranen und andere Matrixkomponenten abbaut $[12,13]$.

AAT wird von den Hepatozyten der Leber synthetisiert und gehört zur Familie der Serpine (Serin-Protease-Inhibitor). Die Z-Variante des Moleküls, welche der am häufigsten mit Lungenerkrankung assoziierte Phenotyp ist, geht mit einer normalen mRNA und Syntheserate des Antitrypsins einher, aber nur 15\% des AAT werden in die Zirkulation freigesetzt.

Der Defekt beruht darauf, dass ungefähr $85 \%$ des synthetisierten AAT in den terminalen sekretorischen Abschnitten der Hepatozyten blockiert werden [14]. Man kann diese „steckengebliebenen Ansammlungen“ als große intrazelluläre Einschlusskörperchen im Zytoplasma der Hepatozyten sehen. Bei der Null-Variante des AAT-Mangels, bei der überhaupt kein AAT-Protein gebildet wird, sieht man keine Einschlusskörperchen, und Lebererkrankungen sind nicht berichtet worden.

Durch die Technik der isoelektrischen Fokussierung gelang es, ungefähr 100 genetische Varianten des AAT zu identifizieren. Die alphabetische Benennung dieser Varianten basiert auf ihrer Beweglichkeit im elektrischen Feld bei einem alkalischen $\mathrm{pH}$ Wert. Die schnell wandernden Varianten werden mit den ersten Buchstaben und die langsameren mit den letzten Buchstaben des Alphabets bezeichnet. Die Z-Variante ist also die langsamste 
Variante. Der häufigste normale Phenotyp ist das PI*MM (mit einer mittleren Beweglichkeit); er findet sich bei 95 - 96\% der weißen Rasse [15,16]. Ungefähr 2-3\% der weißen Bevölkerung sind heterozygot (PI*MZ). Auch in Fernost und Afrika wurden Alpha1-Antitrypsin-Mangelzustände berichtet, sie sind aber relativ selten $[17,18]$.

Auf der Basis großer Übersichtsstudien zur weltweiten Häufigkeit des Alpha-1-Antitrypsin-Mangels schätzt de Serres, dass auf der ganzen Welt etwa 117 Millionen Menschen einen PI*MSund PI*MZ-Phenotyp aufweisen und 3,4 Millionen einen PI*ZZ-, PI*SZ- oder PI*SS-Phenotyp [19-21].

\section{Epidemiologie}

Aufgrund der niedrigen Frequenz des PI*ZZ-Phenotyps in der Allgemeinbevölkerung sind harte Daten zur Prävalenz der betroffenen Personen schwer zu bekommen. Es wurde jedoch eine Reihe von Screening-Untersuchungen durchgeführt (siehe Appendix 2).

Die Prävalenz des AAT-Mangels bei Neugeborenen wurde in großen Bevölkerungsstudien untersucht. Das Screening aller Neugeborenen in Schweden in den Jahren 1972-1974 ist die umfassendste aller Untersuchungen [20]. Von den 200000 Kindern dieser Studie hatten 127 einen PI*ZZ-Phenotyp, was einer Prävalenz von ungefähr $1: 1600$ Neugeborenen entspricht. In anderen Studien aus Oregon [21] St. Louis [22] und New York [23] wurden Prävalenzen von 1:5097, $1: 2857$ und $1: 3694$ bestimmt.

Studien aus verschiedenen Regionen Europas zeigten eine große Variation in der Frequenz der Z-Gene in verschiedenen Ländern [24]. Die Gen-Frequenz für das PI*Z-Allel ist am höchsten in den nordwestlichen Küstenländern Europas, und es hat den Anschein, als hätte sich die Mutation dieses Allels im südlichen Skandinavien ereignet [24]. In den Vereinigten Staaten ist deswegen die Frequenz des Z-Gens am höchsten bei Personen, die aus den nördlichen und westlichen Ländern Europas stammen [25].

Die Verteilung des S-Typs ist unterschiedlich; die Genfrequenz ist am höchsten auf der Iberischen Halbinsel und wahrscheinlich hat die Mutation in dieser Region stattgefunden (siehe Tab. 2). [24].

Die Ergebnisse von Studien zur Prävalenz von PI*ZZ bei Patienten mit der Diagnose einer chronischen obstruktiven Lungenerkrankung (COPD) werden in Appendix 3 zusammengefasst. Der Prävalenzbereich ist im Allgemeinen niedrig und variabel, abhängig vom untersuchten Patientenkollektiv, für PI*ZZ variiert er zwischen $1-4,5 \%$ und für MZ kann er bis zu 17,8\% betragen.

\section{Pathophysiologie des AAT-Mangels}

AAT ist ein 52-kD großes, einkettiges Glykoprotein, das aus 394 Aminosäureresten und 3 mit Asparagin verbundenen Kohlenhydrat-Seitenkettenkomplexen besteht. Das ATT-Gen misst 12,2 kb auf dem menschlichen Chromosom 14q31-32.3 und ist unter-
Tab. 2 Geschätzte Gen-Frequenzen und Prävalenz für die S- und Z-Allele und Phänotypen in Europa und in den Vereinigten Staaten

\begin{tabular}{|c|c|c|}
\hline & Geschätzte Prävalenz (\%) & \\
\hline $\begin{array}{l}\text { Geschätzte Gen-Fre- } \\
\text { quenz (per 1000) }\end{array}$ & Europa & Vereinigte Staaten \\
\hline
\end{tabular}

\begin{tabular}{lllllll}
\hline$S^{1}$ & $1-9$ & $2-4$ & $0,01-2$ & $4-11$ & 0,05 & $3-8$ \\
$Z^{2}$ & $2-24^{3}$ & $1-2$ & $0,02-0,06$ & $2-5^{5}$ & $0,02-0,04$ & $2-4^{5}$ \\
\hline
\end{tabular}

Daten aus den Literaturhinweisen [22, 25, 297].

${ }^{1}$ In Europa ist die Gen-Frequenz für das S-Allel auf der Iberischen Halbinsel am höchsten und in Skandinavien am niedrigsten. In den Vereinigten Staaten ist die Gen-Frequenz für das S-Allel bei der einheimischen spanischen Bevölkerung am häufigsten.

${ }^{2}$ In Europa werden die höchsten Z-Gen-Frequenzen in Nordwesteuropa und die niedrigsten in Osteuropa und auf der Iberischen Halbinsel gefunden. In den Vereinigten Staaten ist die Genfrequenz in der Bevölkerung, die aus Nordoder Westeuropa stammt, am höchsten.

${ }^{3}$ Die Z-Gen-Frequenz ist bei Lappen und Basken praktisch null.

${ }^{4}$ Die Prävalenz des SZ-Phänotyps wird in den USA bei der einheimischen Bevölkerung mit 0,2\%, in Europa mit 0,02-0,3\% angegeben.

${ }^{5}$ Höhere Frequenz als Allel-Frequenz, weil Bestimmungs-Bias in einer Population mit chronisch obstruktiver Lungenerkrankung.

teilt in drei nicht-kodierende (1a, 1b und 1c) Exons und vier (2, 3, 4 und 5) kodierende Exons. Die aktive Stelle des Proteins ist ein einzelnes Peptidband Met $^{385}-$ Ser $^{359}$ in der AAT-Sequenz und ist enkodiert im Exon 5. Hepatozyten sind die Hauptproduktionsstätte des AAT, aber auch andere Zellen, mononukleare Phagozyten und intestinale sowie epitheliale Zellen der Lunge können dieses Protein synthetisieren. Die Hauptfunktion des AAT ist es, eine Reihe von Serinproteinasen zu hemmen, aber kinetische Studien haben gezeigt, dass das bevorzugte Ziel des AAT die neutrophile Elastase (NE), eine omnipotente extra-zelluläre 29-kD Endopeptidase, ist. Die Hemmung vollzieht sich durch Formation eines stabilen $1: 1$ äquimolaren Komplexes, in dem die Proteinase an die aktive Seite des AAT-Moleküls gebunden wird [26] (s. Abb. 2, welche die molekulare Interaktion der Hemmung darstellt).

Der menschliche neutrophile Granulozyt enthält und sezerniert auch eine zweite potente Elastase, die so genannte Proteinase -3 (PR-3). PR-3 ist ebenfalls eine Serum-Proteinase und spaltet Elastin in vitro. PR-3 verursacht ein Lungenemphysem, wenn man es bei Hamstern intratracheal appliziert [27]. Die $\mathrm{NH}_{2}$-terminale Aminosäuresequenz von PR-3 ist identisch mit der des Ziel-Antigens, des anti-neutrophilen, zytoplasmatischen Autoantikörpers, welcher mit der Wegener's Granulomatose assoziiert ist (auch Anti-Protenase-3-positiven Vaskulitis im vorliegenden Dokument genannt) [28]. Proteinase-3 wird durch AAT gehemmt und durch $\alpha_{2}$-Makroglobulin, aber nicht durch den sekretorischen Leukoprotease-Inhibitor (slipi) [28].

AAT ist ein sehr pleiomorphes Protein, d. h. es hat einen pleiomorphen Genlokus mit ungefähr 100 Allelen, die bisher identifiziert wurden, widerspiegelnd. Die Varianten werden ebenfalls kodominant vererbt und entsprechend der Systematik der Protease-Inhibitoren (PI) klassifiziert, wie durch die Plasma-isoelektrische Fokussierung definiert. 


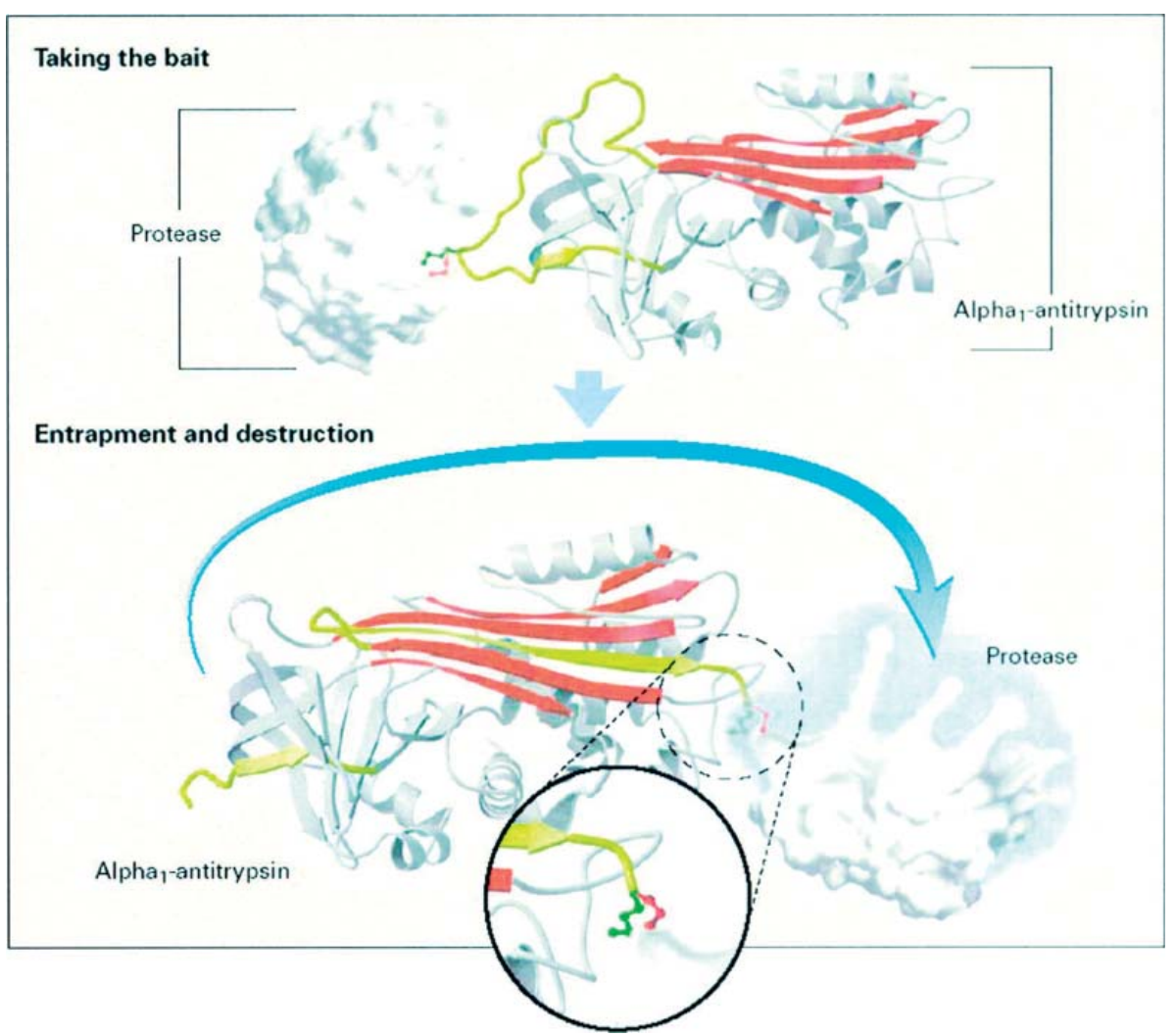

Abb. 2 Schematische Darstellung des Mechanismus, der zur Hemmung von neutrophiler Elastase durch Alpha-1-Antitrypsin(AAT)-Inhibitor führt. Die Rolle des AATMoleküls ist in diesem Modell vergleichbar einer Mausefalle, in welche die Elastase (= Maus) zunächst gelockt (,Taking the bait“) und dann gefangen und zerstört wird („Entrapment and destruction“). Biochemisch gesprochen greift dabei die Elastase zunächst das reaktive Zentrum der Schleife des AAT (gelb) mit ihrem aktiven Serin (kleine rote Seitenkette) an und stellt eine Verbindung zur Aminosäure an der Basis des reaktiven Zentrums des AAT (kleine grüne Seitenkette) her. Die resultierende Spaltung der reaktiven Schleife ermöglicht dem Molekül, in die Haupt- $\beta$-Hülle des AAT (rote Streifen mit Pfeilen) zurückzuschnellen. Diese Bewegung - vergleichbar dem Zurückschlagen der gespannten Feder einer Mausefalle - schleudert die anhaftende Elastase ans gegenüberliegende Ende des AAT-Moleküls, verdreht dabei die aktive Stelle und ändert so die Struktur des Moleküls, so kann es zerstört werden. Das aktive Zentrum des AAT-Moleküls ist MET ${ }^{358}$. Wenn MET ${ }^{358}$ zu Methioninsulfoxid oder Sulfon oxidiert wird, ist die Hemmung der neutrophilen Elastase durch AAT infolge der verminderten Assoziationskonstranten

deutlich reduziert. Die Oxidanzien im unteren Atemtrakt können dem Zigarettenrauchen entstammen, aber auch der Umwelt, neutrophilen Granulozyten oder Makrophagen. Modifiziert mit der Erlaubnis von Carrell und Lomas [295].

AAT-Genotypen, die mit einem erhöhten Risiko zur Entwicklung eines Lungenemphysems einhergehen, sind diejenigen, bei denen das Mangel- oder Null-Allel in homozygotem oder heterozygotem Zustand kombiniert ist und die AAT-Plasmaspiegel kodieren, die unter der protektiven Schwelle liegen, also unter $11 \mu \mathrm{mol} / \mathrm{L}$ [29]. Auf der Basis der Plasmaspiegel und der Funktion des AAT, können die Varianten nach folgendem Schema eingeteilt werden:

Normal: Die üblichen M-Typen, wie sie bei 95\% der weißen Rasse gefunden werden. Sie sind charakterisiert durch normale Plasmaspiegel $(>20 \mu \mathrm{mol} / \mathrm{L})$.

Mangelzustand: Charakterisiert durch Plasmaspiegel $<20 \mu \mathrm{mol} / \mathrm{L}$. Die Z-Variante des AAT ist der häufigste Mangeltyp, mit Plasmaspiegel von 5-6 $\mu \mathrm{mol} / \mathrm{L}$ bei homozygoten Trägern. Dagegen ist die S-Variante häufiger in mediterranen Ländern. Sie geht bei Homozygoten mit Plasmaspiegel um ungefähr 60\% der Norm einher. Andere seltene Mangeltypen werden eingruppiert als „M-ähnliche-“ oder „S-ähnliche“-Typen.

Nullvariante: Eine seltene Form, die mit keinerlei nachweisbaren AAT zirkulierenden Plasma einhergeht.

Dysfunktionale Variante: Hier sei z.B. das AAT Pittsburgh genannt, bei dem aus einem Elastase-Inhibitor ein Thrombin-Inhibitor wurde [30] oder die PI*F-Variante, die mit einer deutlich reduzierten Affinität zu Elastasen gekennzeichnet ist [31].

Die Gene oder Proteinsequenzen der häufigsten Varianten sind bekannt. Die Mechanismen der häufigsten AAT-Mangelzustände hängen zusammen mit den strukturellen Veränderungen des Z-AAT, welches unter physiologischen Bedingungen seine reaktive Schleife spontan in ein $\beta$-Hüllenpolymer transformiert [32] Polymere mit identischem Erscheinungsbild konnten aus Lebern von Patienten mit PI*ZZ isoliert werden.

Die Pathogenese des Lungenemphysems bei AAT-Mangel, aber auch bei Personen mit normalem AAT-Spiegel als Folge des Zigarettenrauchens wird mit einer Imbalance von Proteasen und Antiproteasen erklärt.

Die Hypothese der Proteasen-Antiproteasen-Imbalance geht davon aus, dass das Lungenemphysem bei AAT-Mangel durch eine Imbalance zwischen dem Anti-Elastasen-Schutz der Lunge auf der einen und einer exzessiven Aktivität von Leukozyten-Elastasen auf der anderen Seite entsteht, mit der Folge der Zerstörung von Elastin und anderer Komponenten der extrazellulären Matrix im unteren Respirationstrakt. Diese Hypothese basiert auf der Erkenntnis, dass das AAT der wichtigste Anti-Elastase-Schutz des Alveolarraums ist, und dass Personen mit schwerem AATMangel keinen oder wenig AAT in ihren Alveolen haben und daher Gefahr laufen, ein destruktives Emphysem zu entwickeln [33]. Die Evidenz für die Richtigkeit der These von der ProteaseAntiprotease-Imbalance hat sich über die letzten Jahre durch eine Reihe experimenteller Daten bestätigen lassen.

Bei Untersuchung großer Patientenkollektive konnte klar gezeigt werden, dass weniger als $60 \%$ der Individuen mit schwerem AATMangel eine deutliche Atemflusslimitation entwickeln [6]. Das bedeutet, dass in vielen Fällen der AAT-Mangel allein nicht ausreicht, ein Lungenemphysem zu verursachen [34]. Es wurde auch 
vermutet, dass ein Lungenemphysem dann entsteht, wenn die Reparaturmechanismen der elastischen Faser durch eine massive Elastasen-Attacke aus Entzündungsreaktionen außer Kraft gesetzt werden [35].

Ein wesentlicher pathogenetischer Faktor bei der Entstehung des Lungenemphysems ist der Zigarettenrauch; er enthält Oxidanzien, die wiederum AAT inaktivieren können indem sie die aktive Stelle von Met $^{358}$ zu Methioninsulfoxid umwandeln, das einen etwa 2000-fach geringere Bindungsfähigkeit mit NE hat. Es konnte außerdem gezeigt werden, dass das Z-AAT neutrophile Elastasen langsamer inhibiert als M-AAT (4,5 vs. $9 \times 10^{6} \mathrm{M}^{-1-}$ Sekunde $^{-1}$ ) [36]. Darüber hinaus fand man AAT-Polymere in der bronchoalveolären Lavage bei zwei von fünf Personen mit einem AAT-Mangel-Emphysem [37]. Weil die Polymerisation die reaktive AAT-Schleife unzugänglich macht, wird durch die Faltung des Moleküls die inhibitorische Aktivität gestört. Deshalb können Oxidanzien aus Zigarettenrauch bei einem Alpha-1-AntitrypsinMangel zu einer weiteren Störung des bereits quantitativ und qualitativ funktionsgeminderten AAT führen. Darüber hinaus können im Tiermodell des Elastase induzierten Emphysems Zigarettenrauch und Proteinasen gemeinsam die Resynthese von Elastin der Lunge verhindern [38].

Zigarettenrauch führt auch zur Rekrutierung von Entzündungszellen. Bei AAT-Mangel findet man mehr Neutrophile in den Alveolen als beim Lungenemphysem von Patienten mit normalem AAT-Plasmaspiegel. Das trägt zu einer größeren Belastung der Lunge mit neutrophilen Elastasen (NE) bei [39]. Dieses Phänomen kann zurückgeführt werden auf die Anwesenheit von neutrophilen chemotaktischen Faktoren, hauptsächlich Leukotrien $B_{4}$, welches von Alveolar-Makrophagen freigesetzt wird [40].

Darüber hinaus können Neutrophile und Makrophagen eine Vielzahl von Metalloproteinasen, die ihrerseits die Komponenten der extrazellulären Matrix degradieren können, freisetzen [41]. Auch menschliche Kollagenase spielt bei der Zerstörung der Alveolarwände eine Rolle, wie beim experimentellen Tierversuch gezeigt werden konnte [42]. Metalloproteinasen werden nicht durch AAT inhibiert, können dieses sogar durch begrenzte Proteolyse in der Nähe der aktiven Stelle unwirksam machen [41]. Die C-terminalen Fragmente des AAT, die bei der proteolytischen Inaktivierung freigesetzt werden, sind potente chemotaktische Faktoren für neutrophile Granulozyten [43,44].

\section{Labortests}

Eine niedrige oder fehlende $\alpha_{1}$-Globulinzacke bei einer routinemäßig durchgeführten Plasma-Protein-Elektrophorese sollte den Verdacht auf einen AAT-Mangel lenken; dieser sollte durch quantitative und qualitative Bestimmung des AAT im Serum bestätigt werden (s. Tab. 3).

\section{Quantitative Untersuchungen}

Plasma-AAT-Spiegel werden gewöhnlich mittels Immunelektrophorese, radialer Immundiffusion oder - in neuerer Zeit - nephelometrisch bestimmt. Kommerziell erhältliche Standards, besonders solche für die radiale Immundiffusion, überschätzen tendenziell die AAT-Konzentration um 35-40\% [45]. Um zwischen
Tab. 3 Konzentrationsbereich des Alpha-1-Antitrypsin-Spiegels im Serum je nach Phänotyp

\begin{tabular}{|c|c|c|c|c|c|}
\hline Einheiten & $\begin{array}{l}\text { Phänotyp } \\
\text { PI }^{*} \text { MM }\end{array}$ & $P I^{*} M Z$ & $\mathrm{PI}^{*}$ SS & $P{ }^{*} S Z$ & $P{ }^{*} Z Z$ \\
\hline$\mu M$ & $20-48$ & $17-33$ & $15-33$ & $8-16$ & $2,5-7$ \\
\hline $\mathrm{mg} / \mathrm{dl}$ & $150-350$ & $90-210$ & $100-200$ & $75-120$ & $20-45$ \\
\hline
\end{tabular}

Daten aus den Literaturhinweisen [14, 47, 298].

" Die angegebenen Serumspiegel wurden mittels eines typischen kommerziellen Standards $(\mathrm{mg} / \mathrm{dl})$ und dem gereinigtem Standard $(\mu \mathrm{M})$, wie er beim U.S.-Register benutzt wurde, bestimmt. Ein Serumspiegel von weniger als $11 \mu \mathrm{M}$ ist mit einem erhöhten Emphysemrisiko verbunden.

Tab. 4 Methoden zur quantitativen Bestimmung von Alpha-1-Antitrypsin im Plasma, Normbereichen und protektive Schwellenspiegel

\begin{tabular}{lll}
\hline Methode & Normbereich & $\begin{array}{l}\text { Protektive } \\
\text { Schwellenspiegel }\end{array}$ \\
\hline radiale Immundiffusion & $150 / 200-350 / 400 \mathrm{mg} / \mathrm{dl}^{*}$ & $80 \mathrm{mg} / \mathrm{dl}^{*}$ \\
\hline Nephelometrie & $83 / 120-200 / 220 \mathrm{mg} / \mathrm{dl}^{*}$ & $\left.50 \mathrm{mg} / \mathrm{dl}^{*} ; 11 \mu \mathrm{M}\right)^{1}$ \\
\hline
\end{tabular}

Daten aus den Literaturhinweisen [14, 45, 299].

"Wert bestimmt mittels kommerziell erhältlicher Standards.

${ }^{1}$ Wert bestimmt mittels NHLBI-Standard.

den historischen Werten, die mittels ungereinigter Standards bestimmt wurden, und den mit den reinen Standards des U.S. National Institutes of Health erhobenen Werten unterscheiden zu können, werden erstere in Milligramm pro Deziliter ( $\mathrm{mg} / \mathrm{dl})$ angegeben und letztere in Mikromolar-Einheiten $(\mu \mathrm{mol} / \mathrm{L}$ oder $\mu \mathrm{M})$. Die beiden Einheiten werden in vielen kontinental-europäischen Ländern jedoch oft wechselweise angewandt, unabhängig vom benutzten Standard. Darüber hinaus kann der AAT-Spiegel mit nephelometrischen Methoden wegen der Interferenz mit Lipiden oder Hämoglobin fälschlicherweise zu hoch gemessen werden. Auch muss berücksichtigt werden, dass AAT ein „AkutePhaseprotein" ist und dass entzündliche Erkrankungen bei Z-Heterozygoten zu einem Anstieg des AAT-Plasmaspiegels führen können. Es sollte beachtet werden, dass ein „protektiver Spiegel“ von $11 \mu \mathrm{mol} / \mathrm{L}$ mit gereinigtem Standard bestimmt, einem Spiegel von $80 \mathrm{mg} / \mathrm{dl}$ mittels radialer Immundiffusion und von $50 \mathrm{mg} / \mathrm{dl}$ mittels Nephelometrie entspricht (s. Tab.4). Dieser „protektive Spiegel“ leitet sich von der Beobachtung ab, dass Patienten mit heterozygotem Phänotyp und einem AAT-Spiegel oberhalb dieses Wertes gewöhnlich kein Emphysem entwickeln [29].

\section{Qualitative Untersuchungen}

Die am häufigsten angewandte Methode zur Erkennung von AAT-Varianten ist ihre Aufteilung mit Hilfe des isoelektrischen Punktes durch die isoelektrische Dünnschicht-Fokussierung (IEF). Diese Methode, gemeinhin als Phänotypisierung bezeichnet, erfordert Geschicklichkeit und Erfahrung und sollte nur in Referenzlabors durchgeführt werden. Die Spezifität des IEF kann weiter gesteigert werden in Verbindung mit einem Immu- 
noblot oder bei Anwendung eines immobilisierten $\mathrm{pH}$-Gradient IEF-Gels [46]. Die Phänotypisierung kann an Serum- oder Plasmaproben durchgeführt werden. Einige Labors führen die IEF an getrockneten Blutproben durch. Wenn man einen Bluttropfen auf einem Spezialpapier absorbieren lässt, ist der Transport solcher Proben einfacher. Diese Methode ist zum Screening geeignet, aber die Erkennung einer Mangelvariante bedarf der Bestätigung durch Serum- oder Plasmaproben.

Die Diagnose auf der molekularen Ebene („Genotypisierung“) wird an genomischer DNA durchgeführt, die aus zirkulierenden mononuklearen Blutzellen extrahiert wird. Bekannte Mutationen können durch allel-spezifische Amplifikation oder Analyse bestimmt werden. Lässt sich eine bekannte Mutation nicht erkennen, so muss an das Vorhandensein einer neuen Variante gedacht werden. In diesem Fall sollte ein Gen-Scan mit direkter Sequenzierung durchgeführt werden oder eine denaturierende Gradient-Gel-Elektrophorese [47]. Die Diagnose auf molekularer Ebene ist leichter geworden durch kommerziell erhältliche Kits, welche das S- und Z-Allel im Vollblut oder in der Mundspülflüssigkeit nachweisen können. Die derzeitig erhältlichen Kits können jedoch nicht Null-Allele nachweisen und deswegen sind auch AAT-Plasmaspiegel erforderlich.

\section{Erkennung von Individuen mit AAT-Mangel}

\section{Frühentdeckung: Pränatal}

Der PI*ZZ-Mangel wird autosomal kodominant vererbt. Das Risiko eines homozygoten Nachkommens beträgt bei jeder Geburt 1:4, wenn beide Eltern Träger des Z-Allels sind. Wenn ein Elternteil einen homozygoten PI*ZZ-Mangel hat und der andere einen heterozygoten, dann sind alle Kinder entweder Träger oder betroffen (PI*ZZ).

Es gibt keine Routinemethode, die speziell für die pränatale Diagnose des AAT-Mangels entwickelt wurde. Mittels Amniocentese oder Chorionzottenbiopsie $[48,49]$ kann Material zur genetischen Testung gewonnen werden. Die pränatale Diagnose kann bei einer Familienanamnese mit perinataler Lebererkrankung eines älteren Geschwisters gefragt sein. Das Risiko, eine Lebererkrankung zu entwickeln, steigt in diesem Falle substantiell an $[9,50]$. Es sind mehrere Methoden zur pränatalen Genbestimmung beschrieben worden und in vereinzelten Fällen auch erhältlich. Alle bedienen sich der DNA-Amplifikation und verwenden spezielle Sonden für eine hinreichend spezifische Diagnostik [51,52]. Aber finanzielle und praktische Erwägungen begrenzen ihren Nutzen.

Die postnatale Entdeckung eines AAT-Mangels hängt vom Grad des Verdachts ab. Die Technologien für rasche Screening-Tests sind vorhanden, sie bedienen sich der DNA-Amplifikation aus Blutproben der Ferse [53]. Die postnatale Entdeckung eines AATMangels ergibt sich bei dem Befund einer neonatalen Hepatitis oder einer eindeutigen Familienanamnese. Ansonsten bleiben die meisten Fälle unentdeckt, bis sich ein Lungenemphysem, eine Lebererkrankung oder seltene andere Komplikationen entwickeln. Obwohl der AAT-Mangel eines der häufigsten kodominanten Erbkrankheiten der weißen Rasse ist, werden RoutineSreening-Untersuchungen nicht durchgeführt.

\section{Entdeckung bei Erwachsenen}

Es ist bekannt, dass nicht rauchende Individuen mit homozygotem Z-Phänotyp erstaunlich spät die ersten Symptome entwickeln und einige sogar eine fast normale Lebensspanne haben [54]. Deswegen ist die genaue Prävalenz des AAT-Mangels in den meisten Bevölkerungen unbekannt und viele betroffene Individuen werden nicht diagnostiziert. Screening-Programme neugeborener oder erwachsener Populationen großen Stils wurden weder in den Vereinigten Staaten noch in Europa (mit Ausnahme von Schweden) durchgeführt, hauptsächlich aus Kostengründen und wegen der Probleme, in die Betroffene beim Nachweis einer erblichen Abnormalität geraten können. Weil es derzeit keine Heilung für die Erkrankung gibt, müssen die Betroffenen und ihre Familien den emotionalen Stress aushalten, mit dem Wissen um die Erkrankung in einer Zeit zu leben, in der sie völlig symptomfrei sind. Die Entdeckung einer Abnormalität könnte auch bei Versicherungen und bei der beruflichen Einstellung Nachteile für den Betroffenen bringen. Andererseits kann aber durch Vermeiden von Rauchen und Luftschadstoffen die Prognose von Individuen mit AAT-Mangel verbessert werden durchaus eine medizinische Berechtigung für die Früherkennung. In Abwägung der positiven und negativen Faktoren, die mit der Entdeckung eines AAT-Mangels einhergehen, sollte jedoch nach entsprechender Information die Zustimmung zur Durchführung des diagnostischen Tests vom Betroffenen durch den Arzt nach ausgiebiger Erklärung des Für und Wider eingeholt werden.

Es werden drei verschiedene Kategorien der Gentestung unterschieden (siehe auch die Sektion GENETICS, PSYCHOSOCIAL, ETHICS, AND ECONOMIC ISSUES). Die erste Kategorie wird als diagnostische Testung bezeichnet und meint die Testung von Individuen mit Beschwerden oder klinischen Hinweisen auf eine AATMangel-Erkrankung. Die zweite Kategorie ist überschrieben mit „prädispositionaler“ Testung und meint die Identifizierung von Individuen ohne Symptome, aber mit einem hohen Risiko eines AAT-Mangels. Die dritte Kategorie ist bezeichnet mit „Screening“ und meint Programme, bei denen in bestimmten Populationen nach Individuen mit erblicher Prädisposition für Krankheiten gesucht wird. Das Entscheidende beim Screening ist, dass es keinen vorherigen Verdacht geben sollte, dass irgendein Individuum die Kondition hat, die getestet wird. Spezielle Empfehlungen und die damit zusammenhängende Empfehlungsgrade für die Testung in spezifischen Gruppen von Individuen werden in Tab. 8 der Sektion GENETICS, PSYCHOSOCIAL, ETHICS, AND ECONOMIC ISSUES gegeben.

Personen mit erniedrigtem Blutspiegel sollten weiter untersucht werden, damit das Ausmaß einer eventuellen Erkrankung auf dem Boden eines AAT-Mangels festgestellt werden kann. Selbst Individuen mit grenzwertig normalem AAT-Plasmaspiegel $(12-35 \mu \mathrm{mol} / \mathrm{L}$ oder $90-140 \mathrm{mg} / \mathrm{dl})$ und deren Verwandte 1 . Grades sollten phänotypisiert werden, und zwar deswegen, weil diese grenzwertig normalen Spiegel auch bei den Phänotypen $\mathrm{PI}^{*} \mathrm{SZ}, \mathrm{PI}^{*} \mathrm{SS}$ und PI*MZ vorkommen, und weil so ein Verwandter mit asymptomatischem oder fehldiagnostiziertem AAT-Mangel innerhalb der Familie entdeckt werden kann.

Außer der gelegentlichen Beobachtung einer verminderten oder fehlenden $\alpha_{1}$-Globulinzacke in der Papier-Elektrophorese ist die 
Tab. 5 Empfehlungen zum quantitativen Screening auf Alpha1-Antitrypsin: Die Wahrscheinlichkeit, einen AAT-Mangel zu entdecken, nimmt in absteigender Reihenfolge ab

\section{Empfehlung}

\begin{tabular}{|c|c|}
\hline 1. & $\begin{array}{l}\text { Bestätigung einer fehlenden Alpha-1-Antitrypsin-Zacke in der } \\
\text { Serum-Eiweißelektrophorese. }\end{array}$ \\
\hline 2. & $\begin{array}{l}\text { früh einsetzendes Lungenemphysem (unabhängig vom Rauch- } \\
\text { verhalten). }\end{array}$ \\
\hline 3. & $\begin{array}{l}\text { Familienmitglieder von Patienten, bei denen Alpha-1-Antitrypsin- } \\
\text { Mangel bekannt ist. }\end{array}$ \\
\hline 4. & $\begin{array}{l}\text { Vorkommen von Atemnot und Husten bei mehreren Familien- } \\
\text { mitgliedern der gleichen oder verschiedener Generationen. }\end{array}$ \\
\hline 5. & Lebererkrankung unklarer Ursache. \\
\hline 6. & alle Patienten mit chronisch obstruktiver Lungenerkrankung. \\
\hline 7. & $\begin{array}{l}\text { Erwachsene mit Bronchiektasen unklarer Genese sollten zur Testung }{ }^{1} \\
\text { vorgesehen werden. }\end{array}$ \\
\hline 8. & $\begin{array}{l}\text { Patienten mit Asthma, bei denen spirometrisch keine Normalisierung } \\
\text { der Atemwegsobstruktion unter Therapie nachgewiesen werden kann. }\end{array}$ \\
\hline 9. & Panniculitis und Anti-Proteinase-3-Vaskulitis ohne bekannte Ursache. \\
\hline
\end{tabular}

"S. Tab. 11 der GENETICS, PSYCHOSOCIAL, ETHICS, AND ECONOMIC ISSUES zur besonderen Wichtung dieser Empfehlungen.

${ }^{1}$ Wie in Tab. 11 der Sektion GENETICS, PSYCHOSOCIAL, ETHICS, AND ECONOMIC ISSUES dargestellt, sollte eine Testung auf AAT-Mangel bei Personen mit Bronchiektasen ohne eindeutige Ursache in Betracht gezogen werden (Typ B-Empfehlung). Dieser Empfehlungsgrad berücksichtigt die Tatsache, dass der AAT-Mangel zu selten diagnostiziert wird, dass Bronchiektasen in einigen Publikationen bei Personen mit AAT-Mangel häufig vorkommen, aber dass die Verbindung von Bronchiektasen und AAT-Mangel nicht eindeutig erwiesen ist.

Bestimmung des AAT-Spiegels besonders bedeutungsvoll bei Patienten mit frühem Beginn eines Lungenemphysems, unabhängig von der Raucheranamnese. Die Testung sollte auch durchgeführt werden bei Geschwistern von Individuen mit AAT-Mangel und auch für deren Nachkommen in Betracht gezogen werden sowie in den Fällen, bei denen eine familiäre Häufung von Symptomen mit Atemnot und chronischem Husten beobachtet wird. Außerdem wird empfohlen, bei allen Patienten mit COPD oder Asthma, bei denen die Atemwegsobstruktion nicht komplett reversibel ist, eine AAT-Bestimmung im Serum durchführen zu lassen (s. Tab. 5) [55]. Auch bei Patienten mit ungeklärter Leberzirrhose sollte der Phänotyp bestimmt werden (z. B. PI*ZZ, PI*MZ, $\mathrm{PI}^{*} \mathrm{M}_{\text {malton }}$ ) Ferner sollte bei Patienten mit Wegner'scher Granulomatose (Antiproteinase-3 Vaskulitis) eine AAT-Phänotypisierung durchgeführt werden, da bei ihnen über eine hohe Prävalenz von $\mathrm{PI}^{*} \mathrm{ZZ}$ - und $\mathrm{PI}^{*} \mathrm{MZ}-\mathrm{Phänotypen} \mathrm{berichtet} \mathrm{wurde} \mathrm{und} \mathrm{An-}$ tikörper gegen Proteinase-3 mitbeteiligt sind [9]. Auch bei Erwachsenen mit Bronchiektasen unklarer Genese sollte der Alpha 1-Antitrypsin-Spiegel im Serum bestimmt werden.

\section{Pathologie}

Bei der Obduktion erwachsener Patienten mit schwerem AATMangel findet man immer ein panazinäres Lungenemphysem mit basaler Betonung [56]. Selbst bei einem 11-jährigem Mädchen, das an einer Abdominalblutung im Gefolge einer Leberzirrhose starb, konnte bei der Obduktion ein uniformes panazinäres Emphysem nachgewiesen werden [57]. Gelegentlich sieht man auch ein minimales zentrilobuläres Emphysem in den Oberlap- pen. Bei 14 Obduktionen, bei denen Proben der in Inspiration fixierten Lungen erhältlich waren, wurden in 2 Fällen zylindrische Bronchiektasen beschrieben [56].

Feingewebliche Veränderungen von Bronchiolen und Bronchien AAT-Mangel werden in der Literatur nur selten beschrieben. Der Reid-Index, der die Hypertrophie der Bronchialdrüsen reflektiert, wurde in einem Fall als normal berichtet. In einer zweiten Studie wurde nur eine geringe Drüsenvergrößerung beobachtet. Auch Verlust von Muskel- und elastischen Fasern wurde in den kleinen Bronchien gesehen. Bei Lungengewebsproben von Patienten mit schwerem Lungenemphysem auf dem Boden eines AATMangels, bei denen eine Lungenvolumenreduktionsoperation vorgenommen wurde, waren die Veränderungen auf der Ebene der Bronchiolen (Broncholitis obliterans, Bronchiolektasie, akute und chronische Bronchiolitis, Bronchiolitis mit organisierender Pneumonie) ausgeprägter als bei Patienten mit Emphysem ohne AAT-Mangel [58]. Gelegentlich werden bei Autopsien, aber auch bei Lungenresektaten oder im Röntgenbild, große bullöse Veränderungen, hauptsächlich in den basalen Partien der Lunge beschrieben.

\section{Symptome}

\section{(Siehe Appendix 1.)}

Bei AAT-Mangel entwickelt sich bei Personen mit einer Raucheranamnese die Symptomatik einer obstruktiven Lungenerkrankung gewöhnlich im Alter zwischen 32-41 Jahren [6,59-63]. Die Variabilität des zeitlichen Beginns der Symptome wird sehr unterschiedlich beschrieben, aber die ersten Beschwerden treten vor dem 25. Lebensjahr auf. Obwohl ausgeprägte Beschwerden am häufigsten bei Rauchern oder Exrauchern beobachtet werden, haben einige Raucher und viele Nichtraucher überhaupt keine Beschwerden [64,65].

Das größte Patientenkollektiv mit schwerem AAT-Mangel $(n=1129)$, das mit einem standardisierten Symptom-Fragebogen untersucht wurde, konnte beim Register des National Heart, Lung and Blood Institute (NHLBI) gesammelt werden [67]. In das Register Patienten mit einem AAT-Serumspiegel $<11 \mu \mathrm{m}$ aufgenommen sowie Personen, bei denen durch Familien-Screening ein entsprechender Defekt festgestellt wurde (20\%), oft ohne jegliche Symptomatik. Die häufigste Beschwerde war Atemnot bei Belastung (bei 84\% der Teilnehmer). Giemen während Atemwegsinfekten wurde sehr häufig angegeben (76\%), obwohl Giemen auch unabhängig von Atemwegsinfekten vorkam (65\%).

Husten war bei $42 \%$ der Teilnehmer im NHLBI-Register vorhanden. Vermehrter Husten und Auswurf über wenigstens drei Wochen im Jahr wurde bei $50 \%$ aller Betroffenen beschrieben [67] und war bereits früh im Alter von 18 Jahren vorhanden [68]. Bei anderen Studien wurden chronischer produktiver Husten über drei Monate in wenigstens zwei zusammenhängenden Jahren, vereinbar mit der Diagnose einer chronischen Bronchitis, bei $8-40 \%$ der Patienten mit AAT-Mangel beschrieben [68-70]. Chronischer Husten mit oder ohne Auswurf wurde in Verbindung mit radiologischen Hinweisen auf zylindrische Bronchiektasen beobachtet [70]. 
Auch gelegentliches Giemen und Atemnot, vereinbar mit der Diagnose eines Asthma, wurde bei AAT-Mangel beobachtet. In einer Studie, bei der das Vorhandensein von Giemen, Ansprechen auf Bronchodilatatoren, Atopie und erhöhtes Serum IgE untersucht wurden, konnten drei oder mehr dieser Hinweise auf Asthma bei $22 \%$ der AAT-Mangel-Patienten gefunden werden, verglichen mit 5\% der COPD-Patienten ohne AAT-Mangel [69]. Allergische Rhinitis war häufig, auch wenn keine Atemwegsobstruktion vorhanden war. Im NHLBI-Register berichteten 35\% der Teilnehmer über eine Asthma-Anamnese und mehr als $50 \%$ zeigten in einer wiederholten Ttestung signifikantes Ansprechen auf Bronchodilatatoren bei vorhandener Atemwegsobstruktion (mehr als $12 \%$ und $200 \mathrm{ml}$ ) [67,69]. In diesem Register betrug das mittlere Alter, bei dem das erste Symptom auftrat, nämlich Giemen, 31 Jahre.

Es gibt keine Studie mit einer populationsbasierten Kohorte, in der das Vorkommen lebensbedrohlicher Erkrankungen bei Alpha 1-Antitrypsin thematisiert wird. Die besten Daten, die zu diesem Thema erhältlich sind, kommen aus dem NHLBI-Register [67], in dem die Mehrheit der Todesfälle (72\%) dem Lungenemphysem zugeschrieben werden kann. Die Angabe einer Lungenerkrankung in den vergangenen drei Jahren mit konsekutiver Arbeitsunfähigkeit, Unfähigkeit, das Haus zu verlassen oder Bettlägerigkeit wurde von $68 \%$ der Patienten gemacht. 30\% der Teilnehmer des NHLBI-Registers berichteten krankheitsbedingte Behinderung bei im Mittel 46 Jahren-Hinweis auf eine erhebliche Morbidität im Zusammenhang mit dem AAT-Mangel [67]. Zusammenfassend sind bei Patienten mit AAT-Mangel die Atemwegssymptome mit einem frühen Altersbeginn auffallend.

\section{Klinische Befunde}

Es gibt keine hinreichend sensitiven oder spezifischen physikalischen Untersuchungsmethoden, die bei der Entdeckung von Personen mit AAT-Mangel klinisch von Nutzen sind. Giemen findet man häufig, jedoch kann es bei schwerem Emphysem fehlen. Mit fortschreitender Erkrankung treten Zeichen einer Lungenüberblähung, vermindertes Vesikuläratmen an der Lungenbasis und Muskelatrophie hinzu. Weil Asthma bronchiale die häufigste Fehldiagnose ist, sollte die spirometrische Untersuchung des Patienten die körperliche ergänzen. Bei den meisten Patienten mit adäquat behandeltem Asthma sollten sich die spirometrischen Werte normalisieren.

\section{Lungenfunktionsuntersuchungen}

Die Lungenfunktionsuntersuchungen sollten beinhalten die Spirometrie (vor und nach Inhalation eines Bronchodilatators), die Messung der Lungenvolumina mittels Heliumverdünnungsmethode oder Ganzkörperplethysmographie und die CO-Diffusionskapazität im Single-Breath [71,72].

Die Spirometrie ist die Lungenfunktionsuntersuchung, die am häufigsten bei Betroffenen mit AAT-Mangel durchgeführt wird, weil sie reproduzierbar ist und einen wesentlichen Aspekt der Lungenerkrankung erfasst. Die spirometrischen Abweichungen schließen eine Verminderung des forcierten expiratorischen Vo- lumens in der ersten Sekunde $\left(\mathrm{FEV}_{1}\right)$ und eine normale oder reduzierte Vitalkapazität (FVC) ein. Die obstruktive Ventilationsstörung (Erniedrigung des $\mathrm{FEV}_{1} / \mathrm{FVC}$-Verhältnisses) ist primär bedingt durch den Verlust elastischer Rückstellkräfte des Lungenparenchyms (Lungenemphysem) und dynamischem Kollaps der ansonsten regelrechten Atemwege. Die Flussvolumenkurve zeigt für gewöhnlich eine deutliche Verminderung des Flusses mit abnehmendem Lungenvolumen, was im typischen Fall an der konkaven Verlaufsform der expiratorischen Fluss-VolumenKurve darstellbar ist.

Die Verminderung der Rückstellkräfte hat eine Erhöhung der Lungen-Compliance zur Folge, die wiederum zur Überblähung mit Anstieg des Residualvolumens (RV) und der totalen Lungenkapazität (TLC) führt. Da es innerhalb der kranken Lunge minder ventilierte Abschnitte gibt („air trapping“), werden die statischen Lungenvolumina mittels der Ganzkörperplethysmographie für gewöhnlich größer gemessen als die mittels Verdünnungsmethode über ein Indikatorgas.

Das Lungenemphysem beeinträchtigt auch den Gasaustausch; die Diffusionskapazität ist erniedrigt und der alveolo-arterielle Sauerstoffgradient erhöht. Obwohl beide Phänomene oft verschiedene Aspekte des gleichen pathologischen Prozesses sind, nämlich des Lungenemphysems, korreliert die Erniedrigung des expiratorischen Flusses $\left(\mathrm{FEV}_{1}\right)$ nicht immer gut mit der Verminderung der Diffusionskapazität $[73,74]$; deswegen sollten beide bestimmt werden, wenn man für den Schweregrad der Lungenfunktionsstörung bei AAT-Mangel feststellen will. Zusätzlich gibt der arterielle Sauerstoffdruck Informationen über Störungen des Ventilations-/Perfusionsverhältnisses.

Bei fortgeschrittener Lungenerkrankung kann die Auswirkung des Lungenemphysems auf die Muskelaktivität von Brustkorb und Zwerchfell durch Messung des maximalen in- und expiratorischen Munddrucks bestimmt werden. Sollwerte sind publiziert [75].

Der kardiopulmonale Zustand kann auch durch Belastungsuntersuchungen festgestellt werden. Während bei Normalpersonen der Sauerstoffpartialdruck sich unter Belastung nicht ändert oder sogar ansteigen kann, findet man bei Personen mit AATMangel eine deutliche Erniedrigung des $\mathrm{Pa}_{02}$ und eine Erhöhung des alveolo-arteriellen Sauerstoffgradienten. Personen mit AATMangel haben in Ruhe eine erhöhte Atemfrequenz und erreichen unter leichter körperlicher Belastung rasch mehr als $80 \%$ vom Soll ihres Atemgrenzwertes, ein Hinweis, dass die Ventilation bei höheren Arbeitsbelastungen zum limitierenden Faktor wird [76].

Obwohl bei einem Großteil der Patienten mit AAT-Mangel Symptome wie Husten oder Giemen, die auf eine Atemwegsüberempfindlichkeit hinweisen, vorhanden sind, und einige anfangs sogar als Asthmatiker diagnostiziert werden, ist die Reversibilität der Atemwegsobstruktion nach Applikation eines Dosieraerosols mit Bronchodilatatoren gewöhnlich nicht sehr groß [69].

\section{Schlussfolgerungen}

Als optimale klinische Untersuchung ist bei Personen mit AATMangel eine komplette Lungenfunktionsuntersuchung unter 
Einschluss der Spirometrie angezeigt. Diese sollte die statischen Lungenvolumina, die arteriellen Blutgasanalyse und den Transferfaktor beinhalten. Sie sollten bei Patienten mit obstruktiver Lungenerkrankung als Ausgangspunkt des Funktionsstatus dokumentiert werden $[77,78]$.

Weil Patienten mit AAT-Mangel in der Hauptsache eine fixierte Atemwegsobstruktion entwickeln, erscheint es bei den meisten Patienten mit AAT-Mangel nicht gerechtfertigt, die Variabilität der Atemwegsobstruktion mittels regelmäßiger Peak-Flow-Messung zu bestimmen. Jedoch sollte bei den Patienten jährlich die Spirometrie kontrolliert werden.

\section{Bildgebende Verfahren (einschließlich Computertomo-} graphie und Ventilations-/Perfusionsszintigraphie)

\section{Lungenemphysem}

Im Frühstadium der Erkrankung ist das Röntgenbild des Thorax gewöhnlich unauffällig. Bei fortgeschrittener Erkrankung fallen Überblähung und erhöhte Strahlentransparenz der Lungen auf, insbesondere in den basalen Segmenten. Die Zwerchfelle stehen tief und sind abgeflacht, das Herz tropfenförmig und steil stehend, der anteriore-posteriore Durchmesser des Brustkorbs ist vergrößert und der retrosternale Luftgehalt der Lunge ist vermehrt. Die Abflachung des Zwerchfells in der seitlichen Projektion ist von allen genannten Kriterien wahrscheinlich das spezifischste. Die Gefäßzeichnung ist rarifiziert, hauptsächlich in den basalen Lungenabschnitten im Gegensatz zum vorwiegenden Befall der Oberlappen bei Patienten mit Lungenemphysem ohne AAT-Mangel [63,79-83]. Die gleichzeitige Verbreiterung der Pulmonalgefäße ist ein Hinweis auf eine mögliche pulmonale Hypertonie.

Beim Nachweis eines Lungenemphysems hat die Computertomographie des Thorax eine viel größere Sensitivität als die Röntgenuntersuchung des Thorax oder als die Lungenfunktionstestung $[74,83,84]$. Die hochauflösende Bildfrequenzrekonstruktion (high resolution computed tomography [HRCT]) ist bei der Aufdeckung morphologischer Veränderungen wie Bullae oder Bronchiektasen sensitiver. Im HRCT ist das Lungenemphysem durch Areale mit abnorm niedriger Dichte charakterisiert; diese Dichte-Differenzen können durch ein niedriges HoundsfieldFenster (-600 bis -800 Houndsfield-Einheiten [HU]) bildlich abgesetzt werden gegen das umgebende normale Lungengewebe Die klassischen Veränderungen beim ATT-Mangel zeigen ein panazinäres Emphysem mit uniform niedriger Dichte der Lobuli und ein deutliches Überwiegen dieser Veränderungen in den Unterlappen. Die Lungengefäße in den befallenen Lungenabschnitten erscheinen kleiner und an Zahl vermindert [85], während sich radiologisch geringe und selbst mittelschwere Veränderungen im Sinne eines panakinären Lungenemphysems nur sehr subtil darstellen lassen und schwer zu entdecken sind [86]. Während fokale Areale mit Lungenemphysem für gewöhnlich keine eindeutige Wandung zeigen, demarkieren sich bullöse Veränderungen scharf durch eine dünne Wand gegenüber dem umgebenden Lungengewebe. Sie haben einen Durchmesser von mindestens $1 \mathrm{~cm}$. Bollae werden häufig auch bei „gewöhnlichem Lungenemphysem“ ohne AAT-Mangel beobachtet [79].

\section{Bronchiektasie}

Obwohl die enge Beziehung zwischen AAT-Mangel und früher Emphysem-Entwicklung wohl bekannt ist, existieren zur Frage „AAT-Mangel und Bronchiektasen“ nur eine kleine Zahl von Studien. In der Originalarbeit von Eriksson wurden bei 23 Patienten über zwei Fälle mit Bronchiektasen berichtet [59]. Guest und Hanssell beobachteten eine Verdickung der Bronchialwand und/ oder eine Erweiterung des Bronchiallungens bei 7 von 17 Patienten $(41 \%)$ mit AAT-Mangel [82], und King u. Mitarb. fanden Hinweise auf Bronchiektasen bei 6 von 14 Patienten mit AAT-Mangel (entsprechend 43\%) [87]. Cuvelier u. Mitarb. berichteten über keine Häufigkeit des AAT-Mangel-Allels bei Patienten mit Bronchiektasen, während in anderen Studien Bronchiektasen bei spanischen Patienten häufiger beobachtet wurden [88]. Die Untersuchung von Cuvelier u. Mitarb. legt nahe, dass Bronchiektasie eher das Ergebnis der emphysematösen Veränderungen des Lungenparenchyms ist als Ausdruck des AAT-Mangels per se [88].

\section{Lungendichtemessung}

Pixelwerte von CT-Bildern zeigen die Gewebsdichte an. Dies ermöglicht die Berechnung densitometrischer Parameter aus Pixelhäufigkeitshistogrammen innerhalb der Lunge. Die densitometrischen Parameter geben uns die Möglichkeit, die Ausdehnung des Emphysems quantitativ zu bestimmen. In der Literatur gibt es verschiedene Methoden zur Berechnung der densitometrischen Parameter. Mit der Methode der „Dichtemaske“ kann man Areale mit abnorm niedriger Lungendichte hervorheben; man benutzt dabei ein Computerprogramm, mit dessen Hilfe man durch Hervorhebung der Pixel eine Dichtemaske für jeden gewünschten Bereich herstellen kann. Der „Dichtemaske-Parameter" ist definiert als der prozentuelle Anteil des hervorgehobenen Lungenareals im Vergleich zum gesamten. Die Hervorhebung aller Pixel mit Dichtewerten unter -910 HU korreliert gut mit dem pathologisch-anatomischen Schweregrad und ist vergleichbar der visuellen Abschätzung [89]. Die „Perzentilen“-Methode legt den Schweregrad des Emphysems durch einen Grenzwert fest, der eine gegebene Perzentile des Histogramms bestimmt (z. B. die 10. Perzentile wird aus dem Histogramm als derjenige Dichtewert in Houndsfield-Einheiten extrahiert, bei welchem 10\% der Pixel niedrigere Dichtewerte besitzen) [90]. Eine dritte Möglichkeit, das Ausmaß des Lungenemphysems abzuschätzen, erfolgt über die „mittlere Lungendichte“ [91].

Die Ventilations-/Perfusionsszintigraphie ist eine nützliche Methode, um frühe Veränderungen im Zusammenhang mit AATMangel festzustellen, selbst Personen mit relativ normaler Lungenfunktion können bereits ein pathologisches Szintigramm aufweisen [63, 76, 92 -95]. Dabei zeigt das Ventilationsszintigramm typischerweise eine symmetrische Verteilung des radioaktiven Edelgases 133 Xenon in der Äquilibrationsphase über alle Lungenzonen, in der folgenden Auswaschphase sieht man dagegen eine deutliche Verzögerung der Abatmung des radioaktiven Edelgases, hauptsächlich in der Lungenbasis und im mittleren Lungenbereich. Ebenso beobachtet man im Perfusionsszintigramm eine symmetrische Minderung der Lungendurchblutung, am ausgeprägtesten an der Lungenbasis.

Zusammenfassend sollte bei der Erstuntersuchung eine Röntgenaufnahme des Thorax zum Ausschluss von eventuell gleichzeitig vorhandener Lungenherden und zum Nachweis von lokali- 
sierten, bullösen Veränderungen durchgeführt werden. Die CTUntersuchung des Thorax unter Einschluss von Dünnschnitten für morphologische und dicken Schnitten für densitometrische Untersuchungen ist zur Zeit die wichtigste Methode, um bei AAT-Mangel das Vorhandensein eines Emphysems und ggf. sein Ausmaß festzustellen.

\section{Verlaufsparameter:}

FEV $_{1}$, Desmosin und Computertomographie

Die Standardmethode, um das Fortschreiten des Lungenemphysems zu beurteilen, ist die Lungenfunktionsuntersuchung. Der Abfall der $\mathrm{FEV}_{1}$ ist mit Abstand der am häufigsten gemessene Parameter bei Longitudinal-Untersuchungen. Die Spirometrie hat bei der Untersuchung von Patienten mit Lungenemphysem aber auch ihre methodischen Tücken: Weil die Atemwegsobstruktion hauptsächlich durch den dynamischen Atemwegskollaps bedingt ist, hängen die Ergebnisse der Spirometrie ganz wesentlich davon ab, wie kooperativ der Patient bei der Untersuchung ist und wie sehr er sich dabei anstrengt. Die „inspiratorische“ Vitalkapazität mit langsamer Ausatmung (IVC) ist gewöhnlich größer als die „forcierte“ Vitalkapazität (FVC) mit forcierter Ausatmung. Entsprechen kann die $\mathrm{FEV}_{1}$ bei einer submaximalen Anstrengung höher ausfallen als bei einem maximal forcierten Atemmanöver.

Der Vorteil der Spirometrie liegt darin, dass sie einfach durchführbar und häufig leicht wiederholbar ist. Es hat sich jedoch gezeigt, dass häufige Messungen in Abständen von weniger als 3-6 Monaten nutzlos sind, weil Messungen in kurzen Intervallen wenig zusätzliche Informationen im Vergleich zu Messungen über längere Zeitabschnitte bringen [96].

Die $\mathrm{FEV}_{1}$ wird im Allgemeinen als gut reproduzierbar angesehen. In mehreren großen multizentrischen Studien [97] hatte die Spirometrie, mit hoher technischer Qualität an verschiedenen Tagen durchgeführt, eine Standardabweichung von ungefähr $100 \mathrm{ml}$. Dieser Messfehler ist jedoch groß im Vergleich zum jährlichen Abfall des $\mathrm{FEV}_{1}$, welcher bei normalen Erwachsenen ungefähr $30 \mathrm{ml}$ und bei Personen mit AAT-Mangel ungefähr $60 \mathrm{ml}$ beträgt. Der Messfehler impliziert einen Standardfehler von wenigstens $100 \mathrm{ml} / \mathrm{Jahr}$, wenn man den $\mathrm{FEV}_{1}$-Abfall bei Personen ermittelt, die nicht länger als ein Jahr kontrolliert wurden. Der Standardfehler ist umgekehrt proportional zu der Beobachtungsperiode (d.h. bei einer Beobachtungsperiode von 10 Jahren reduziert sich der Standardfehler des $\mathrm{FEV}_{1}$-Abfalls auf $10 \mathrm{ml} / \mathrm{Jahr}$, was immer noch ziemlich hoch ist).

Die Diffusionskapazität für Kohlenmonoxid im Ein-AtemzugVerfahren $\left(\mathrm{D}_{\mathrm{L}} \mathrm{CO}-\mathrm{SB}\right)$ variiert bei wiederholten Messungen stärker als die $\mathrm{FEV}_{1}$; deswegen ist die Diffusionskapazität als Verlaufsparameter weniger geeignet. Obwohl die arteriellen Blutgase und die Diffusionskapazität für Kohlenmonoxid bei der Betreuung von AAT-Mangel-Patienten häufig gemessen werden, ist ihre Eignung in der Nachsorge in keiner Studien nachgewiesen.

Vom Konzept her könnten Änderungen der Dichte, wie man sie bei wiederholten CT-Scans messen kann, ein sensitiver und spezifischer Parameter des emphysematösen Umbaus sein und möglicherweise lässt sich das Fortschreiten des Emphysems, wie Flenley vor mehr als einem Jahrzehnt vermutete, besser durch wiederholte quantitative CT-Messungen als durch $\mathrm{FEV}_{1}$-Messungen beurteilen $[98,99]$.

\section{Radiologie}

Die Hauptursache für die Schwankungen bei Messungen der Lungendichte ist die Tiefe der Einatmung. Die Lungendichte kann sich zwischen maximaler Inspiration und maximaler Expiration mehr als verdoppeln [100-102]. Das Gasvolumen in der Lunge kann man über CT-Bilder bestimmen, also Histogramme mit CT-Dichtewerten [102-104]. Die Lungendichte wird zu 50\% durch das Blut in der Mikrozirkulation bestimmt [105]. Bei einer tiefen Einatmung wird nicht nur das Gasvolumen der Lunge erhöht, sondern es wird auch Blut in die Lunge „gesaugt“, und das kompliziert die Beziehung zwischen Inspirationstiefe und Lungendichte noch weiter.

Nach Ansicht einiger Untersucher lässt sich durch spirometrische Kontrolle der Ventilation während des Scanvorgangs die Reproduzierbarkeit und Genauigkeit von Dichtemessungen verbessern [106-108]. Allerdings sind Patienten mit COPD nicht in der Lage, Atemmanöver, die mit maximaler Expiration und Inspiration einhergehen, so gut $\mathrm{zu}$ reproduzieren, als dass damit eine Standardisierung gelingen könnte [109,110].

Bei der Analyse von CT-Scans bei verschiedenen Inspirationstiefen konnte bei Einzelpersonen die Abhängigkeit der Lungendichte vom aktuellen Lungenvolumen gezeigt werden. Auf der Basis dieser Daten lassen sich densitometrische Parameter durch logtransformierte Lungenvolumina standardisieren und damit Differenzen im Lungenvolumen zwischen den Scans korrigieren. Spirometrisch kontrollierte Computertomogramme erübrigen sich damit [111]. Wenn man eine große Bandbreite von PixelPerzentilen von der 10. bis zur 30. Perzentile (korrespondierend zur Dichteskala von -950 bis $-890 \mathrm{HU}$ ) benutzt, lassen sich jährliche Veränderungen von $2 \mathrm{HU}$ finden, entsprechend dem Verlust an Lungengewebe von 2 g/l Lungenvolumen [111]. Die Quantifizierung des Lungenemphysems durch densitometrische Parameter scheint demnach eine sensitivere Methode, das Fortschreiten des Lungenabbaus zu messen als die Lungenfunktion (z. B. FEV 1 ) $[98,112,113]$. Inspirations-Computertomogramme sind Expirations-Computertomogrammen beim Nachweis der Langzeitveränderungen der Lungenstruktur durch Alterung und Rauchen überlegen [113], und die Pixelperzentile war gegenüber dem Pixelindex der robustere Parameter zur Messung des Fortschreitens des Lungenemphysems [111].

In einer randomisierten klinischen Studie zur AAT-Substitutionsbehandlung über einen Zeitraum von drei Jahren mit 56 Patienten konnte gezeigt werden, dass die Sensitivität der Messung des Progresses des Lungenemphysems durch die Perzentilen-Methode 3-4fach höher war als jeder andere Parameter, der mit Hilfe der Spirometrie oder der CO-Diffusionskapazität gemessen wurde. Die bedeutet, dass neue medikamentöse klinische Studien, die CT als „outcome Parameter“ heranziehen, mit einer 5fach geringeren Zahl von Patienten durchführbar sind [112].

Da gezeigt werden konnte, dass die Lungendichtemessung abhängig ist vom Alter, sollten Normalwerte für CT-Lungendichte 
als Funktion des Alters erstellt werden [117]. Ein Problem beim Einsatz des CT zur Messung der Progredienz des Lungenemphysems ist die Strahlenbelastung. Wenn man die Untersuchung auf einen einzelnen Schnitt $5 \mathrm{~cm}$ unterhalb der Karina begrenzt, könnte die Strahlendosis deutlich reduziert werden. Tatsächlich erhält man bei Berechnung auf der Basis eines Dünnschnitts ähnliche Ergebnisse wie bei Ganzlungen-Scans [111]. Auch eine Reduktion der Stromstärke (mA) bis zu 10 Mal unterhalb des Standardpegels hat keinen wesentlichen Einfluss auf die Messung der Lungendichte $[118,119]$.

\section{Biochemische Marker}

Da man allgemein annimmt, dass die Schädigung der Lunge bei AAT-Mangel aus der Imbalance zwischen neutrophiler Elastase (NE) und AAT resultiert, kann man logischerweise vermuten, dass Faktoren, die mit der Aktivität der NE und/oder dem Stoffwechsel der extrazellulären Lungenmatrix zu tun haben, als Indikatoren für die Zerstörung der Lunge infrage kommen [120]. Die ersteren (aktive NE und NE-spezifische fibronogene A $\alpha$-Peptide) [121] sind indirekte Marker, die letzteren (Desmosin/Isodesmosin) [DES/IDES] und Peptide aus dem Elastin-Abbau) sind direkte Marker des Elastinabbaus und deswegen enger mit der klinischen Entwicklung eines Emphysems verknüpft [122]. Peptide aus dem Elastin-Abbau können mittels immunologischer Methoden im Plasma oder Urin gemessen werden, sie sind, wie man gefunden hat, bei Patienten mit COPD signifikant erhöht, verglichen mit Kontrollpersonen - sowohl bei der direkten Messung [123] wie auch im Radioimmunassay [124]; die unvollständige biochemische Charakterisierung des immun reaktiven Materials lässt jedoch Zweifel aufkommen, ob diese Methode für kontrollierte klinische Studien nutzbar eingesetzt werden kann.

DES und IDES sind miteinander verbundene Aminosäuren, typisch für reifes Elastin. Sie sind in Form von Peptiden aus dem Elastin-Abbau im Blutstrom vorhanden und werden im Urin ausgeschieden. DES-Spiegel im Urin sind bei Rauchern mit einem raschen Abfall der Lungenfunktion höher als bei solchen mit einem langsamen [125]. Außerdem sind sie bei Personen mit AAT-Mangel ebenso erhöht wie bei Patienten mit COPD ohne AAT-Mangel [123]. Aufgrund vorläufiger Hinweise, dass die Substitution mit AAT die Urinausscheidung von DES bei Personen mit AAT-Mangel vermindert [126], wurde bei klinischen Studien zur kurzzeitige Substitution mit AAT die Reduktion der DES/IDES-Rate im Urin als primärer Endpunkt gewählt. Eine dieser Studien konnte allerdings die vorläufigen Ergebnisse nicht bestätigen [127]. Zusammengenommen sprechen zwar bisherige Studien dafür, die Urinausscheidung von DES/IDES als möglichen Verlaufsparameter für den Progresses des Lungenemphysems und für die Wirksamkeit der Substitutionstherapie bei AAT-Mangel einzusetzen, es bedarf jedoch weiterer Untersuchung, um die methodische Zuverlässigkeit und die klinische Relevanz nachzuweisen.

Zusammengefasst gibt es hinreichend Untersuchungen zur Verlässlichkeit von $\mathrm{FEV}_{1}$ und CT-Densitometrie zum Nachweis der Progredienz des Lungenemphysems bei AAT-Mangel. Die Spirometrie sollte anfänglich in jährlichen Abständen durchgeführt werden, bis klar erkennbar ist, dass das Fortschreiten nicht so rasch ist und die Frequenz der Untersuchung gesenkt werden kann.

\section{Risikofaktoren}

Zahlreiche Studien haben die Rolle verschiedener Risikofaktoren für die Entwicklung von COPD bei Patienten mit einem PI*ZZPhenotyp gezeigt (s. Tab. 6 und APPENDIX 3 und 4). Es ist eindeutig, dass beim AAT-Mangel vom PI*ZZ-Typ Rauchen der wichtigste Risikofaktor bei der Entstehung eines Lungenemphysems ist. Der jährliche Abfall der $\mathrm{FEV}_{1}$ bei Rauchern mit AAT-Mangel beträgt etwa $130 \mathrm{ml}$, bei Exrauchern $70 \mathrm{ml}$ [67,128-130]. In einer nachfolgenden Untersuchung konnte jedoch gezeigt werden, dass der mittlere Abfall bei Rauchern $70 \mathrm{ml} / J a h r$ betrug, bei Nierauchern $47 \mathrm{ml} / \mathrm{Jahr}$ und bei Exrauchern $41 \mathrm{ml} / \mathrm{Jahr}$, also ein Hinweis für ähnlichen Abfall pro Zeit bei Nichtrauchern und Exrauchern [131]. Bei Untersuchung von Umweltfaktoren und endogenen Ursachen, die zum Abfall der Lungenfunktion beitragen, muss man sicherstellen, dass die Teilnehmer Nichtraucher sind; man vermeidet damit Fehlschlüsse durch den führenden Effekt des aktiven Rauchens. In den schwedischen, dänischen und nordamerikanischen Registern gibt es eine große Anzahl von Patienten, bei denen Nachfolgeuntersuchungen durchgeführt wurden.

In drei Untersuchungen wird die Bedeutung von Umweltfaktoren auf den Lungenfunktionsabfall auf der Basis von Eigenbeobachtungen untersucht. Bei 225 nicht rauchenden Personen mit PI*ZZ in Schweden mit einer FEV 1 von $84 \pm 28 \%$ des Sollwertes (Mittelwert \pm einfache Standardabweichung) wurden die berufliche Exposition gegenüber Gas, Rauch oder Staub über mindestens drei Monate, die Häufigkeit von jährlichen Erkältungen und die Zahl der Lungenentzündungen als möglicher Risikofaktor bei der Lungenfunktion abgefragt und analysiert [132]. Zunehmendes Alter, männliches Geschlecht und Giemen als Symptom konnten als unabhängige Größen, die den $\mathrm{FEV}_{1}$-Abfall beeinflussen, erkannt werden. Bei Männern über 50 Jahre waren Giemen und berufliche Belastung mit inhalativen Noxen unabhängige Determinanten der Lungenfunktion. Ein nachfolgender Bericht über die gleichen Patienten zeigte, dass Passivrauchen mit einem erhöhten Risiko einer chronischen Bronchitis einherging und dass Gebrauch von Kerosinheizungen und Berufstätigkeit in einem landschaftlichen Betrieb über mehr als 10 Jahre unabhängig voneinander mit einer Verminderung der Lungenfunktion korrelierte [133]. Im Hinblick auf Passivrauchen konnte auch in anderen Studien ein schädigender Einfluss mit Entwicklung von pulmonalen Symptomen gezeigt werden [34,68]. In einer prospektiven Studie an 103 schwedischen Kindern mit AAT-Mangel, der bei der Geburt entdeckt worden war, konnte gezeigt werden, dass sie bei Erreichen des Erwachsenenalters eine normale Lungenfunktion hatten, ein Hinweis dafür, dass Atemwegsinfekte in der Kindheit kein wesentlicher Risikofaktor bei der Entwicklung eines Lungenemphysems ist [134]. In einer dänischen Studie an Nierauchern mit PI*ZZ ohne klinische Symptome konnten keine Veränderungen der Lungenfunktion festgestellt werden[135]. Über die schwedische Studie hinaus berichten Seersholm und Kok-Jensen über 27 symptomatische und 48 asymptomatische Personen. Sie konnten keinen negativen Effekt des Passivrauchens auf die Entwicklung des Lungenemphysems finden [136]. Eine weitere Analyse der Daten aus dem dänischen AAT-MangelRegister zeigte, dass Raucherentwöhnung sich günstig niederschlug: die Exraucher zeigten eine Verminderung des jährlichen $\mathrm{FEV}_{1}$-Abfalls [128]. Der mittlere $\mathrm{FEV}_{1}$-Abfall war $81 \mathrm{ml} / \mathrm{Jahr}$, bei 
Tab. 6 Risikofaktoren, die bei PI*ZZ-Personen zur Entwicklung einer Lungenerkrankung führen

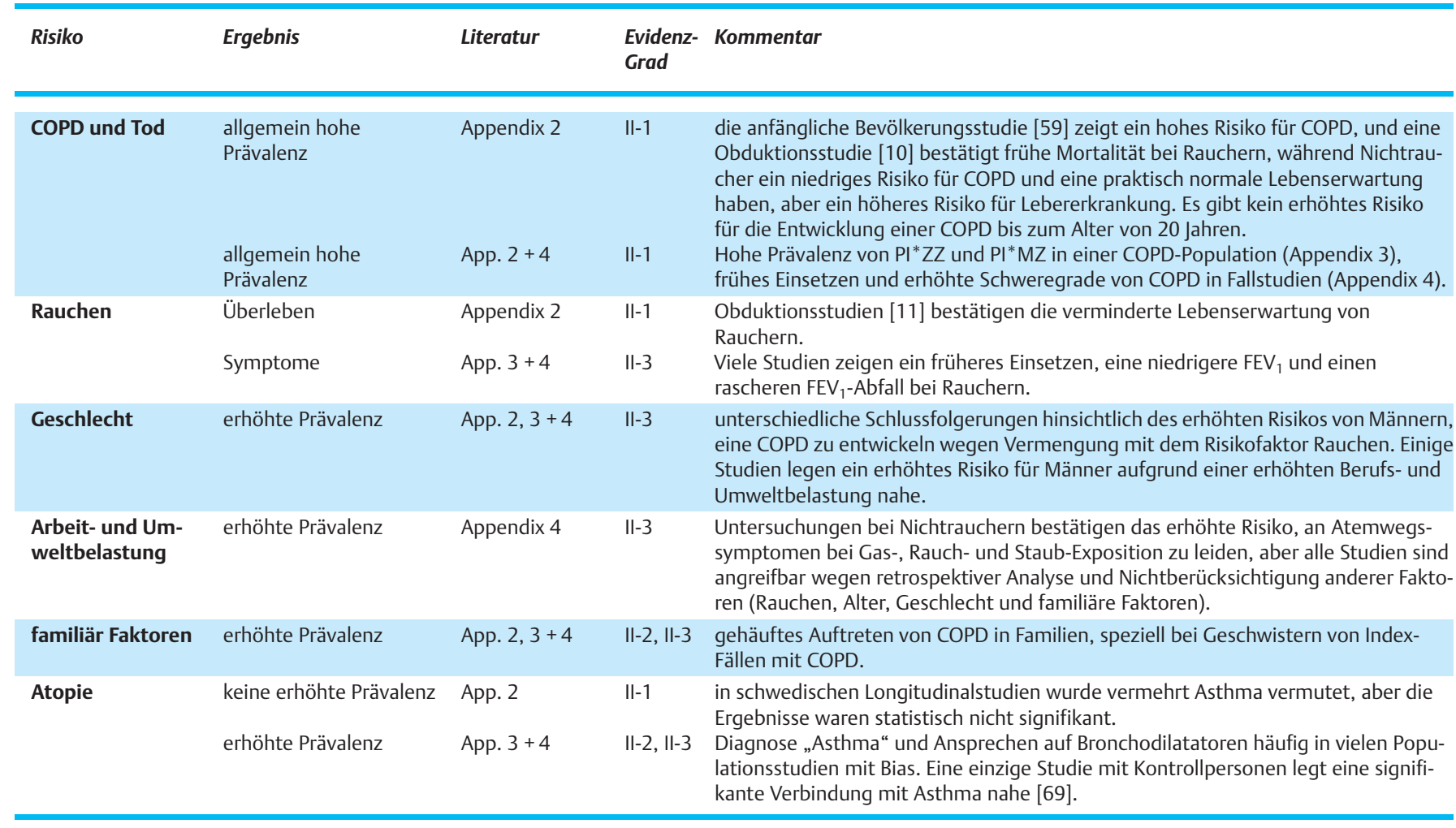

Definition der Abkürzung: $C O P D$ = chronic obstructive pulmonary disease .

den Rauchern $132 \mathrm{ml} / \mathrm{Jahr}$, bei den Patienten, die das Rauchen während der Studienperiode aufgegeben hatten, $58 \mathrm{ml} / \mathrm{Jahr}$, und bei Nierauchern $86 \mathrm{ml} / \mathrm{Jahr}$. Die Rate des $\mathrm{FEV}_{1}$-Abfalls war, bezogen auf den Sollwert des anfänglichen $\mathrm{FEV}_{1}$, U-förmig. Dabei zeigten die Patienten mit einem initialen $\mathrm{FEV}_{1}$ von 30-64\% Soll den schnellsten Abfall.

Im nordamerikanischen NHLBI-Register wurden 1129 Patienten mit schwerem AAT-Mangel über einen Zeitraum von 3,5 - 7 Jahren nachuntersucht [137]. Der mittlere $\mathrm{FEV}_{1}$-Abfall war $54 \mathrm{ml} /$ Jahr, Männer zwischen 30 und 44 Jahren hatten einen rascheren Abfall, ebenso aktive Raucher mit einem $\mathrm{FEV}_{1}$ zwischen 35 und $79 \%$ des Sollwertes und Patienten, deren Lungenfunktion sich auf Bronchodilatatoren besserte.

Mayer u. Mitarb. [138] untersuchten 128 Personen mit AATMangel vom PI*ZZ-Phänotyp, um die Beziehung zwischen chronischen Atemwegssymptomen, Atemwegsobstruktion, Behandlungsbedarf und semiquantitativer Abschätzung der beruflichen Exposition gegenüber Dampf, Rauch und Gas zu analysieren. Eine Häufung von chronischem Husten und Arbeitsverlust wegen Atemlosigkeit wurden bei Personen mit hoher Steinstaubexposition häufiger beobachtet als bei solchen ohne entsprechende Exposition. Personen mit hoher Steinstaubexposition hatten signifikant niedrigere $\mathrm{FEV}_{1}$ (31\% des Sollwertes), verglichen mit Individuen ohne entsprechende Exposition (40\% vom Sollwert). Aktives Tabakrauchen war ein signifikanter Risikofaktor für die Entwicklung der meisten pathologischen Befunde, aber es konnte keine Interaktion mit der beruflichen Exposition gezeigt werden.
Zusammenfassend beschleunigen aktives Zigarettenrauchen, Giemen in der Anamnese und einige distinkte Umweltnoxen wie Heizen mit Kerosin in Innenräumen und Arbeiten in landwirtschaftlichen Betrieben die Entwicklung des Emphysems bei Männern über 50 Jahre. Auch ist die berufliche Exposition gegenüber inhalativen Schadstoffen unabhängig assoziiert mit Atemwegssymptomen und Atemwegsobstruktion. Es gibt durchaus Hinweise dafür, dass die Exposition gegenüber Passivrauchen schädlich sein kann [34,68,133].

\section{Krankheitsverlauf}

Von den 200000 Kindern, die in Schweden gescreent wurden, hatten 127 den Phänotyp PI*ZZ. Die Kinder wurden von Geburt an prospektiv nachuntersucht sowohl klinisch als auch mit Messungen von Leber- und Lungenfunktion. Während der ersten zwei Lebensdekaden blieb die Lungenfunktion in der schwedischen Kohorte normal [139]. Untersuchungen zum Verlauf des AAT-Mangels haben gezeigt, dass die Entwicklung eines Emphysems, das zum vorzeitigen Tod führen kann, in der 3. und 4. Lebensdekade beginnt. In einer Untersuchung zur Lebenserwartung bei 246 Personen, die Larsson durchführte [6], lag das mediane Alter beim Tode für Raucher bei ungefähr 40 Jahren und bei Nierauchern bei 65 Jahren. Bei einer Untersuchung an einem Zuweisungsklientel von 124 AAT-Mangel-Patienten konnten Brantly u. Mitarb. eine kumulative Überlebenswahrscheinlichkeit von $52 \%$ bis zum Alter von 50 Jahren und nur eine $16 \%$ ige Überlebenschance jenseits dem 60. Lebensjahr nachweisen [63]. Jedoch basierten beide Studien auf Patientengruppen, die wegen 
pulmonaler Symptome aus den Krankenhaus-Archiven herausgesucht wurden, und die Schätzung der Lebenserwartung ist wegen dieses Selektionsbias zu einem gewissen Grade wahrscheinlich zu pessimistisch. Die Ergebnisse bei 347 Patienten des dänischen Registers [140] zeigten, dass der $\mathrm{FEV}_{1}$ der wichtigste Prädiktor des Überlebens war. Das mediane Überleben betrug für Patienten mit einem $\mathrm{FEV}_{1}$ von weniger als $25 \%$ des Sollwertes 6,3 Jahre, für Patienten mit einem Atemstoß von 25\% bzw. $50 \%$ des Sollwertes 10,5 bzw. 14,2 Jahre.

Tobin u. Mitarb. untersuchten den klinischen Verlauf und das Überleben von 166 Patienten mit AAT-Mangel, von denen 40 Nonindex-Fälle waren, d.h. man hatte sie bei Familienuntersuchungen herausgefunden [141]. In der Nonindex-Gruppe fanden sich deutlich weniger pulmonale Symptome als in der Indexgruppe, und es wurde kein vorzeitiger Todesfall in der NonindexGruppe gefunden verglichen mit 23 in der Index-Gruppe. Die Studie legt nahe, dass der klinische Verlauf der Erkrankung sehr variabel ist und dass diese Variabilität nicht nur durch die Raucheranamnese erklärt werden kann. Bei der Untersuchung der Lungenfunktion fanden Silvermann u. Mitarb. große Unterschiede bei 22 Index- und 30 Nonindex-Fällen, einige Personen der Nonindex-Gruppe hatten überhaupt keine pulmonalen Symptome [34]. Daraus zog man den Schluss, dass wohl andere familiäre Faktoren den Schweregrad des klinischen Verlaufes beeinflussen.

Um weitere Einsichten in den Verlauf des AAT-Mangels, insbesondere der Nonindex-Fälle zu erhalten, wurde im Jahre 1978 das dänische AAT-Mangel-Register ins Leben gerufen [54]. Patienten mit AAT-Mangel werden von allen dänischen Ärzten gemeldet, eine Familienanamnese wird erstellt und die Familienmitglieder auf PI-Phänotyp untersucht. Bis Dezember 1998 führte das Register 695 Personen mit AAT-Mangel vom Typ PI*ZZ oder PI*ZO. Mehr als 200 davon wurden bei Familienuntersuchungen entdeckt.

Mit den Daten dieses Registers war es möglich, nicht nur die Analyse der Lebenserwartung, die Larsson im Jahre 1978 durchgeführt hatte [6], zu wiederholen, sondern auch die Lebenserwartung einer großen Zahl von Nonindex-Patienten ohne Lungensymptome zu untersuchen [54]. Die rauchenden NonindexPatienten hatten eine mediane Überlebenserwartung von 49 Jahren, während die mediane Lebenserwartung von nicht rauchenden Patienten 69 Jahre betrug und sich statistisch nicht von der normalen dänischen Bevölkerung unterschied. Die weitere Analyse der Daten unter Kontrolle der lebenslangen Raucheranamnese zeigten, dass der Unterschied in der Lebenserwartung zwischen Index- und Nonindex-Fällen nicht allein durch Unterschiede in der Raucheranamnese zu erklären war und dass einige Raucher niemals ein schweres Lungenemphysem entwickelten [54].

Andere Risikofaktoren als Rauchen können genetisch oder umweltbedingt sein, wie z. B. Exposition gegenüber Staub und Rauch, häufige Lungeninfektionen oder Asthma [34,68,142-144]. Die Möglichkeit, dass eine bronchiale Hyperreagibilität mit einem größeren Verlust der $\mathrm{FEV}_{1}$ über die Zeit einhergehen könne, ist bei AAT-Mangel noch nicht vollständig geklärt [137]. Der beste Ansatz wäre die Untersuchung des klinischen Verlaufes und der Prognose von Nierauchern mit AAT-Mangel, es gibt jedoch nur wenige solche Studien mit kleinen Patientenzahlen und kurzen Verlaufskontrollen.

In einer schwedischen Untersuchung bei 225 Personen mit PI*ZZ, die angaben, nie geraucht zu haben, hatten die meisten bis zum 50. Lebensjahr eine normale Lungenfunktion und nur wenige Symptome von Seiten der Atemorgane. Nach dem 50. Lebensjahr gab es zwischen den einzelnen Personen große Unterschiede in der Lungenfunktion, die Mittelwerte (in Prozent des Sollwertes) verschlechterten sich deutlich mit dem Alter. Bei den Männern war das Risiko der Lungenfunktionsverschlechterung ausgeprägter als bei Frauen; asthmatische Symptome sowie berufliche Exposition gegenüber Atemwegsnoxen bildeten zusätzliche Risikofaktoren [132]. In einer Studie, die Veränderungen des $\mathrm{FEV}_{1}$ bei 211 Nierauchern, 354 Exrauchern und 46 Rauchern mit PI*ZZPhänotyp analysierte, betrug die mittlere jährliche Änderung des $\mathrm{FEV}_{1}$ bei Nierauchern $47 \mathrm{ml} / \mathrm{Jahr}$, bei Exrauchern $41 \mathrm{ml} / \mathrm{Jahr}$ und bei aktiven Rauchern $70 \mathrm{ml} / \mathrm{Jahr}$. Bei Nierauchern wurde nach dem 50. Lebensjahr ein stärkerer $\mathrm{FEV}_{1}$-Abfall gefunden als davor. Geschlechtsunterschiede beim Abfall des FEV $_{1}$ wurden dagegen nicht beobachtet [128].

In einer britischen Studie [145] fand man in der Gesamtpopulation einen Abfall des $\mathrm{FEV}_{1}$ von $45 \mathrm{ml} / \mathrm{Jahr}$, ohne dass Tabakabstinenz einen Effekt hatte. Auch sah man in dieser Studie einen langsameren Funktionsabfall bei Patienten mit einem initial niedrigen $\mathrm{FEV}_{1}$. Dieser Befund hat wahrscheinlich etwas mit dem Überlebenseffekt, zu tun, d. h. von den Patienten mit einem initial niedrigen $\mathrm{FEV}_{1}$ überlebten nur die mit einem langsameren Funktionsabfall lange genug, um genügend Untersuchungen zur Berechnung des $\mathrm{FEV}_{1}$-Abfalls zu generieren. In einer gemeinsamen amerikanisch-schwedischen Studie [146] wurde der $\mathrm{FEV}_{1}$-Abfall mit $100 \mathrm{ml} / \mathrm{Jahr}$ bestimmt und in einer Studie von Janus u. Mitarb. [147] ein $\mathrm{FEV}_{1}$-Abfall von $316 \mathrm{ml} / \mathrm{Jahr}$ bei Rauchern und $80 \mathrm{ml} / \mathrm{Jahr}$ bei Nierauchern. In den beiden genannten Studien wurde der Effekt der Rauchentwöhnung nicht untersucht.

Aufgrund einer Reihe von Studien konnte geklärt werden, dass die Verschlechterung der Lungenfunktion im Einzelfall von anderen Faktoren als dem Zigarettenrauchen abhängt [32]. Ergebnisse der Longitudinal-Untersuchung bei Patienten mit COPD und normalem AAT-Spiegel zeigen, dass die bronchiale Hyperreagibilität ein eindeutiger prognostischer Indikator für den Verlust von $\mathrm{FEV}_{1}$ in der Zeiteinheit ist [137]. Wenn gleichzeitig Asthma bronchiale vorhanden ist, dürfte der $\mathrm{FEV}_{1}$-Verlust durch vermehrte Entzündung der Atemwege bei fehlender anti-inflammatorischer Reaktion infolge AAT-Mangel höher ausfallen. In mehreren Untersuchungen wurde über die Verbindung zwischen Asthma und AAT-Mangel berichtet [69]. Obwohl es keine Untersuchungen gibt, die den Nutzen einer anti-inflammatorischen Therapie zur Verminderung des $\mathrm{FEV}_{1}$-Abfalls bei AAT-Mangel gibt, empfehlen wir derzeit, dass Patienten mit AAT-Mangel und Asthma aggressiv mit Medikamenten behandelt werden sollten, da diese die Atemwegsüberempfindlichkeit reduzieren und damit auch eine mögliche, unkontrollierte Atemwegsentzündung.

Über die Verbindung von sakkulären und zylindrischen Bronchiektasen mit AAT-Mangel mit und ohne begleitendes Lungenemphysem wurde berichtet [87]. Bronchiektasen scheinen bei spanischen Patienten häufiger zu sein [148]. 


\section{Vaskulitis und andere Organmanifestationen}

Wie in dem Kapitel „Leber und andere Erkrankungen“ diskutiert, wurde eine Vielzahl von anderen Krankheiten beschrieben, die mit einem AAT-Mangel einhergehen. Dazu gehören die systemische Vaskulitis, wie die ANCA-positive Wegener's Granulomatose und die nekrotisierende Panniculitis [149-152], die periphere Neuropathie [153] sowie cerebrale und periphere arterielle Aneurysmen [154]. Letztere konnten in größeren Studien nicht bestätigt werden [155]. Einige berichten eine Verschlechterung der Vaskulitis-Symptome durch $\alpha_{1}$-Antiproteinase-Behandlung $[149,156]$. Es ist bemerkenswert, dass im NHLBI-Registers mit 1.129 Patienten außer Lungen- und Lebererkrankungen keine anderen tödlichen Krankheiten beobachtet wurden [137].

\section{Nekrotisierende Panniculitis}

Eine seltene Komplikation bei Patienten mit PI*ZZ ist die Entwicklung einer nekrotisierenden Panniculitis [157,158]. Diese Erkrankung ist eine Entzündungsreaktion auf einen unbekannten Stimulus mit typischen nekrotisierenden Herden in der Subkutis und in der Kutis, die sehr ausgedehnt sein können.

\section{Lebererkrankung}

Nur 2,5\% der Neugeborenen, bei denen eine Phänotyp PI*ZZ diagnostiziert wird, sterben an akutem Leberversagen. Patienten über 50 Jahre können auch ein hepatozelluläres Karzinom und Leberzirrhose entwickeln [9]. Das beeindruckendste Ergebnis neuerer Studien $[10,11]$ ist jedoch die beherrschende Rolle der Leberzirrhose als Todesursache, insbesondere bei älteren Nierauchern. Die Leberzirrhose und ihre Komplikationen waren die Haupttodesursache bei 12 von 41 Patienten und fanden sich bei 14 von 41 Patienten. Aber nur bei 2 von 23 Rauchern starben an den Folgen der Leberzirrhose, verglichen mit 12 von 17 Nierauchern $(p<0,001)$. Ein hepatozelluläres Karzinom trat bei 5 Patienten mit Leberzirrhose auf, wurde aber nie in einer nicht zirrhotischen Leber gefunden.

Die Prävalenz der Leberzirrhose bei AAT-Mangel wurde bisher unterschätzt. Die Zahl von $5 \%$, wie sie in einem Bericht der World Health Organization genannt wurde [56], erscheint heute als zu niedrig. Das lebenslange Risiko, an einer Leberzirrhose zu erkranken, liegt nach einer realistischen Schätzung im Bereich von $30-40 \%[9,10]$. Bei der Pathogenese der Leberzirrhose wird ursächlich die Polymerisation des AAT-Proteins vermutet, aber der exakte Mechanismus ist nicht bekannt.

Risiken der MZ- und SZ-Phänotypen für die Entwicklung von Lungenemphysem und COPD

Es ist unklar, ob Personen mit einem heterozygoten AAT-Mangel vom Phänotyp MZ oder MS empfänglicher für die Entwicklung eines Lungenemphysems und einer COPD sind als Personen mit einem MM-Phänotyp. Nach den ersten Berichten über den Zusammenhang von PI*ZZ, AAT-Mangel und Lungenemphysem wurde vielerorts der Versuch unternommen, den klinischen Verlauf von Patienten mit PI*MZ-Phänotyp zu beschreiben. Leider wurde bis heute keine genügend große bevölkerungsbasierte Screening-Untersuchung durchgeführt, bei der Personen mit $\mathrm{PI}^{*} \mathrm{MZ}$ - gleichmäßig verteilt nach Alter, Geschlecht, Beruf und Rauchgewohnheiten - mit einer Kontrollkohorte verglichen
Tab. 7 Risikofaktoren, die bei Personen mit PI*MZ zur Lungenerkrankung führen

\begin{tabular}{|c|c|c|c|}
\hline Risikofaktor & Literatur & $\begin{array}{l}\text { Evidenz- } \\
\text { Grad }\end{array}$ & Kommentar \\
\hline $\begin{array}{l}\text { familiäre Häufung } \\
\text { von COPD }\end{array}$ & Appendix 5 & II-1 & $\begin{array}{l}\text { dazu wird es nie eine rando- } \\
\text { misierte, kontrollierte Studie } \\
\text { geben. }\end{array}$ \\
\hline Rauchen & Appendix 6 & II-1 & $\begin{array}{l}\text { dazu wird es nie eine rando- } \\
\text { misierte, kontrollierte Studie } \\
\text { geben. }\end{array}$ \\
\hline $\begin{array}{l}\text { Arbeitsumwelt als } \\
\text { Risiko }\end{array}$ & Appendix 7 & II-2 & $\begin{array}{l}\text { weitere Forschung zur Strati- } \\
\text { fizierung des Risikos nach } \\
\text { Schwere und Art der Inhalati- } \\
\text { onsexposition sind erforder- } \\
\text { lich. }\end{array}$ \\
\hline Atopie & Appendix 8 & II-3 & $\begin{array}{l}\text { die Ergebnisse sind kontro- } \\
\text { vers bei widersprüchlichen } \\
\text { Studien. }\end{array}$ \\
\hline kinderlose Frauen & $\begin{array}{l}\text { Horne u. Mitarb. } \\
1992[300]\end{array}$ & II-3 & $\begin{array}{l}\text { Unterschiede wurden bei } \\
\text { subtilen spirometrischen } \\
\text { Tests gefunden, aber nicht } \\
\text { bei der FEV } \text {. Diese Studie }_{\text {bleib die einzige zu diesem }} \\
\text { Thema und wurde nicht wie- } \\
\text { derholt. }\end{array}$ \\
\hline
\end{tabular}

Zur Definition der Abkürzung s. Tab. 6.

wurden hinsichtlich Verlaufskontrollen von Lungenfunktion und bronchialer Hyperreagibilität. Stattdessen wurde eine Fülle von Daten aus kleineren Fallkontrolluntersuchungen und populationsbasierten Studien zu Risikofaktoren einer obstruktiven Lungenerkrankung bei PI* MZ (s. Tab. 7).

\section{MZ-Prävalenz bei Patienten mit COPD}

Die ersten Hinweise für ein erhöhtes COPD-Risiko bei PI*MZMangel fand man, als man Patienten mit manifester Atemwegserkrankung phänotypisierte und dabei eine höhere PI*MZ-Prävalenz fand, als nach der Genfrequenz der Allgemeinbevölkerung zu erwarten war [159-168]. Nur in wenigen Studien fand sich eine solche Beziehung nicht [169-172].

\section{Familiäre Einflüsse}

Bei vielen dieser anfänglichen Untersuchungen wurden die $\mathrm{PI}^{*} \mathrm{MZ}$-Personen über ihre familiäre Beziehung zu symptomatischen PI*ZZ-Patienten herausgefunden. Als man bei diesen Patienten obstruktive Lungenfunktionsveränderungen fand [173 - 176], wurden die Studien kritisiert, mit der Begründung, dass die Atemwegsobstruktion Folge anderer genetischer oder Umweltfaktoren sein könnte, und nicht nur Ausdruck des AATMangels. Tatsächlich müsste man - bei der Häufung von COPD in Familien ohne AAT-Mangel - zur Beantwortung dieser Frage einen Personenkreis untersuchen, der sich aus der Gesamtbevölkerung und nicht aus Verwandten symptomatischer Patienten zusammensetzt (siehe Appendix 2).

Die größte bisherige Studie zur Untersuchung von PI*MZ-Patienten von Seersholm u. Mitarb. konnte zeigen, dass in Dänemark 9\% aller Patienten, die mit der Diagnose „COPD-Exazerbation“ im Krankenhaus aufgenommen wurden ( $\mathrm{n}=17061)$, den Phäno- 
typ PI*MZ aufwiesen [177]. Damit hat der PI*MZ-Phänotyp, verglichen mit PI*MM-Patienten, ein relatives Risiko der „Hospitalisation wegen COPD“ von 2,2 (95\% Konfidenzintervall, 1,5-3,0). Darüber hinaus hatten Verwandte ersten Grades von PI*ZZ-Indexfällen im Alter von 40 - 79 Jahren ein zusätzliches Risiko. Damit wurde die familiäre Neigung bei PI*MZ-Heterozygoten, eine COPD zu entwickeln, bestätigt. Bemerkenswert ist auch die hohe Prävalenz von PI*MZ-Phänotypen bei Personen mit Cor pulmonale. Weitere Untersuchungen zur familiären Häufung von COPD bei PI*MZ-Personen finden sich in Appendix 5.

\section{Tabakrauchen und COPD bei PI* MZ-Patienten}

In kleineren, bevölkerungsbasierten Studien wurde der Frage nachgegangen, ob Personen mit PI* MZ bei gleichem Tabakkonsum eine höhere COPD-Prävalenz haben. Dabei fanden sich bis auf wenige Ausnahmen ähnliche $\mathrm{FEV}_{1}$-Werte bei PI*MM- wie bei PI*MZ-Patienten [178 - 189].

Jedoch beobachtete man bei PI*MZ-Patienten diskrete Störungen der Lungenfunktion. So konnte gezeigt werden, dass der elastische Lungendruck, der mittlere forcierte expiratorische Fluss während der mittleren FVC-Hälfte $\left(\mathrm{FEF}_{25-75 \%}\right)$ [173,174,181, 190,191], die Frequenzabhängigkeit des Gesamtlungenwiderstandes [192], die Frequenzabhängigkeit der dynamischen Compliance [173], die Inhomogenität der Ventilation [192] und der arterielle Sauerstoffpartialdruck sich bei Patienten mit PI*MZ und PI* MM unterschiedlich verhielten. Die meisten Autoren vermuten, dass diese geringgradigen Störungen keine klinische Bedeutung haben.

Bevölkerungsbasierte Obduktionsuntersuchungen sind im Ergebnis ebenfalls uneinheitlich. So zeigte eine Obduktionsstudie bei MZ-Patienten eine erhöhte Emphysem-Prävalenz, obwohl sich keine Verbindungen von prämorbiden Symptomen oder vorzeitigem Tod ergaben [193]. In einer anderen Untersuchung konnten keine Unterschiede in der Emphysem-Prävalenz bei PI*MZ und PI*MM-Patienten nachgewiesen werden [194].

Um diese Studien in Einklang zu bringen und den kovariaten Einfluss des Zigarettenrauchens auf die Atemwegsobstruktion weiter zu analysieren, konstruierten Silverman u. Mitarb. [195] Regressionsgleichungen für $\mathrm{FEV}_{1}$ und $\mathrm{FEF}_{25-75 \%}$ im Vergleich zum kumulativen Anzahl der gerauchten Zigaretten (Packungsjahre) bei PI*MZ-Verwandten von PI*ZZ-Kranken. Sie konnten zeigen, dass PI*MZ-Patienten ein erhöhtes Risiko zur Entwicklung einer Atemwegsobstruktion haben, in einer Größenordnung, die zwischen dem von Patienten mit PI*MM und denen mit PI*ZZ-Phänotyp liegt. Eine andere populationsbasierte Longitudinalstudie von Eriksson u. Mitarb. [196] untersuchte die FEV ${ }_{1}$ regelmäßig 6 Jahre lang bei Personen mit PI*MZ. Der FEV ${ }_{1}$-Abfall war bei den Rauchern mit $75 \mathrm{ml} / \mathrm{Jahr}$ größer als bei nicht rauchenden PI* MZPersonen mit $40 \mathrm{ml} / \mathrm{Jahr}(\mathrm{p}<0,05)$.

Zusätzliche Daten aus der NHLBI Lung Health Studie bestätigen das Risiko des MZ-Phänotyps bei einer rauchenden Bevölkerung. Unter den 5.887 männlichen und weiblichen Rauchern, die für die NHLBI Lung Health Studie rekrutiert werden konnten, wurden 283 Personen mit dem raschesten $\mathrm{FEV}_{1}$-Abfall $(\Delta$ $\mathrm{FEV}_{1}=-154 \pm 3 \mathrm{ml} / \mathrm{Jahr}$ ) und mit 308 Personen ohne $\mathrm{FEV}_{1}$-Abfall $\left(\Delta \mathrm{FEV}_{1=}+15 \pm 2 \mathrm{ml} / \mathrm{Jahr}\right.$ ) gesondert untersucht und zwar im
Hinblick auf den Polymorphismus im AAT-Protein und auf mikrosomale Epoxidhydrolase, Vitamin D-bindendes Hormon und Tumor Nekrose-Faktor-Gen. Ein rascher Abfall des $\mathrm{FEV}_{1}$ war verbunden mit einem MZ-Genotyp des AAT-Gens (odds ratio [OR] 2,$8 ; p=0,03$ ). Diese Verbindung war stärker, wenn COPD in der Familienanamnese und der Genotyp MZ zusammen auftraten $(\mathrm{OR}, 9,7 ; \mathrm{p}=0,03)$. Diese Ergebnisse legen nahe, dass der MZ-Genotyp mit einem beschleunigten Abfall der Lungenfunktion einhergeht und mit anderen familiären Faktoren interagiert. Die mikrosomalen Epoxidpolymorphismen gingen, wie PI*MZ AAT, mit einem rascheren Abfall der Lungenfunktion einher. Nicht assoziiert mit einem beschleunigten Abfall der Lungenfunktion jedoch waren in dieser Studie der AAT S und 3̧Polymorphismus, die Isoformen des Vitamin D-bindenden Proteins und die Tumor Nekrose-Faktoren (TNF- $\alpha$-200304467oc G308A und TNF- $\alpha$-A252G) [197].

Zusammengenommen hat sich aufgrund vieler Studien die Einsicht verdichtet, dass Zigarettenrauchen bei Personen mit PI*MZ ein Risiko zur Entwicklung einer COPD darstellt (s. Appendix 6).

\section{Umweltrisiken zur Entwicklung einer COPD bei PI*MZ-Patienten}

In einigen bevölkerungsbasierten PI*MZ-Kohorten konnten Atemnot [198] und Giemen häufiger beobachtet werden als bei PI*MM-Personen, insbesondere wenn sie den Belastungen von Umweltrauch oder Tabakrauch ausgesetzt waren. Andere Untersucher konnten diese Befunde bei großen Populationen nicht bestätigen [178,182,198-201].

Der Einfluss der Arbeitsumwelt wurde in Baumwollmühlen bei Arbeitern mit einem erhöhten Byssinose-Risiko untersucht. Mit Hilfe multivariater Analysen, bei welchen auch der Endotoxinspiegel gemessen und berücksichtigt wurde, konnte nachgewiesen werden, dass der PI*MZ-Phänotyp ein Risiko zur Entwicklung von respiratorischen Symptomen mit sich bringt $[202,203]$. In anderen Studien konnte keine Verbindung zwischen Patienten mit PI* MZ und Byssinose-Symptomen nachgewiesen werden [204,205], diese Studien berücksichtigten jedoch nicht das stärkere Risiko der Endotoxinexposition. Andere Arbeitsplätze mit einem erhöhtem Staubrisiko findet man möglicherweise bei der Getreideverarbeitung [206] und im Bergbau [207]. Aktuelle Studien, die sich mit der Luftqualität als Risikofaktor für COPD bei Personen mit PI*MZ umfassen, sind in Appendix 7 aufgelistet.

\section{Der Einfluss des PI* MZ-Phänotyps auf atopische Erkrankungen}

Die Datenlage ist bei atopischen Erkrankungen ziemlich lückenhaft (s. Appendix 8). Obwohl der PI*MS-Heterozygote ein erhöhtes Asthma-Risiko haben könnte [208,209], findet man die PI*MZ-Genprävalenz einmal höher als bei einer allgemeinen Population von Asthma-Patienten [186], das andere Mal wieder nicht [201,210 - 212]. In anderen Studien wird über eine Häufung von PI*MZ bei Aspirin-sensitivem Asthma [213], Nasenpolypen und Sinusitis [214,215] berichtet.

Zu den anderen Lungenerkrankungen, bei denen in der Literatur über ein gehäuftes Auftreten von PI* MZ berichtet wird, zählen die ambulant erworbene Pneumonie [216], die Rheumalunge [217] und die Wegener'sche Granulomatose [10]. 


\section{Zusammenfassung}

Der Einfluss des PI*MZ-Phänotyps auf Erkrankung der Lunge in Form eines erhöhten COPD-Risikos erscheint gesichert. Das Konzept eines multifaktoriellen Zusammenwirkens von genetischer Disposition, Zigarettenrauchen und Umwelt bei Patienten mit $\mathrm{PI}^{*} \mathrm{MZ}$ ist nach der vorhandenen Datenlage schlüssig. Ein Mensch mit einem PI*MZ-Phänotyp, der raucht, entwickelt gewöhnlich später im Leben eine leichte Lungenfunktionsstörung. Das Risiko, eine symptomatischen COPD zu entwickeln, kann jedoch deutlich höher sein bei starken Zigarettenrauchern mit einer zusätzlichen Umwelt- oder Arbeitsplatzbelastung, insbesondere bei Verwandten von Patienten mit obstruktiver Lungenerkrankung.

\section{Der SZ-Phänotyp}

Studien haben gezeigt, dass Rauchen das Hauptrisiko für die Entwicklung eines Lungenemphysems ist und dass das Emphysemrisiko bei Nichtrauchern vernachlässigbar klein ist [218-220] (s. Tab. 8 und Appendix 9). Die Auswirkungen des Zigarettenrauchens jedoch sind tiefgreifend und führen zu einer Verschlechterung der Lungenfunktion; diese ist oft so ausgeprägt, wie bei rauchenden PI*ZZ-Patienten. Obwohl es keine Studien zur Bedeutung berufsbezogener Schadstoffe oder von Umweltnoxen bei Personen mit SZ-Phänotyp gibt, kann man mit gutem Grund annehmen, dass sie ebenso empfänglich sind wie Personen mit PI*ZZ-Phänotyp.

\section{Prognose}

Mehrere Studien haben nachgewiesen, dass die $\mathrm{FEV}_{1}$ der wichtigste Prädiktor für das Überleben von Patienten mit Lungenemphysem bei AAT-Mangel ist. Im dänischen AAT-Mangel-Register war die 2-Jahres-Überlebenszeit so lange normal, wie die $\mathrm{FEV}_{1}$ über 35\% des Sollwertes lag. Bei Personen mit einer FEV $_{1}$ unter $35 \%$ des Sollwertes stieg die Mortalität exponentiell mit dem Abfall der $\mathrm{FEV}_{1}$ an [221]. Jedoch ist der Krankheitsverlauf bei AATMangel bis heute wegen der beschränkten Zahl der prospektiven Studien nicht völlig geklärt. Bei Rauchern, die nicht aufhören können mit dem Rauchen, ist die Lebenserwartung, nachdem die Diagnose eines AAT-Mangels gestellt wurde, geringer als 20 Jahre. Der Abfall der $\mathrm{FEV}_{1}$ ist am schnellstens, wenn der $\mathrm{FEV}_{1}$-Wert zwischen 30 und 65\% des Solls liegt [222]. In den Nachsorgestudien, die bis zu 19 Jahren liefen, betrug die Mortalitätsrate, nicht bereinigt, $41 \%$ [223]. Ist die Lungenfunktion erst einmal gestört, findet man beim Abfall der $\mathrm{FEV}_{1}$-Kurve zwischen aktiven Rauchern und Exrauchern keinen signifikanten Unterschied, Exraucher leben aber länger - so das Ergebnis zweier Studien [223,224]. Bei 282 Patienten mit PI*ZZ wurde anhand der 2-Jahres-Überlebensrate die Mortalität in Abhängigkeit von der $\mathrm{FEV}_{1}$ berechnet. In einer einfachen Exponentialfunktion war die Überlebensrate nahezu 100\%, solange die $\mathrm{FEV}_{1}$ über $1 / 3$ des Sollwertes lag. Die 2-Jahres-Mortalität war $50 \%$, wenn die $\mathrm{FEV}_{1} 15 \%$ des Sollwertes und weniger betrug [224]. Bei Non Index-Patienten, die nie in ihrem Leben geraucht hatten, konnte eine normale Lebenserwartung beobachtet werden [135,221].
Tab. 8 Zusammenfassung der Risikofaktoren, die beim PI*SZ-Phänotyp zur Entwicklung von Lungenerkrankungen führen

\begin{tabular}{|c|c|c|}
\hline Risikofaktor & $\begin{array}{l}\text { Evidenz-Grad } \\
\text { für ein Risiko }\end{array}$ & Kommentare \\
\hline Rauchen & II-2 & $\begin{array}{l}\text { erhöhte Evidenz für Emphysem } \\
\text { aufgrund radiologischer Kriterien. } \\
\text { Vermehrt Atemwegsobstruktion bei } \\
\text { Rauchern, signifikant korreliert mit } \\
\text { den Packungsjahren verglichen mit } \\
\mathrm{PI}^{*} \mathrm{ZZ} \text {. Weniger PI*SZ-Raucher als } \\
\mathrm{PI}^{*} \text { ZZ-Raucher entwickeln ein Lun- } \\
\text { genemphysem. }\end{array}$ \\
\hline $\begin{array}{l}\text { PI*SZ selbst und/ } \\
\text { oder andere Um- } \\
\text { welt-genetische } \\
\text { Faktoren }\end{array}$ & $11-3$ & $\begin{array}{l}\text { bei Gelegenheitsrauchern radiologi- } \\
\text { sche Hinweise auf Emphysem und } \\
\text { Atemwegsobstruktion. }\end{array}$ \\
\hline $\begin{array}{l}\text { Serum AAT-Spie- } \\
\text { gel }\end{array}$ & II-3 & $\begin{array}{l}\text { Häufung von Husten und Giemen } \\
\text { nach Angabe der Patienten bei } \\
\text { Serumspiegel }<11 \mu \mathrm{M} \text {. } \\
\text { Insgesamt korrelierten die Serum- } \\
\text { spiegel nicht mit der Lungenfunk- } \\
\text { tion. }\end{array}$ \\
\hline
\end{tabular}

\section{Prävention von Lungenerkrankung}

Um die Entwicklung des Lungenemphysems zu verhindern, genügt es, das Zigaretten rauchen zu vermeiden und Umweltnoxen zu verhindern. Von der Lung Health Studie wissen wir, dass der $\mathrm{FEV}_{1}$-Abfall pro Jahr sich bei Personen, die das Rauchen mit Erfolg aufgeben, deutlich verringert [225]. Frühe Raucherabstinenz ist besonders wichtig bei Personen mit einem homozygoten Phänotyp. Leider sprechen junge Erwachsene auf solche Appelle am wenigsten an. Es gibt mittlerweile eine ganze Reihe pharmakologischer Hilfen zur Raucherentwöhnung; sie sollten von Rauchern, die mit dem Zigarettenrauchen aufhören wollen, genutzt werden. Auch ist theoretisch zu erwarten, dass die Kontrolle von Atemwegsinfekten und bronchialer Hyperreagibilität die Belastung der Lungen- und Atemwege durch neutrophile Granulozyten vermindert. Die Exposition gegenüber Atemwegsnoxen, passivem Zigarettenrauchen sowie Staub und Rauch sollte minimiert werden. Bei regelmäßiger Exposition gegenüber schädlichen Umweltstoffen sollte ein Arbeitsplatzwechsel vorgenommen werden.

Präventive Strategien wie Influenza- oder Pneumokokken-Impfung sind zu empfehlen. Wegen der Möglichkeit eines Mitbefalls der Leber empfehlen wir die Durchführung der Hepatitis-Serologie. Was die Hepatitis-Impfung von Personen mit AAT-Mangel ohne manifeste Lebererkrankung oder bei alleiniger Lungenerkrankung anbelangt, so schlagen wir vor, den allgemeinen Impfempfehlung des betreffenden Landes nachzukommen. Eine Hepatitis-Impfung ist jedoch zu empfehlen bei Patienten mit AATMangel und manifester Lebererkrankung. Die Arbeitsgruppe ist der Meinung, dass eine Immunisierung gegen Hepatitis B vor Beginn einer AAT-Substitutionstherapie bei Patienten ohne Lebererkrankung nicht erforderlich ist, da Infektionen mit Hepatitis B unter Substitutionstherapie nicht berichtet wurden. 
Allgemeine medizinische Behandlung

Die Leitlinien zur Therapie von Erkrankungen mit COPD ohne AAT-Mangel sind in früheren Publikationen ausreichend dargelegt und sind auf die pulmonalen Manifestationen bei AAT-Mangel anwendbar $[77,78]$.

Die meisten Patienten mit AAT-Mangel und obstruktiver Lungenerkrankung geben eine symptomatische Besserung nach Anwendung von Bronchodilatatoren an, selbst wenn sich keine objektive Besserung der Lungenfunktion nachweisen lässt. Viele Patienten benutzen diese Medikamente, um die Atemnot bei Belastung zu verringern; Überdosierung ist jedoch häufig und kann zu Zittrigkeit und Beklemmung führen. Die Patienten sollten ermutigt werden, körperlich aktiv zu bleiben, aber die körperliche Belastung nicht zu übertreiben, um Hyperventilation und „air trapping“ zu vermeiden. Patienten mit einer bronchialen Hyperreagibilität sollten inhalative Steroide erhalten, unter der Annahme, dass eine Verminderung der Atemwegsentzündung auch den zeitlichen $\mathrm{FEV}_{1}$-Abfall verringert. Eine Studie kam zu dem Ergebnis, dass Patienten mit AAT-Mangel und Lungenerkrankung aus der Behandlung mit inhalierten Steroiden Nutzen ziehen, obwohl nicht eindeutig ist, welche Patienten dies sind [226].

Antibiotika sollten bei Patienten mit Hinweisen auf Bronchitis oder Infekte der oberen Atemwege verabreicht werden. Obwohl es keine Studien zur Bedeutung der infektinduzierten, granulozytären Entzündung auf die Lungenfunktion gibt, erscheint ein aggressives Vorgehen gerechtfertigt. Insbesondere Makrolide können die Entzündung mit Neutrophilen vermindern [227]. Jedoch sollten auch $\beta$-Laktam-Antibiotika oder Quinolone eingesetzt werden, um die Entwicklung von bakteriellen Resistenzen gegen Makrolide zu vermeiden. Patienten mit Bronchiektasen sollten über einen längeren Zeitraum antibiotisch behandelt werden.

Sauerstoff sollte zur Anwendung kommen bei Patienten, bei denen unter körperlicher Belastung ein Abfall der Sauerstoffsättigung nachgewiesen ist. Sauerstoffzufuhr erhöht die körperliche Belastbarkeit derjenigen Patienten, die unter Belastung entsättigen. Positive Auswirkungen auf Lebensqualität oder körperliche Kondition, die über die Effekte der Lungenrehabilitation hinausgehen, konnten jedoch nicht nachgewiesen werden [228,229]. Bei schwerer Hypoxämie sollte die Langzeit-Sauerstofftherapie entsprechend den Kriterien der American Thoracic Society und der European Respiratory Society eingeleitet werden [76,77].

Orale Kortikosteroide sind von Nutzen bei Patienten mit einer eindeutigen asthmatischen Komponente ihrer Erkrankung, sollten aber über längere Zeiträume wegen des Verlustes der Knochensubstanz nur mit Vorsicht eingesetzt werden [230]. Die Verkürzung der Wirbelsäule bei Osteoporose trägt zum Verlust von Lungenvolumen und zu körperlicher Behinderung infolge von Wirbelsäulenschmerzen bei.

Depressionen treten bei Patienten mit chronischer Lungenerkrankung häufig auf, und Patienten mit AAT-Mangel bilden dabei keine Ausnahme. Frühe Hinweise auf Depression wie Appetitverlust sollten rechtzeitig erkannt und entsprechend behandelt werden. Trizyklische Antidepressiva werden von Patienten mit chronischer Sputumproduktion schlecht vertragen, können aber bei einigen Patienten zur Schlafinduktion von Nutzen sein. Die neueren selektiven Inhibitoren der Serotonin -Wiederaufnahme sind wirksame Medikamente.

Panikreaktionen treten bei Patienten mit Lungenemphysem ebenfalls häufig auf [231,232]; sie lassen sich pharmakologisch mit kurzwirksamen Benzodiazepinen behandeln. Nebenwirkungen bei einigen Patienten limitieren jedoch ihren Einsatz. Buspiron, ein 5-Hydroxytryptamin-Rezeptor-Teilagonist, ist in entsprechend hoher Dosierung besonders effektiv. In letzter Zeit haben sich selektive Inhibitoren der Serotonin-Wiederaufnahme als besonders günstig bei angstbesetzten Störungen erwiesen [233]. Einige Patienten finden nicht pharmakologische Entspannungstechniken wie Yoga hilfreich.

Das Konzept der pulmonalen Rehabilitation kombiniert ein multimodales Therapie-Regime mit Verbesserung des Selbstvertrauens und der Stresskontrolle [234]. Die meisten Fachleute sind sich darüber einig, dass die Rehabilitation die Dauerleistungsfähigkeit verbessert, die Atemnot reduziert und die Zahl der Krankenhausaufenthalte vermindert [234]. Viele der bisher veröffentlichten Rehabilitationsprogramme funktionieren. Der genaue Aufbau des Programms erscheint weniger wichtig als ein strukturiertes Vorgehen, die Motivation des Therapeuten und die körperliche Belastbarkeit des Patienten. Der Übungseffekt verschwindet mit der Zeit, sobald die Therapie beendet ist. Weil Patienten mit AAT-Mangel für gewöhnlich jünger sind und weniger an Begleiterkrankungen leiden als die meisten Patienten mit COPD, wird höhere körperliche Belastung gut vertragen. Da die meisten Patienten noch im Arbeitsprozess stecken, können viele den Kauf von Ergometern für zu Hause verkraften und die Sauerstoffsättigung mit portablen Pulsoximetern kontrollieren.

Gewichtsverlust und Unterernährung sind ein häufiges Problem bei Patienten mit Lungenemphysem [235], wohl als Folge eines gesteigerten Stoffwechsels bei vermehrter Atemarbeit [236]. Eine intensivierte Nahrungszufuhr zur Wiederherstellung eines idealen Körpergewichtes hat sich im Großen und Ganzen als erfolglos erwiesen, trotzdem können kleinere und häufigere Mahlzeiten den Meteorismus vermindern und damit die Atemnot reduzieren.

\section{Substitutionstherapie}

Der Fokus der Therapie von Patienten mit Lungenemphysem infolge eines schweren AAT-Mangels war immer auf die Korrektur des Mangelzustandes ausgerichtet: Wenn es gelänge, den Mangel zu beheben, ließe sich auch die weitere Zerstörung von Lungengewebe verhindern und die Erkrankung stabilisieren. Folgende therapeutischen Ansätze zur Behebung des AAT-Mangels kommen in Betracht: (1) die intravenöse Substitutionstherapie mit Plasmaprodukten, (2) die inhalative Substitutionstherapie, (3) die Substitutionsbehandlung mit rekombinantem AAT und (4) die Therapie mit synthetischen Elastasehemmern (s. Tab. 9 und Appendix 10) [237].

\section{Intravenöse Substitutionstherapie mit Plasmaprodukten}

In den frühen 80er Jahren konnte gezeigt werden, dass die intravenöse Verabreichung von gereinigtem menschlichen AAT-Kon- 
Tab. 9 Zusammenfassende Evidenz-Tabelle zur Substitutionstherapie bei Alpha-1-Antitrypsin-Mangel: Indikation und Durchführung

\begin{tabular}{|c|c|c|c|}
\hline Verfahren & Messwert & $\begin{array}{l}\text { Evidenz- } \\
\text { Grad }\end{array}$ & Kommentare \\
\hline $\begin{array}{l}\text { Laboruntersu- } \\
\text { chung }\end{array}$ & $\begin{array}{l}\text { Alpha-1-Anti- } \\
\text { trypsin-Serum- } \\
\text { spiegel } \\
<11,0 \mu \mathrm{M}\end{array}$ & II-2 & $\begin{array}{l}\text { die Indikation zur Behand- } \\
\text { lung ist unabhängig vom } \\
\text { Phänotyp und wird begrün- } \\
\text { det durch den Serumspiegel } \\
\text { und den Nachweis einer ob- } \\
\text { struktiven Lungenerkran- } \\
\text { kung. }\end{array}$ \\
\hline $\begin{array}{l}\text { Lungenfunktions- } \\
\text { untersuchung }\end{array}$ & $\begin{array}{l}\mathrm{FEV}_{1} \text { (nach Bron- } \\
\text { chodilatantien) } \\
\text { zwischen } 30 \text { und } \\
65 \% \text { des Soll- } \\
\text { wertes }\end{array}$ & II-2 & $\begin{array}{l}\text { Patienten mit normaler oder } \\
\text { nahezu normaler Lungen- } \\
\text { funktion können behandelt } \\
\text { werden, wenn die Lungen- } \\
\text { funktion sich rasch ver- } \\
\text { schlechtert ( } \Delta \mathrm{FEV}_{1} \\
>120 \mathrm{ml} / \mathrm{J} \text { ahr). Patienten } \\
\text { mit sehr schlechter Lungen- } \\
\text { funktion, die schon substitu- } \\
\text { iert werden, sollten weiter } \\
\text { behandelt werden. }\end{array}$ \\
\hline $\begin{array}{l}\text { Dosierung und } \\
\text { Frequenz }\end{array}$ & & II-3 & $\begin{array}{l}\text { die Serumspiegel sollten } \\
\text { durchgehend } 35 \% \text { des Soll- } \\
\text { wertes überschreiten. Der } \\
\text { untere Schwellenwert im } \\
\text { Serumsollte am Tag } 7 \text { un- } \\
\text { mittelbar vor der nächsten } \\
\text { Infusion über } 15 \mu \mathrm{M} \text { liegen. } \\
\text { Wenn monatlich die } \\
\text { 4-fache Dosis von Prolastin } \\
\text { gegeben wird, ist der } \\
\text { Patient für einige Tage } \\
\text { ohne Schutz. }\end{array}$ \\
\hline
\end{tabular}

zentrat zu einer Erhöhung des AAT-Spiegels in der Lunge von Personen mit AAT-Mangel führte $[238,239]$. Die anti-neutrophile Elastasekapazität im Flüssigkeitsfilm des Lungenepithels, mittels bronchoalveolärer Lavage gewonnen, stieg bei homozygotem AAT-Mangel auf bis zu 60-70\% der Norm an, wenn man 1 $\mathrm{x}$ wöchentlich AAT-Konzentrat als Plasmaprodukt in einer Dosis von $60 \mathrm{ml} / \mathrm{kg}$ Körpergewicht verabreichte. Auf der Basis dieser Untersuchungen wurde ein gereinigtes AAT-Konzentrat hergestellt, das aus fraktioniertem Plasma (Prolastin) gewonnen wurde. Es erwies sich als biologisch wirksam [240-242]. Es gibt derzeit noch weitere Antiproteasen-Zubereitungen aus gepooltem menschlichen Plasma [240], auch sind rekombinante Wirkstoffe in der technischen Entwicklung.

Auf der Basis dieser Studienergebnisse erfolgte die Zulassung durch die „US Food and Drug Administration“ im Jahre 1988 und danach auch die Zulassung durch die entsprechenden Regulationsbehörden in Kanada, Deutschland, Spanien und Italien. Bis heute gibt es lediglich eine einzige randomisierte, Plazebo kontrollierte Studie mit der Fragestellung, ob durch die Substitutionstherapie die Entwicklung des Lungenemphysems hinausgezögert werden kann [112]. Studien dieser Art sind sehr schwierig durchzuführen, zudem auch - wegen der großen Zahl von Patienten und der langen Zeit, die eine solche Studie für eine adäquate Aussage benötigt - teuer. Empfehlungen zur Substitutionstherapie wurden in früheren Jahren durch die American Tho- racic Society [243] und durch die Canadian Thoracic Society $[244,245]$ veröffentlicht.

In zwei kontrollierten Beobachtungsstudien wurde der Frage nach der klinischen Wirksamkeit der Substitutionstherapie nachgegangen: in einer deutsch-dänischen Studie $[246,247]$ und in einer Studie des NHLBI-Registers der Vereinigten Staaten [137]. Die erste Studie hatte das Ziel, den $\mathrm{FEV}_{1}$-Abfall zwischen dänischen Patienten, welche nie eine Substitutionstherapie erhalten hatten, und deutschen Patienten, die wöchentlich mit AAT substituiert wurden, zu vergleichen. Der jährliche Abfall der $\mathrm{FEV}_{1}$ in der behandelten Gruppe $(-53 \mathrm{ml})$ war signifikant niedriger als in der unbehandelten Gruppe $(-75 \mathrm{ml})(\mathrm{p}=0,02)$. Es ist allerdings anzumerken, dass sich die beiden Gruppen hinsichtlich der Geschlechtsverteilung und des initialen $\mathrm{FEV}_{1}$ unterschieden. Beim Vergleich der verschiedenen Schweregrade konnte ein signifikanter Behandlungseffekt nur bei Patienten mit einem initialen $\mathrm{FEV}_{1}$ von 31 - $65 \%$ des Sollwertes nachgewiesen werden. Die Autoren ziehen aus dieser nicht randomisierten Studie den Schluss, dass die wöchentliche Infusion mit menschlichem AAT bei Patienten mit einer mittelschwer beeinträchtigten Lungenfunktion den jährlichen Abfall der $\mathrm{FEV}_{1}$ verlangsamt.

Im NHLBI-Register wurden 1129 Patienten mit schwerem AATMangel (Serumspiegel $<11 \mu \mathrm{m}$ ) erfasst und 3,5 - 7 Jahren nachuntersucht. Die 5-Jahres-Mortalität betrug 19\%. In einer multivariaten Analyse konnte gezeigt werden, dass die Mortalitätsrate bei den Substituierten niedriger war als bei den Nichtsubstituierten $(\mathrm{OR}, 0,79 ; \mathrm{p}=0,02)$. Der mittlere $\mathrm{FEV}_{1}$-Abfall betrug $54 \mathrm{ml} /$ Jahr, und es gab gesamthaft keinen Unterschied zwischen den Substituierten und den Nichtsubstituierten. Bei Patienten mit mittelschwer ausgeprägtem Lungenemphysem (d.h. Emphysem vom Schweregrad II nach den Kriterien der American Thoracic Society mit $\mathrm{FEV}_{1}$ von $35-49 \%$ des Sollwertes) fiel jedoch der $\mathrm{FEV}_{1}$-Abfall unter Substitution signifikant geringer aus $(\mathrm{p}=0,03)$.

Diese zwei Beobachtungsstudien legen nahe, dass das Fortschreiten des Lungenemphysems bei Patienten mit mittelschwer ausgeprägtem Lungenemphysem ( $\mathrm{FEV}_{1} 31-65 \%$ des Sollwertes) verlangsamt werden kann. Darüber hinaus kann die Mortalität bei Patienten mit einem niedrigen $\mathrm{FEV}_{1}$ gesenkt werden.

Zur Frage der Wirksamkeit der Substitutionstherapie wurden in einer kleinen randomisierten klinischen Studie 26 dänische und 32 holländische Patienten untersucht [112]. Die aktive Behandlung beinhaltete die monatliche Infusion von $250 \mathrm{mg} A A T / \mathrm{kg}$ Körpergewicht; als Plazebo diente Albumin. Die 2-Jahres-Studie war zu klein, um Unterschiede im Verlauf der Lungenfunktion nachweisen zu können, aber beim Rückgang der Lungendichte im CT zeigte sich einen Trend zugunsten der aktiv behandelten Gruppe (50\%ige Reduktion des Abfalls, $p=0,07$ ). Mit dieser Studie konnte die Bedeutung der Lungendichtemessung mit $\mathrm{CT}$ als einen möglichen Endpunkt des Wirksamkeitsnachweises herausgearbeitet werden.

Unerwünschte Nebenwirkungen nach intravenöser Gabe von AAT-Konzentrat sind selten. Zwischen Februar 1989 und Dezember 1995 wurden 443 Patienten 58000 Infusionen verabreicht [247]. Über 124 geringe Nebenwirkungen (Fieber, Schüttelfrost, Atemnot) wurde bei 65 Patienten berichtet. Drei Patienten been- 
deten die Behandlung mit AAT-Konzentrat wegen wiederholtem Schüttelfrost und Fieber unmittelbar nach der Infusion. Bei vier Patienten trat eine anaphylaktische Reaktion auf, in jedem Fall mit vollständiger Erholung. In einem Fallbericht wird eine IgEvermittelte, anaphylaktische Reaktion nach der 3. Infusion beschrieben [248]. Da bisher keine Ansteckung mit Viren beobachtet werden konnte, hält diese Arbeitsgruppe die Immunisierung gegen Hepatitis B vor Beginn der Substitutionstherapie für verzichtbar.

\section{Substitutionsbehandlung mit Aerosolen}

Die Applikation von AAT als Aerosol führt bei Patienten mit AATMangel zu einer Erhöhung der AAT-Konzentration und der AntiElastase-Aktivität im unteren Atemtrakt, und zwar dosisabhängig [249]. Auch konnte gezeigt werden, dass die Deposition von radioaktiv markiertem AAT bei Patienten mit leichtgradigem Lungenemphysem zu einer vermehrten peripheren Deposition führt, während Patienten mit fortgeschrittenem Lungenemphysem eine mehr zentrale Deposition des inhalierten AAT im Atemtrakt aufweisen [250]. Das Auftreten von Bronchospasmus wurde nicht berichtet. Vorläufige Daten legen nahe, dass die Verabreichung von AAT als Aerosol, 1 oder $2 \times$ täglich verabreicht, einen anhaltenden Anti-Elastase-Schutz in der Lunge gewährleistet.

\section{Substitutionstherapie mit rekombinantem AAT}

Eine Reihe rekombinanter AAT-Produkte wie auch ein rekombinanter Leukoprotease-Inhibitor konnten bereits entwickelt werden [251]. Auch gelang es, menschliches AAT-Gen in Schafembryonen zu transferieren mit dem Ergebnis, dass diese Tiere Mannose-glykolysiertes AAT mit der Milch ausscheiden [252].

\section{Synthetische Inhibitoren}

Derzeit werden mehrere niedermolekulare synthetische Elastaseinhibitoren untersucht. Über ihre klinische Wirksamkeit und Sicherheit gibt es jedoch noch keine Angaben.

\section{Zusammenfassung}

Es gibt keine randomisierten, kontrollierten Studien, welche die klinische Wirksamkeit der Substitutionstherapie eindeutig beweisen. In diesem Kontext sprechen die Ergebnisse der vorliegenden Studien zur klinischen Wirksamkeit der AAT-Substitutionstherapie dafür, dass die Gesamtmortalität reduziert wird und dass sich der jährliche $\mathrm{FEV}_{1}$-Verlust bei den substituierten Patienten mit einer $\mathrm{FEV}_{1}$ von 35 - $65 \%$ des Sollwertes verlangsamt. Mit der Messung der Lungendichte über hoch auflösende CTScans steht für zukünftige Studien eine viel versprechende, praktikable und quantitative Methode zum Wirksamkeitsnachweis der Substitutionstherapie zur Verfügung.

\section{Operative Maßnahmen}

Die Lungentransplantation (LT) ist heute eine Option für viele Patienten im Endstadium pulmonaler Erkrankungen. Ungefähr 12\% aller Lungentransplantationen werden wegen Emphysems bei AAT-Mangel vorgenommen [253]. Wegen des Mangels an Spenderorganen werden die meisten LTs als einseitige LT durchgeführt, obwohl die doppelseitige Lungentransplantation einen besseren funktionellen Erfolg bringt.
Die aktuarische 5-Jahres-Überlebensrate nach LT liegt bei 50\% [254]. Bei Patienten nach einseitiger oder doppelseitiger Lungentransplantation wurden signifikante Unterschiede im aktuarischen Überleben 1, 2 und 3 Jahre nach Transplantation beobachtet. Die funktionellen Ergebnisse nach LT sind gut [254], aber die Bronchiolitis obliterans ist nach wie vor die häufigste Todesursache.

Die Substitutionstherapie mit AAT-Konzentrat nach der Transplantation wird nicht allgemein empfohlen. In einer Studie wurde die Proteinase-Antiproteinase-Balance bei AAT-Mangel nach Lungen- und Herz-/Lungentransplantation mittels bronchoalveolärer Lavage untersucht [255]. Während Phasen klinischer Stabilität konnte in der bronchoalveolären Spülflüssigkeit der wegen AAT-Mangel Lungentransplantierten keine freie Elastase entdeckt werden. Während Phasen pulmonaler Erkrankungen konnte bei einigen Transplantierten mit AAT-Mangel dagegen freie Elastase-Aktivität gefunden werden. Danach sollte eine AAT-Substitution beim Auftreten von entzündlicher Veränderungen der Atemwege erwogen werden, möglicherweise auch während einer chronischen Abstoßungsreaktion, da bei Lungentransplantierten mit AAT-Mangel in dieser Phase eine chronische Entzündung im Atemtrakt nachweisbar ist [256].

Bei der operativen Lungenvolumenreduktion (LVR) werden 20-30\% der am schwersten befallenen Emphysembereiche mit unzureichender Perfusion („Zielzonen“) reseziert. Zielzonen können präoperativ mit Hilfe des CT oder der Perfusions-Szintigraphie, intraoperativ durch „air trapping“ abgegrenzt werden [257]. Als Kandidaten für diese Operation kommen Patienten mit weit fortgeschrittenen Lungenemphysem und starker Behinderung durch Atemnot, die sich auch nach optimaler medikamentöser und rehabilitativer Behandlung nicht bessert, in Betracht. Bei geeigneter Selektion kann durch die operative LVR die körperliche Belastbarkeit von Patienten mit „gewöhnlichem Lungenemphysem" verbessert und die Atemnot gelindert werden. Es ist jedoch nicht klar, ob die operative LVR die Lungenfunktion bei Patienten mit Lungenemphysem in Gefolge eines AAT-Mangels in ähnlicher Weise verbessert.

In einer prospektiven Studie wurde die Funktionsverbesserung im mittelfristigen Verlauf konsekutiv bei 12 Patienten mit fortgeschrittenem Emphysem auf dem Boden eines AAT-Mangels und bei 18 Patienten mit „Raucheremphysem “ untersucht. Bei allen Patienten wurde eine bilaterale operative LVR vorgenommen. Vor der Operation unterschieden sich die beiden Gruppen statistisch nicht im Hinblick auf den 6-Minuten-Gehtest, den Dyspnoe-Score, die Atemmechanik und die Lungenfunktion außer, dass der $\mathrm{FEV}_{1}$ bei der AAT-Mangel-Gruppe niedriger war (24 vs. $31 \%$ des Sollwertes, $\mathrm{p}<0,05$ ). In beiden Gruppen kam es nach der bilateralen operativen LVR zu einer signifikanten Verbesserung der Atemnot, der 6-Minuten-Gehstrecke, der Lungenfunktion und der Atemmechanik. Bei den Patienten mit AAT-Mangel ging die Atemfunktion jedoch zwischen dem 6. und 12. Monat nach Operation auf den Ausgangspunkt zurück mit Ausnahme des 6-Minuten-Gehtestes. 24 Monate nach Operation zeigt sich sogar eine weitere Verschlechterung der Lungenfunktion [258].

Der Funktionszustand der Gruppe mit „Raucheremphysem“ blieb dagegen über die gesamte Periode gegenüber dem präope- 
rativen Status signifikant gebessert. Die Arbeitsgruppe schließt daraus, dass die operative LVR den meisten Patienten mit einem Lungenemphysem auf dem Boden eines AAT-Mangels nur kurzfristig nützt und empfiehlt den Eingriff für diese Patientengruppe solange nicht, bis weitere Studien zur Wirksamkeit der operativen LVR bei AAT-Mangel vorliegen, die dann auch eine bessere Patientenselektion ermöglichen [258-264].

\section{Spezielle Situationen}

Es besteht allgemeiner Konsens darüber, dass sich Patienten mit AAT-Mangel in den meisten Merkmalen außer dem Alter, nicht von Patienten mit COPD vergleichbaren Schweregrades unterscheiden. Es gibt beispielsweise keine Hinweise dafür, dass das Pneumothorax-Risiko in den beiden Populationen unterschiedlich ist. In Anbetracht der klaren biochemischen Vorstellungen, die wir von dieser Krankheit haben, ist es naheliegend, jegliche Mehrbelastung der Lunge mit neutrophilen Granulozyten zu vermeiden. Ob sich die Lungenfunktion allerdings nach einer Bronchitis, einer Pneumonie oder einem akuten „respiratorischen distress syndrom" verschlechtert, ist nicht bekannt.

Es gibt Hinweise dafür, dass die Schwangerschaft bei einigen Patientinnen mit AAT-Mangel bei PI*ZZ problematisch ist [265]. In Fallstudien wurde eine Häufung von Fehl- und Totgeburten beobachtet, die sich auf $29 \%$ der 38 Schwangerschaften bei 8 Patientinnen summierte [266]. Es gibt auch Fallberichte über das Auftreten eines Pneumothorax während der Schwangerschaft bei Patientinnen mit vorher bestehenden bullösen Veränderungen [267]. Nichts desto trotz können auch Patientinnen mit schwerem Lungenemphysem die Schwangerschaft erfolgreich beenden [266].

Vor Flugreisen sollten Patienten mit Lungenemphysem vom Spezialisten untersucht werden. Bei Patienten ohne Hypoxämie auf Meereshöhe kann der Einfluss des Kabinendruckes auf den arteriellen Sauerstoffwert während des Fluges berechnet werden. Kennt man die arteriellen Blutgase auf Meereshöhe, kann man über Regressionsgleichungen den Sauerstoffpartialdruck in der Kabine bei unterschiedlichen Drucken berechnen [268]. Wenn der vorausberechnete Sauerstoffpartialdruck im hypoxämischem Bereich liegt (d.h. $<55 \mathrm{~mm} \mathrm{Hg}$ ), wird die Zufuhr von 1-21 Sauerstoff pro Minute mittels Nasenkanüle während des Fluges empfohlen, um eine hypoxämieinduzierte pulmonale Hypertonie zu vermeiden [269]. Patienten, bei denen bereits auf Meereshöhe eine bekannte Hypoxämie bekannt ist, und die bereits Sauerstoff erhalten, sollte man raten, den Sauerstofffluss während des Fluges um 1 oder 21 pro Minute zu erhöhen. Man sollte möglichst verhindern, dass der arterielle Sauerstoffpartialdruck $55 \mathrm{~mm} \mathrm{Hg}$ (7,0 kPa) unterschreitet.

Aufgrund der chirurgischen Erfahrung mit der Lungentransplantation und der operativen Lungenvolumenreduktion wissen wir, dass auch bei Patienten mit einem $\mathrm{FEV}_{1}$ von weniger als 1,01 die Anästhesie vertragen. Bei Operationen im oberen Abdomen ist es während der Narkose und in der unmittelbaren postoperativen Aufwachphase wichtig, den Patienten mit längeren Expirationszeiten zu beatmen. Die postoperative Sekretelimination ist wichtig. Indikationen für postoperative mechanische Beatmung sind respiratorische Azidose, schwere Hypoxämie, Atelektase und Pneumonie [270]. Urologische, gynäkologische und kolorektale Eingriffe sollten möglichst in Lokal- oder Epiduralanästhesie vorgenommen werden.

\section{Zulkünftige Richtungen in der Forschung bei AAT-Mangel}

In der Forschung müssen noch viele Entwicklungen weiter voran getrieben werden, bis eine effektive Behandlung des AAT-Mangels und der mit dem Defekt zusammenhängenden Erkrankungen erreicht ist. Der erbliche Fehler könnte durch eine Korrektur der genetischen Störung geheilt werden. In der Gentherapie bedarf es effektiver und effizienter Methoden, um hinreichend genetisches Material zu den Zielzellen zu transferieren. Bisherige Strategien zum Gentransfer haben sich Retroviren, Adenoviren und nichtvirale Vektoren zu Nutze gemacht, um die Zielzellen zu erreichen, und zwar Lymphozyten, Fibroblasten, Hepatozyten und Zellen des Atemwegsephitels.

Retroviren sind RNA-Viren, die mittels spezifischer Rezeptoren in die Zelle Eingang finden. Die reverse Transkriptase, die von Viren eingebracht wird, wandelt die RNA zu DNA um und das doppelstrangige DNA-Virus schleust Genome in die Zelle ein, indem es die Information auf dem 5' und 3' terminalen Wiederholungszeichen nutzt. Wenn das Retrovirus als Vehikel für die Gentherapie dient, wird er so verändert, dass es keine Infektion produziert, nachdem es in die Zelle eingeschleust ist [271]. Diese Technik wurde verwandt, um eine geklonte Population von Mäusefibroblasten herzustellen, welche imstande sind, normales menschliches AAT-Protein zu sezernieren [272]. Diese Studie zeigte, dass es möglich ist, menschliches AAT-Protein außer in Hepatozyten auch in anderen Zellen herzustellen, jedoch war die Ausbeute mengenmäßig gering. Auch könnte die Implantation von Fibroblasten im Gewebe zu lokaler Fibrose führen.

In anderen Studien wurden Hepatozyten aus resezierten Leberlappen benutzt. Bei Tierversuchen wurden $10-15 \%$ der Hepatozyten infiziert; damit konnte die Produktion von menschlichem AAT-Protein über mehr als 6 Monate aufrecht erhalten werden [273]. Diese Methode würde die Hepatektomie und die Reinfusion modifizierter Hepatozyten erfordern. Die Transplantation allogener Hepatozyten hätte den Nachteil, dass man mit immunologischer Abstoßung rechnen müsste und daher eine immunsuppressive Behandlung erforderlich wäre.

Die direkte Infusion rekombinanter Retroviren mit AAT cDNA in die Lebervene ist ein weiterer Ansatz. Damit konnte AAT-Protein über 6 Monate produziert werden, allerdings in subtherapeutischen Mengen [273].

T-Lymphozyten wurden direkt in die Lunge transplantiert, mit dem Ergebnis einer lokalen, aber subtherapeutischen Produktion von AAT [274]. Retroviren als Vektoren wurden ebenfalls eingesetzt, um die Zellen des Atemwegsepithels zu erreichen. Die Transfektion war aber ineffizient, da die Retroviren auf sich rasch teilende Zellen angewiesen sind. Epithelzellen des Atemtrakts replizieren aber langsam. 
Adenoviren sind Viren, die aus einer Doppelstrang-DNA bestehen und eine besondere Affinität zum Atemwegsepithel haben [275]. Anders als bei Retroviren entfaltet die DANN der Adenoviren ihre Wirkung auf einem extrachromosomalen Weg. Damit ist die theoretische Möglichkeit einer Mutagenese nach der Insertion ausgeschlossen. Die Gentherapie mit Adenoviren müsste das sei angemerkt - periodisch appliziert werden, da die genetische Modifikation der Zielzellen nicht auf seine Vorläuferzellen übertragen wird.

Auch benötigt das Adenovirus für den Gentransfer und die Genexpression nicht die Replikation der Wirtszelle. So wurden in einer Studie Adenoviren als Vektoren direkt in das Atemwegsepithel von Baumwollratten eingebracht, sowohl in vitro als auch in vivo. Nach der trachealen in vivo-Gabe konnte in den Zellen des respiratorischen Epithels menschliches AAT gefunden werden. Auch waren entsprechende Spiegel im Flüssigkeitsfilm des Epithels eine Woche lang messbar [276]. Andere gentherapeutische Versuche mit Adenoviren hatten Leber und Peritoneum als Zielorgane [277,278]; auch bei diesen Versuchen wurden therapeutische AAT-Spiegel erreicht [279]. Im Prinzip könnte das Alveolarepithel der menschlichen Lunge als Zielorgan des AATTransfer und damit zur Produktion von cDNA dienen. Allerdings wäre denkbar, dass dies keinen ausreichenden Schutz gegen den Abbau von Matrixkomponenten unterhalb der Epithelschicht bietet.

Song u. Mitarb. [280] haben DNA von menschlichem AAT in den Mäusemuskel übertragen, in dem sie ein Zytomegalievirus als Vektor benutzten. Die Ergebnisse waren ermutigend: über 15 Wochen konnten anhaltende Konzentrationen von menschlichem AAT mit Spiegeln über $800 \mu \mathrm{g} / \mathrm{ml}$ aufrecht erhalten werden.

Der Einsatz der Gentherapie bei AAT-Mangel ist theoretisch auch ohne virale Vektoren möglich, indem man Liposomen oder molekulare Konjugate anwendet. So verabreichte man Kaninchen ein Plasmid, welches das AAT cDNA und ein Zytomegalie-Virus-Promoter enthielt, gebunden an kationische Liposomen intravenös und über ein Aerosol [281]. Dabei konnte das AAT-Protein durch immunhistochemische Färbung im Lungenendothel nach intravenöser Verabreichung und in den Zellen des Alveolar-Epithels nach Aerosolverabreichung nachgewiesen werden. Es ist fraglich, ob sich die Inhalation solcher liposomaler Systeme als protektiv gegenüber den Abbauprozessen im Lungenparenchym erweist.

Molekulare Konjugate sind ein weiteres Transfersystem, das zur Übertragung von AAT cDNA eingesetzt wurde, in Form eines Plasmid-DNA gebunden an Polylysine und in Form eines Moleküls, das die DNA-Bindung an einen spezifischen Zellrezeptor avisiert. Derzeit sind diese Systeme beim Gentransfer jedoch weniger wirksam als virale Vektoren und müssen noch weiter entwickelt werden [282]. Kren u. Mitarb. [283] benutzten bei ihrer Strategie zur Reparatur genetischer Lebererkrankungen wie des AAT-Mangels chimere Moleküle, um in Zellkulturen einzelne Nukleotide in episomale oder genomische DNA zu verwandeln.

Insgesamt haben die Experimente in vitro und in vivo gezeigt, dass AAT cDNA auf verschiedene Zellen der Lunge übertragen werden kann. Wendet man diese Strategien beim Menschen an, müssten bei den Methoden des Gentransfers folgende Fragen geklärt werden: (1) die Invasivität und die Risiken der Gentherapie, verglichen mit der derzeit möglichen intravenösen AAT-Substitutionstherapie oder möglicherweise der AAT-Aerosol-Substitution, (2) die Kontrolle der Wirksamkeit des Gentransfers sowie die Durchführbarkeit und Notwendigkeit von Gentransfer zur Behandlung des AAT-Mangels in Abhängigkeit davon, ob in Zukunft wirksame, aber weniger invasive therapeutische Methoden zur Verfügung stehen werden.

Zwei weitere Substanzgruppen, Hyaluronsäurederivate und Retinoide, kommen als Therapieoption des Lungenemphysems bei AAT-Mangel und der COPD generell in Betracht: So konnte gezeigt werden, dass Hyaluronan als Aerosol im Stande ist, die Entwicklung eines durch intratracheale Elastaseapplikation erzeugten experimentellen Lungenemphysems zu begrenzen [284] und das Lungenelastin vor der Zerstörung durch Elastase in vitro zu schützen [285]. Damit wäre die Möglichkeit eröffnet, das Fortschreiten des Emphysems zu verhindern, sobald es sich in der menschlichen Lunge entwickelt.

Bei Anwendung von all-trans-Retionid-Säure kann man nach ersten Berichten bei Ratten mit Elastase-induziertem Lungenemphysem die Zahl der Alveolen erhöhen [286] und bei der erwachsenen „tight skinned“ Maus teilweise die fehlende, durch Glukokortikoide induzierte Septierung der Alveolen wieder herstellten [287].

Die Entdeckung der abnormen Polymerisation infolge Fehlfaltung im AAT-Protein beim Z-Phänotyp, die durch den Ersatz von Lysin durch Glutaminsäure in der Position 342 zustande kommt, war für das bessere Verständnis der abnormen Faltung des Proteins im Hepatozyten hilfreich [32]. Ermutigt durch diese Erkenntnis, untersuchen Forscher eine Reihe therapeutischer Substanzen, von denen man hofft, dass sie die abnorme Faltung und Polymerisation des Moleküls verhindern können. Damit könnte man die Sekretion des Moleküls aus den Hepatozyten erleichtern und die Bildung von AAT-Globuli als wahrscheinliche Ursache der Leberzirrhose in den Hepatozyten verhindern.

Die neutrophile Elastase zeigt vielfältige biologische Wirkungen; man könnte sich daher vorstellen, in Zukunft Patienten mit schwerem AAT-Mangel außer mit natürlichem AAT auch mit einem synthetischen Elastasehemmer zu behandeln, der sicher und wirksam ist. Außer der Spaltung von Elastin hat die neutrophile Elastase noch viele potenziell pathogene biologische Effekte wie die Aktivierung von Komplement, die Spaltung und Komplexbildung mit AAT, die Anregung von Epithelzellen zur Produktion und Sekretion von Interleukin-8 [288] und die Stimulation von Makrophagen zur Freisetzung von Leukotrien $\mathrm{B}_{4}$. Auch wird wahrscheinlich die Produktion des sekretorischen Leukoprotease-Inhibitors durch Zellen des Atemtraktes durch Elastasen reduziert [289]. Derartige Effekte könnten die Entzündung in den Atemwegen perpetuieren, da die im Überschuss vorhandenen neutrophilen Elastasen nicht durch ihre natürlichen Inhibitoren gehemmt wird. Durch Spaltung von Immunglobulinen durch die Elastase könnte zudem die Bindung von Bakterien durch Globulin-Eiweißkörper inkomplett und damit die Opsonierung und Phagozytose von Bakterien ineffektiv werden [290]. Es ist auch 
denkbar, dass die neutrophile Elastase die Schlagfrequenz der Zilien herabsetzt und die Sekretion von Mukus steigert, was die Beeinträchtigung der mukoziliären Clearance zur Folge hätte. Bei Bronchiektasie mit oder ohne zystische Fibrose lassen sich Elastase im Bronchialsekret oft dauerhaft nachweisen [291]. Antiproteasen könnten sich unter diesen Bedingungen als therapeutisch wirksam erweisen.

Eine Stoßtherapie mit neutrophilen Elastaseinhibitoren, natürlich oder synthetisch, könnte bei akuter Exazerbation nutzbringend sein, vielleicht eher noch bei chronischen Zuständen, wenn die Sicherheit dieser Stoffgruppen bewiesen ist.

Synthetische Protease-Inhibitoren könnten auch nachteilige Auswirkungen haben, spielen doch die neutrophilen Elastasen eine wichtige Rolle bei bestimmten Abwehrfunktionen der Zelle. Möglicherweise benötigen die neutrophilen Granulozyten ihre Elastase, um während ihrer Wanderung das Gewebe zu durchdringen [292]. Denkbar ist auch, dass Protease-Inhibitoren sich störend auf chemotaktische Reaktionen, die von der ProteaseAktivität abhängig sind, auswirken [293]. Auch könnten Protease-Inhibitoren nach dem Eindringen in die Zelle die Differenzierung der Neutrophilen verändern und zur Ausreifung von Zellen ohne neutrophile Elastase-Aktivität führen. Aus diesen Gründen dürfte es das Beste sein, Protease-Inhibitoren nur in begrenzten Organbereichen und nur für einen kurzen Zeitraum zu applizieren.

Nachdem erkannt war, dass das homozygote Z-Allel zu einer Fehlfaltung und Polymerisierung des AAT-Moleküls führt und damit die normale Sekretion von AAT aus der Leberzelle verhindert, versuchten Burrows u. Mitarb. [294], die Fehlfaltung des Moleküls zu korrigieren. Sie konnten zeigen, dass mehrere „chemical chaperones“, die im Stande sind, die Fehlfaltung und die Fehllokalisation des Proteins rückgängig zu machen, eine vermehrte Sekretion von AAT aus den Leberzellen bewirken. Besonders 4-Phenylbuttersäure führte in der Zellkultur beim Z-Phänotyp zu einem deutlichen Anstieg. Carrell und Lomas [295] haben die ganze Bandbreite der Faltungsabnormalitäten und der dadurch verursachten Erkrankungen dargestellt. Die Korrektur von abnormen Faltungen mit dem Ziel der Erhöhung des fehlenden AAT-Spiegels ist ein viel versprechender Forschungsansatz.

Ein weiteres Gebiet, auf dem die Versorgung von Patienten mit AAT-Mangel verbessert werden könnte, ist die Früherkennung, mit dem erklärten Ziel, das Zigarettenrauchen rechtzeitig zu untersagen und die Exposition gegenüber Schadstoffen der Umwelt zu verhindern. Hier gibt es bereits Ansätze und Programme mit Erwachsenen- und in einigen Bereichen auch NeugeborenenScreening $[20,296]$. Die breite Durchführung von Neugeborenen-Screening-Programmen ist bisher nicht auf allgemeine $\mathrm{Zu}$ stimmung gestoßen. Jedoch sollten noch mehr Anstrengungen unternommen werden, die Bereitschaft der Allgemeinmediziner und der spezialisierten Ärzte zur Früherkennung des AAT-Mangels zu verbessern.

Viel bleibt noch zu erforschen über die Mechanismen, die bei schwerem AAT-Mangel zum Lungenemphysem führen. Gerade weil das Lungenemphysem bei Personen mit $\mathrm{PI}^{*}$ ZZ-Phänotyp in ganz unterschiedlichem Ausmaß entsteht, auch bei Nierauchern, müssen wir in Erfahrung bringen, welche Faktoren das Risiko eines Lungenemphysems minimieren. Dazu müssen wir die Rolle der Proteasen, die aus Neutrophilen und Makrophagen stammen, besser verstehen, aber auch den Einfluss anderer Inhibitoren - außer AAT - erforschen, die möglicherweise bei der Verhinderung des Emphysems von Bedeutung sind.

In gleicher Weise müssen wir mehr über die Faktoren erfahren, die bei einigen Patienten mit PI*ZZ-Phänotyp zu schweren Leberfunktionsstörungen prädisponieren.

\section{Spezieller Forschungsbedarf bei AAT-Mangel}

1. Die genauere Beschreibung der pathologischen Veränderungen beim Lungenemphysem infolge AAT-Mangel. Die Untersuchungen sollten das Lungenparenchym und die Bronchien mit einschließen und besonders darauf achten, in welchem Ausmaß die Bronchien, die Bronchiolen und die Blutgefäße vom Entzündungsprozess erfasst werden und auf welche Weise die Mitbeteiligung der Bronchien das Fortschreiten der Erkrankung beeinflusst.

2. Die eindeutige Klärung der Frage, wie häufig Bronchiektasen in Verbindung mit AAT-Mangel auftreten, um welchen Typus es sich dabei handelt und wie die klinischen und physiologischen Manifestationen zusammenhängen.

3. Die Herausarbeitung von Risikofaktoren, die bei AAT-Mangel außer dem Zigarettenrauchen zur Entwicklung von Lungenerkrankungen führen. Dazu dürften Infektionen, Atopie, familiäre Faktoren und Umweltverschmutzung zählen.

4. Die Implementierung einer Plazebo kontrollierten klinischen Studie zur intravenösen Substitutionstherapie. Bei einer solchen Studie sollten die Elastinabbau-Peptide im Blut und im Urin mitbestimmt und die Effektivität des HRCT evaluiert werden. In Teilen dieser Studie könnten auch die optimale Dosierung des AAT-Konzentrats und die Frequenz der AAT-Gabe geklärt werden.

5. Die Klärung der besonderen Rolle der AAT-Substitution bei der Lungentransplantation.

6. Die Evaluation des therapeutischen Effekts von inhalierten AAT-Präparationen.

7. Die Erforschung der Pathomechanismen, die bei AAT-Mangel der Entstehung von Lebererkrankung zugrunde liegen. Dies schließt die Abklärung der Rolle von Antioxidantien in Therapie und Prävention von Lebererkrankungen ein. Bei den Lebererkrankungen sollte die Rolle von viralen Hepatitis-Infektionen für die Entstehung von Leberzirrhose und hepatozellärem Karzinom geklärt werden. Ebenso die Wirksamkeit einer Impfung gegen Hepatitis B und möglicherweise auch Hepatitis C, wenn eine solche Vakzine zur Verfügung steht.

8. Die epidemiologische Untersuchung der Genfrequenz von AAT-Mangel-Allelen in verschiedenen Ethnien und Kulturen, auch in der dritten Welt. Über derartige Studien könnten wir mehr zu Kosten und Nutzen von Frühdiagnostik erfahren und aufbauend auf diese Erkenntnisse Programme zum Frühgeborenen-Screening auf AAT-Mangel entwerfen. 
Appendices

Appendix 1. Primäre Evidenztabelle: Zusammenfassung der Studien zu den klinischen Besonderheiten des Phänotyps PI*ZZ bei Alpha-1-Antirypsinmangel

Appendix 2. Studien bei Allgemeinpopulationen: Prävalenz der PI-Varianten und Risiken der damit zusammenhängenden Lungenerkrankung

Appendix 3. Studien bei Populationen mit chronisch obstruktiven Lungenerkrankungen: Prävalenz der PI-Varianten und Risiken der damit zusammenhängenden Lungenerkrankung

\section{Appendix 4. Verlaufsstudien bei PI*ZZ: Risikokategorien}

Appendix 5. Studien zum Risiko von Personen mit dem Phänotyp PI*MZ und einer „COPD-Familienanamnese“

Appendix 6. Rauchen als Risikofaktor bei der Entwicklung von Lungenkrankheiten bei Personen mit dem Phänotyp PI*MZ

Appendix 7. Umweltbedingte Risiken bei der Entwicklung von Lungenerkrankung bei Individuen mit dem Phänotyp PI*MZ

Appendix 8. Der Phänotyp PI*MZ als möglicher Risikofaktor bei der Entstehung atopischer Erkrankungen

Appendix 9. Primäre Evidenz des Emphysemrisikos bei Individuen mit dem Phänotyp PI*SZ

Appendix 10. Zusammenfassende Tabelle mit Studien zur primären Evidenz der Wirksamkeit der Substitution mit Alpha1-Antitrypsin

Die Appendices sind aus der Website

(http://ajrccm.atsjournals.org/search.dtl) zu ersehen.

\section{Literatur}

${ }^{1}$ U.S. Preventive Services Task Force. Guide to Clinical Prevention Services: report to the U.S. Preventive Services Task Force, 2nd ed. Baltimore, MD: Williams \& Wilkins, 1996: 231 -246

${ }^{2}$ Laurell C-B, Eriksson S. The electrophoretic-1-globulin pattern of serum in $\alpha$-1-antitrypsin deficiency. Scand J Clin Lab Invest 1963; 15: $132-140$

${ }^{3}$ Cox DW, Woo SLC, Mansfield T. DNA restriction fragments associated with $\alpha-1$ antitrypsin indicate a single origin for deficiency allele PIZ. Nature 1985; 316: 79-81

${ }^{4}$ Cox DW, Billingsley GD, Mansfield T. DNA restriction site polymorphisms associated with the $\alpha-1$ antitrypsin gene. Am J Hum Genet 1987; 41: $891-906$

${ }^{5}$ Tobin MJ, Cook PJL, Hutchison DCS. Alpha-1 antitrypsin deficiency: the clinical and physiological features of pulmonary emphysema in subjects homozygous for Pi type Z. Br J Dis Chest 1983; 77: 14 - 27

${ }^{6}$ Larsson C. Natural history and life expectancy in severe $\alpha-1$ antitrypsin deficiency, PiZ. Acta Med Scand 1978; 204: 345 - 351

${ }^{7}$ Sveger T. Liver disease in 1 antitrypsin deficiency detected by screening of 200,000 infants. N Engl J Med 1976; 294: 1316-1321

${ }^{8}$ Sharp HL. Alpha-one antitrypsin deficiency. Hosp Pract 1971; 6: $83-96$
${ }^{9}$ Eriksson S, Carison J, Velez R. Risks for cirrhosis and primary liver cancer in $\alpha-1$ antitrypsin deficiency. $\mathrm{N}$ Engl J Med 1986; 314: $736-739$

${ }^{10}$ Elzouki AN, Eriksson S. Risk of hepatobiliary disease in adults with severe $\alpha-1$ antitrypsin deficiency: an additional risk factor for cirrhosis and hepatocellular carcinoma? Eur J Gastroenterol Hepatol 1996; 8: 989-994

${ }^{11}$ Eriksson S. Alpha-1 antitrypsin deficiency: natural course and therapeutic strategies. In: Proceedings of the Falk Symposium no. 115. Dordrecht, The Netherlands: Kluwer Academic, 1999: 307-315

12 Stockley RA. The pathogenesis of chronic obstructive lung diseases: implications for therapy. QJ Med 1995; 88: 141-146

${ }^{13}$ Sandhaus RA. Elastase may play a central role in the neutrophil migration through connective tissue. In: Taylor JC, Mittman C (eds.). Pulmonary emphysema and proteolysis. Orlando, FL: Academic Press, 1997: 227-233

${ }^{14}$ Brantly M, Nukiwa T, Crystal RG. Molecular basis of $\alpha-1$ antitrypsin deficiency. Am J Med 1988; 84 (Suppl 6A): 13-31

${ }^{15}$ Cox DW. Alpha-1 antitrypsin deficiency. In: Scriver CR, Beaudet AL, Sly WS, Valle D (eds.). The molecular and metabolic basis of inherited disease, 7th ed. New York: McGraw-Hill, 1995

${ }^{16}$ Kamboh MI. Biochemical and genetic aspects of human serum $\alpha-1$ proteinase inhibitor protein. Dis Markers 1985; 3: 135

17 Mitsuyasu K, Oshima S. Studies on the serum alpha 1-antitrypsin (alpha $1 \mathrm{AT}$ ) in healthy people and patients with respiratory diseases. Bull Chest Dis Res Inst Kyoto Univ 1981; 14: 15-21

${ }^{18}$ Awotedu AA, Adelaja AB. Alpha-1-antitrypsin levels and prevalence of Pi variant phenotypes in adult Nigerian asthmatics. Afr J Med Sci 1990; 19: $285-290$

${ }^{19}$ de Serres F. Worldwide racial and ethnic distribution of alpha 1-antitrypsin deficiency: summary of an analysis of published genetic epidemiologic surveys. Chest 2002; 122: 1 - 12

${ }^{20}$ Sveger T. Alpha-1-antitrypsin deficiency in early childhood. Pediatrics 1978; 62: $22-25$

${ }^{21}$ O'Brien ML, Buist NRM, Murphey WH. Neonatal screening for $\alpha-1$ antitrypsin deficiency. J Pediatr 1978; 92: $1006-1010$

22 Silverman EK, Miletich SP, Pierce JH et al. Alpha-1-antitrypsin deficiency: high prevalence in the St. Louis area determined by direct population screening. Am Rev Respir Dis 1989; 140: 961 - 966

${ }^{23}$ Colp C, Pappas J, Moran D et al. Variants of $\alpha-1$ antitrypsin in Puerto Rican children with asthma. Chest 1993; 103: 812-815

${ }^{24}$ Hutchison DC. -1 antitrypsin deficiency in Europe: geographical distribution of Pi types S and Z. Respir Med 1998; 92: 367-377

${ }^{25}$ Dykes D, Miller S, Polesky H. Distribution of alpha- 1 antitrypsin in a US white population. Hum Hered 1984; 34: 308 - 310

${ }^{26}$ Travis J, Salvesen GS. Human plasma proteinase inhibitors. Annu Rev Biochem 1983; 52: 655-709

${ }^{27}$ Kao RG, Wehner NG, Skubitz KM et al. Proteinase-3 a distinct human polymorphonuclear leukocyte proteinase that produces emphysema in hamsters. J Clin Invest 1988; 82: 1963 - 1973

${ }^{28}$ Rao HV, Wehner HG, Marshall BC et al. Characterization of proteinase-3 (PR-3) a neutrophil serine proteinase: structural and functional properties. J Biol Chem 1991; 266: 9540-9548

${ }^{29}$ Crystal RG. Alpha-1-antitrypsin deficiency, emphysema and liver disease: genetic basis and strategies for therapy. J Clin Invest 1998; 85: $1343-1352$

30 Owen MC, Brennan SO, Lewis JH et al. Mutation of antitrypsin to antithrombin $\alpha-1$ antitrypsin Pittsburgh (358-Met $\rightarrow$ Arg), a fatal bleeding disorder. N Engl J Med 1983; 309: 694-698

31 Okayama H, Brantly M, Holmes $M$ et al. Characterization of the molecular basis of the $\alpha-1$ antitrypsin F-allele. Am J Hum Genet 1991; 48: $1154-1158$

32 Lomas DA, Evans DLI, Finch JT et al. The mechanism of $Z \alpha-1$ antitrypsin accumulation in the liver. Nature 1992; 357: 605-607

${ }^{33}$ Gadek JE, Fells GA, Zimmerman RL et al. Anti-elastase of the human alveolar structures: implications for the protease-antiprotease theory of emphysema. J Clin Invest 1981; 68: 889-898

${ }^{34}$ Silverman EK, Pierce JA, Province MA et al. Variability of pulmonary function in $\alpha-1$ antitrypsin deficiency: clinical correlates. Ann Intern Med 1989; 111: 982 - 991

${ }^{35}$ Stone PJ, Morris SM, Thomas KM et al. Repair of elastase-digested elastin fibers in acellular matrices by replating with nenatal rat-lung lipid interstitial fibroblasts or other elastogenic cell types. Am J Respir Cell Mol Biol 1997; 17: 289-301 
${ }^{36}$ Ogushi F, Fells GA, Hubbard RC et al. Z-type $\alpha-1$ antitrypsin is less competent than M1-type $\alpha-1$ antitrypsin as an inhibitor of neutrophil elastase. J Clin Invest 1987; 80: 1366-1374

${ }^{37}$ Elliott PR, Bilton D, Lomas DA. Lung polymers in $\mathrm{Z} \alpha-1$ antitrypsin related emphysema. Am J Respir Crit Care Med 1998; 18: 670-674

38 Osman M, Cantor JO, Roffman S et al. Cigarette smoke impairs elastin resynthesis in lungs of hamsters with elastase-induced emphysema. Am Rev Respir Dis 1985; 132: 640-643

${ }^{39}$ Morrison HM, Kramps JA, Burnett D et al. Lung lavage fluid from patients with $\alpha$-1-proteinase inhibitor deficiency or chronic obstructive bronchitis: anti-elastase function and cell profile. Clin Sci 1987; 72: $373-381$

${ }^{40}$ Hubbard RC, Fells G, Gadek J et al. Neutrophil accumulation in the lung in $\alpha-1$ antitrypsin deficiency: spontaneous release of leukotriene B4 by alveolar macrophages. J Clin Invest 1991; 88: 891 - 897

${ }^{41}$ Hautamaki RD, Kobayashi DK, Senior RM et al. Requirement for macrophage elastase for cigarette smoke-induced emphysema in mice. Science 1997; 277: 2002-2004

42 D'Armiento J, Dalai SS, Okada Y et al. Collagenase expression in the lungs of transgenic mice causes pulmonary emphysema. Cell 1992; 71: $955-961$

${ }^{43}$ Banda MJ, Rice AG, Griffin GL et al. Alpha-1 proteinase inhibitor in a neutrophil chemoattractant after proteolytic inactivation by macrophage elastin. J Biol Chem 1988; 263: 4481 - 4484

${ }^{44}$ Banda MJ, Rice AG, Griffin GL et al. The inhibitory complex of human 1 proteinase inhibitor and human leukocyte elastase in a neutrophil chemoattractant. J Exp Med 1988; 167: 1608 - 1615

${ }^{45}$ Brantly M, Wittes JT, Vogelmeier CF et al. Use of a highly purified $\alpha-1$ antitrypsin standard to establish ranges for the common normal and deficiency phenotypes. Chest 1991; 100: 703-708

${ }^{46}$ Gorg A, Postel W, Weser J et al. Improved resolution of Pi (-1 antitrypsin) phenotypes by a large-scale immobilized $\mathrm{pH}$ gradient. Am J Hum Genet 1985; 37: $922-930$

${ }^{47}$ Brantly M. Laboratory diagnosis of $\alpha-1$ antitrypsin deficiency. In: Crystal RG (ed.). Alpha 1-antitrypsin deficiency. New York: Marcel Dekker, 1996: 211 - 226

48 Dry PJ. Rapid detection of $\alpha-1$ antitrypsin deficiency by analysis of a PCR-induced TaqI restriction site. Hum Genet 1991; 87: 742 - 744

${ }^{49}$ Forrest SM, Dry PJ, Cotton RG. Use of the chemical cleavage of mismatch method for prenatal diagnosis of $\alpha-1$ antitrypsin deficiency. Prenatal Diagn 1992; 12: 133-137

${ }^{50}$ Cox DW, Smyth S. Risk for liver disease in adults with $\alpha-1$ antitrypsin deficiency. Am J Med 1983; 74: 221 - 227

51 Braun A, Meyer P, Cleve H et al. Rapid and simple diagnosis of the two common alpha-1-proteinase inhibitor deficiency alleles Pi*ZZ and $\mathrm{Pi}^{*} \mathrm{X}$ by DNA analysis. Eur J Clin Chem Clin Biochem 1996; 34: $761-764$

52 Abbott CM, Lovegrove JU, Whitehouse DB et al. Prenatal diagnosis of $\alpha-1$ antitrypsin deficiency by PCR of linked polymorphisms: a study of 17 cases. Prenat Diagn 1992; 12: 235-240

${ }^{53}$ Andresen BS, Knudsen I, Jensen PK et al. Two novel nonradioactive polymerase chain reaction-based assays of dried blood spots, genomic DNA or whole cells for fast, reliable detection of $\mathrm{Z}$ and $\mathrm{S}$ mutations in $\alpha$ - 1 antitrypsin gene. Clin Chem 1992; 38: 2100-2107

${ }^{54}$ Seersholm N, Kok-Jensen A, Dirksen A. Survival of patients with severe $\alpha-1$ antitrypsin deficiency with special reference to non-index cases. Thorax 1994; 49: 695-698

55 World Health Organization. Alpha-1-antitrypsin deficiency: memorandum from a WHO meeting, 1997. Bull World Health Organ 1997; 75: $397-415$

${ }^{56}$ World Health Organization. Alpha- 1 antitrypsin deficiency: memorandum from a WHO meeting [Table 8]. Bull World Health Organ 1997; 75: $397-415$

${ }^{57}$ Glasgow JF, Lynch MJ, Hercz A et al. Alpha-1 antitrypsin deficiency in association with both cirrhosis and chronic obstructive lung disease in two sibs. Am J Med 1973; 54: $181-194$

${ }^{58}$ Theegarten D, Teschler H, Stamatis G et al. Pathologico-anatomical results in surgical lung volume reduction of advanced emphysema. Pneumologie 1998; 52: $702-706$

${ }^{59}$ Eriksson S. Studies in $\alpha-1$ antitrypsin deficiency. Acta Med Scand 1965; 432: $1-85$

${ }^{60}$ Tobin MJ, Cook PJL, Hutchinson DCS. Alpha-1 antitrypsin deficiency: the clinical and physiological features of pulmonary emphysema in subjects homozygous for Pi type Z. Br J Dis Chest 1983; 77: 14-27
${ }^{61}$ Janus ED, Phillips NT, Carrell RW. Smoking, lung function and $\alpha-1$ antitrypsin deficiency. Lancet 1985; 1: $152-154$

${ }^{62}$ Rawlings Jr W, Kreiss P, Levy D et al. Clinical, epidemiological and pulmonary function studies in alpha- 1 antitrypsin deficient subjects of PI*ZZ type. Am Rev Respir Dis 1976; 114: 945 - 953

${ }^{63}$ Brantly ML, Paul LD, Miller BH et al. Clinical features and history of the destructive lung disease associated with alpha-1-antitrypsin deficiency of adults with pulmonary symptoms. Am Rev Respir Dis 1988; 138: 327-336

${ }^{64}$ Stoller JK, Smith P, Yang P et al. Physical and social impact of $\alpha-1$ antitrypsin deficiency: results of a survey. Cleve Clin J Med 1994; 61: $461-467$

${ }^{65}$ Wall M, Moe E, Eisenberg J et al. Long-term follow-up of a cohort of children with $\alpha-1$ antitrypsin deficiency. J Pediatr 1990; 116: $248-251$

${ }^{66}$ Ferris BG. Epidemiology standardization project. Am Rev Respir Dis 1978; $118: 1-120$

${ }^{67}$ McElvaney NG, Stoller JK, Buist AS et al. Baseline characteristics of enrollees in the National Heart, Lung, and Blood Institute Registry of $\alpha-1$ Antitrypsin Deficiency. Chest 1997; 111: 394-403

68 Piitulainen E, Sveger T. Effect of environmental and clinical factors on lung function and respiratory symptoms in adolescents with $\alpha-1$ antitrypsin deficiency. Acta Paediatr 1998; 87: 1120-1124

${ }^{69}$ Eden E, Mitchell D, Mehlman B et al. Atopy, asthma and emphysema in patients with severe $\alpha-1$ antitrypsin deficiency. Am J Respir Crit Care Med 1997; 156: 68-74

${ }^{70}$ Shin MS, Ho KJ. Bronchiectasis in patients with $\alpha-1$ antitrypsin deficiency: a rare occurrence? Chest 1993; 104: 1384-1386

${ }^{71}$ Quanjer PH, Tammeling JE, Cotes JE et al. Standardized lung function testing: lung volumes and forced ventilatory flows. Eur Respir J 1993; 6: $5-40$

72 Cotes JE, Chinn DJ, Quanjer PH et al. Standardized lung function testing: standardization of the measurement of transfer factor. Eur Respir J 1993; 6: $41-53$

${ }^{73}$ McElvaney NG, Crystal RD. Clinical manifestations of $\alpha-1$ antitrypsin deficiency. In: Crystal RG (eds.). Lung Biology in Health and Disease, Vol. 88: Alpha 1-antitrypsin deficiency. New York: Marcel Dekker 1996

${ }^{74}$ Wilson JS, Galvin JR. Normal diffusing capacity in patients with PiZ alpha-1-antitrypsin deficiency, severe airflow obstruction, and significant radiographic emphysema. Chest 2000; 118: 867-871

${ }^{75}$ Carpenter MA, Tockman MS, Hutchinson RG et al. Demographic and anthropometric correlates of maximal inspiratory pressure. Am J Respir Crit Care Med 1999; 159: 415-422

${ }^{76}$ Siafakas NM, Vermeire P, Pride NB et al. Optimal assessment and management of chronic obstructive pulmonary disease (COPD): a consensus statement of the European Respiratory Society (ERS). Eur Respir J 1995; 8: 1398 - 1420

${ }^{77}$ American Thoracic Society. Standards for the diagnosis and care of patients with chronic obstructive pulmonary disease. Am J Respir Crit Care Med 1995; 152: S77-S120

${ }^{78}$ British Thoracic Society. BTS guidelines for the management of chronic obstructive pulmonary disease. Thorax 1997; 52 (Suppl 5): 1-28

${ }^{79}$ Gishen P, Saunders AJS, Tobin MJ et al. Alpha- 1 antitrypsin deficiency: the radiological features of pulmonary emphysema in subjects of Pi-type-Z and Pi-type-SZ. A survey by the British Thoracic Association. Clin Radiol 1982; 33: $371-377$

${ }^{80}$ Foster Jr WL, Gimenez EI, Roubidoux MA et al. The emphysemas: radiologic-pathologic correlations. Radiographics 1993; 13: 311 - 328

${ }^{81}$ Guenter CA, Welch MH, Russell TR et al. The pattern of lung disease associated with alpha-1 antitrypsin deficiency. Arch Intern Med 1968; 122 : $254-257$

82 Guest PJ, Hansell DM. High resolution computed tomography (HRCT) in emphysema associated with alpha-1-antitrypsin deficiency. Clin Radiol 1992; 45: 260-266

${ }^{83}$ Beinert T, Brand P, Behr J et al. Peripheral airspace dimensions in patients with COPD. Chest 1995; 108: $998-1003$

${ }^{84}$ Schwaiblmair M, Beinert T, Seemann M et al. Relations between cardiopulmonary exercise testing and quantitative high-resolution computed tomography associated in patients with alpha-1-antitrypsin deficiency. Eur J Med Res 1998; 3: 527-532

${ }^{85}$ Stein PD, Leu JD, Welch MH et al. Pathophysiology of the pulmonary circulation in emphysema associated with alpha-1-antitrypsin deficiency. Circulation 1971; 43: 227-239 
${ }^{86}$ Miller RR, Muller NL, Vedal S et al. Limitations of computed tomography in the assessment of emphysema. Am Rev Respir Dis 1989; 139: 980-983

${ }^{87}$ King MA, Stone JA, Diaz PT et al. Alpha 1-antitrypsin deficiency: evaluation of bronchiectasis with CT. Radiology 1996; 199: 137-141

${ }^{88}$ Cuvelier A, Muir JF, Hellot MF et al. Distribution of alpha-1-antitrypsin alleles in patients with bronchiectasis. Chest 2000; 117: 415-419

${ }^{89}$ Muller NL, Staples CA, Miller RR et al. "Density mask": an objective method to quantitate emphysema using computed tomography. Chest 1988; 94: $782-787$

${ }^{90}$ Gould GA, MacNee W, McLean A et al. CT measurements of lung density in life can quantitate distal airspace enlargement - an essential defining feature of human emphysema. Am Rev Respir Dis 1988; 137: $380-392$

91 Zagers H, Vrooman HA, Aarts NJM et al. Assessment of the progression of emphysema by quantitative analysis of spirometrically gated computed tomography images. Invest Radiol 1996; 31: 761 - 767

${ }^{92}$ Jamadar DA, Kazerooni EA, Marinez EJ et al. Semi-quantitative ventilation/perfusion scintigraphy and single-photon emission tomography for review and evaluation of lung volume reduction surgery candidates: description and prediction of clinical outcome. Eur J Nucl Med 1999; 26: $734-742$

93 Salzman SH. Can CT measurement of emphysema severity aid patient selection for lung volume reduction surgery? Chest 2000; 118: $1231-1232$

${ }^{94}$ Satoh K, Takahashi K, Kobayashi T et al. The Usefulness of 99mTcTechnegas scintigraphy for diagnosing pulmonary impairment caused by pulmonary emphysema. Acta Med Okayama 1998; 52: 97-103

95 Thurnheer R, Engel H, Weder W et al. Role of lung perfusion scintigraphy in relation to chest computed tomography and pulmonary function in the reviewuation of candidates for lung volume reduction surgery. Am J Respir Crit Care Med 1999; 159: 301 - 310

${ }^{96}$ Dirksen A, Holstein-Rathlou N-H, Madsen F et al. Long range correlations of serial $\mathrm{FEV}_{1}$ measurements in emphysematous and normal subjects. J Appl Physiol 1998; 85: 259-265

${ }^{97}$ Enright PL, Connett JE, Kanner RE et al. Spirometry in the Lung Health Study. II. Determinants of short-term intraindividual variability. Am J Respir Crit Care Med 1995; 151: 406-411

98 Biernacki W, Ryan M, MacNee W et al. Can the quantitative CT scan detect progression of emphysema? [abstract]. Am Rev Respir Dis 1989; 131: A120

${ }^{99}$ Flenley DC. Diagnosis and follow-up of emphysema. Eur Respir J Suppl 1998; 9: 5s-8s

100 Robinson PJ, Kreel L. Pulmonary tissue attenuation with computed tomography: comparison of inspiration and expiration scans. J Comput Assist Tomogr 1979; 3: 740-748

101 Rosenblum LJ, Bauceri RA, Wellenstein DE et al. Density patterns in the normal lung as determined by computed tomography. Radiology 1980; 137: 409-416

102 Kauczor HU, Heussel CP, Fischer B et al. Assessment of lung volumes using helical CT at inspiration and expiration: comparison with pulmonary function tests. AJR Am J Roentgenol 1998; 171: 1091 - 1095

${ }^{103}$ Kinsella M, Muller NL, Abboud RT et al. Quantitation of emphysema by computed tomography using a "density mask" program and correlation with pulmonary function tests. Chest 1998; 97: 315-321

104 Perhoma M, Jauhianinen J, Lahde S et al. CT lung densitometry in assessing intralobular air content: an experimental and clinical study. Acta Radiol 2000; 41: $242-248$

${ }^{105}$ Levant MN, Bass H, Anthonisen N et al. Microvascular circulation of the lungs in emphysema: correlation of results obtained with roentgenologic and radioactive-isotope techniques. J Can Assoc Radiol 1968; 19: $130-134$

106 Kalender WA, Fichte H, Bautz W et al. Semiautomatic review procedures for quantitative CT of the lung. J Comput Assist Tomogr 1991; 15: $248-255$

${ }^{107}$ Lamers RJ, Thelissen GR, Kessels AG et al. Chronic obstructive pulmonary disease: review and evaluation with spirometrically controlled CT lung densitometry. Radiology 1994; 193: 109-113

${ }^{108}$ Lamers RJ, Kemerink GJ, Drent M et al. Reproducibility of spirometrically controlled CT lung densitometry in a clinical setting. Eur Respir J 1998; $11: 942-945$

${ }^{109}$ Kalender WA, Rienmuller R, Seissler W et al. Measurement of pulmonary parenchymal attenuation: use of spirometric gating with quantitative CT. Radiology 1990; 175: 265-268
${ }^{110}$ Kohz P, Stabler A, Beinert T et al. Reproducibility of quantitative, spirometrically controlled CT. Radiology 1995; 197: 539-542

111 Dirksen A, Friis M, Olesen KP et al. Progress of emphysema in severe $\alpha-1$ antitrypsin deficiency as assessed by annual CT. Acta Radiol 1997; 38: 826-832

112 Dirksen A, Dijkman JH, Madsen F et al. A randomized clinical trial of $\alpha-1$ antitrypsin augmentation therapy. Am J Respir Crit Care Med 1999; 160: 1468 - 1472

113 Soejima K, Yamaguchi K, Kohda E et al. Longitudinal follow-up study of smoking-induced lung density changes by high-resolution computed tomography. Am J Respir Crit Care Med 2000; 161: $1264-1273$

114 Gevenois PA, Scillia P, de Maertelaer V et al. The effects of age, sex, lung size and hyperinflation on CT lung densitometry. AJR Am J Roentgenol 1996; 167: 1169-1173

115 Hedlund LW, Vock P, Effmann EL. Computed tomography of the lung: densitometric studies. Radiol Clin North Am 1983; 21: 775 - 788

116 Gould GA, Redpath AT, Ryan M et al. Lung CT density correlates with measurements of airflow limitation and the diffusing capacity. Eur Respir J 1991; 4: 141 - 146

117 Stoel BC, Vrooman HA, Stolk J et al. Sources of error in lung densitometry with CT. Invest Radiol 1999; 34: 303-309

118 Dirksen A. Personal communication 2001

${ }^{119}$ Mishima M, Hirai T, Jin Z et al. Standardization of low attenuation area versus total lung area in chest X-ray $\mathrm{CT}$ as an indicator of chronic pulmonary emphysema. Front Med Biol Eng 1997; 8: 79-86

120 Rosenbloom J, Campbell EJ, Mumford R et al. Biochemical/immunological markers of emphysema. Ann NY Acad Sci 1991; 624 (Suppl): $7-12$

${ }^{121}$ Weitz J. Development and application of assays for elastase-specific fibrinogen fragments. Ann NY Acad Sci 1991; 624: 154-167

122 Fleming TR, DeMets DL. Surrogate end points in clinical trials: are we being misled? Ann Intern Med 1996; 125: 605-613

${ }^{123}$ Viglio S, Zanaboni G, Luisetti M et al. Micellar electrokinetic chromatography for the determination of urinary desmosine and isodesmosine in patients affected by chronic obstructive pulmonary disease. J Chromatogr B Biomed Sci Appl 1998; 714: 87 - 89

${ }^{124}$ Scriver EE, Davidson JM, Sutcliffe MC et al. Comparison of elastin peptide concentrations in body fluids from healthy volunteers, smokers and patients with chronic obstructive pulmonary disease. Am Rev Respir Dis 1992; 145: 762 - 766

125 Gottlieb DF, Stone PJ, Sparrow D et al. Urinary desmosine excretion in smokers with and without rapid decline of lung function: the Normative Aging Study. Am J Respir Crit Care Med 1996; 154: 1290 - 1295

${ }^{126}$ Stone PJ, Morris III TA, Franzblau C et al. Preliminary evidence that augmentation therapy diminishes degradation of cross-linked elastin in $\alpha-1$ antitrypsin deficient humans. Respiration (Herrlisheim) 1995; 62: $76-79$

${ }^{127}$ Gottlieb DJ, Luisetti M, Stone PJ et al. Short-term supplementation therapy does not affect elastin degradation in severe AAT deficiency. Am J Respir Crit Care Med 2000; 162: 2069-2072

128 Seersholm N, Kok-Jensen A, Dirksen A. Decline in FEV1 among patients with severe hereditary $\alpha-1$ antitrypsin deficiency type PiZ. Am J Respir Crit Care Med 1995; 152: 1922 - 1925

${ }^{129}$ Hutchinson DCS. Natural history of alpha-1-protease inhibitory deficiency. Am J Med 1988; 84 (Suppl 6A): 3-12

130 Buist AS, Burrows B, Eriksson S et al. The natural history of air-flow obstruction in PiZ emphysema. Am Rev Respir Dis 1982; 127: S43-S50

131 Piitulainen E, Eriksson S. Decline in $\mathrm{FEV}_{1}$ related to smoking status in individuals with severe $\alpha-1$ antitrypsin deficiency (PI*ZZ). Eur Respir J 1999; 13: $247-251$

132 Piitulainen E, Torning G, Eriksson S. Effect of age and occupational exposure to airway irritants on lung function in non-smoking individuals with $\alpha-1$ antitrypsin deficiency (Pi*ZZ). Thorax 1997; 52: $244-248$

133 Piitulainen E, Torning G, Eriksson S. Environmental correlates of impaired lung function in non-smokers with severe $\alpha$ - 1 antitrypsin deficiency (Pi*ZZ). Thorax 1998; 53: 939-943

${ }^{134}$ Sveger T, Piitulainen E, Arborealius Jr M. Clinical features and lung function in 18-year old adolescents with $\alpha-1$ antitrypsin deficiency. Acta Paediatr 1995; 84: 815-816

135 Seersholm N, Kok-Jensen A, Dirksen A. Survival of patients with severe $\alpha-1$ antitrypsin deficiency with special reference to non-index cases. Thorax 1994; 49: 695-698 
${ }^{136}$ Seersholm N, Kok-Jensen A. Clinical features and prognosis of lifetime non-smokers with severe $\alpha-1$ antitrypsin deficiency. Thorax 1998; 53: $265-268$

137 Alpha-1-Antitrypsin Deficiency Registry Study Group. Survival and $\mathrm{FEV}_{1}$ decline in individuals with severe deficiency of $\alpha-1$ antitrypsin. Am J Respir Crit Care Med 1998; 158: 49-59

138 Mayer AS, Stoller JK, Bartelson BB et al. Occupational exposure risks in individuals with PI*ZZ $\alpha-1$ antitrypsin deficiency. Am J Respir Crit Care Med 2000; 161: 1-6

${ }^{139}$ Sveger T, Piitulainen E, Arborelius Jr M. Lung function in adolescents with alpha-1-antitrypsin deficiency. Acta Paediatr 1994; 83: $1170-1193$

140 Seersholm N, Kok-Jensen A. Survival in relation to lung function and smoking cessation of patients with severe hereditary $\alpha-1$ antitrypsin deficiency. Am J Respir Crit Care Med 1995; 151: 369- 373

141 Tobin MJ, Cook PJ, Hutchison DC. Alpha-1-antitrypsin deficiency: the clinical and physiological features of pulmonary emphysema in subjects homozygous for Pi-type-Z. A survey by the British Thoracic Association. Br J Dis Chest 1983; 77: 14-27

142 Silverman EK, Province MA, Campbell EJ et al. Variability of pulmonary function in $\alpha-1$ antitrypsin deficiency: residual family resemblance beyond the effect of the Pi locus. Hum Hered 1998; 40: $340-355$

${ }^{143}$ Silverman EK, Province MA, Rao DC et al. A family study of the variability of pulmonary function in $\alpha-1$ antitrypsin deficiency: quantitative phenotypes. Am Rev Respir Dis 1990; 142: 1015 - 1021

${ }^{144}$ Niggemann B, Albani M. Bronchial asthma and homozygous $\alpha-1$ antitrypsin deficiency ( $\mathrm{Pi}^{*} \mathrm{ZZ}$ ) in three members of a family. Klin Padiatr 1989; 201: $412-415$

${ }^{145}$ Hutchison DC, Tobin MJ, Cooper D et al. Longitudinal studies in $\alpha-1$ antitrypsin deficiency: a survey by the British Thoracic Society. In: Taylor JC, Mittman C (eds.). Pulmonary emphysema and proteolysis. Orlando, FL: Academic Press, 1987

${ }^{146}$ Buist AS, Burrows B, Eriksson S et al. The natural history of air-flow obstruction in PiZ emphysema: report of an NHLBI workshop. Am Rev Respir Dis 1983; 127: S43-S45

147 Janus ED, Phillips NT, Carrell RW. Smoking, lung function and $\alpha-1$ antitrypsin deficiency. Lancet 1985; 1: $152-154$

148 Rodriguez-Cintron W, Guntupalli K, Fraire AE. Bronchiectasis and homozygous ( $\left.\mathrm{Pi}^{*} \mathrm{ZZ}\right) \alpha-1$ antitrypsin deficiency in a young man. Thorax 1995; 50: $424-425$

${ }^{149}$ Mazodier P, Elzouki AN, Segelmark M et al. Systemic necrotizing vasculitides in severe $\alpha-1$ antitrypsin deficiency. Q J Med 1996; 89: 599-611

${ }^{150}$ Hendrick SJ, Silverman AK, Solomon AR et al. Alpha-1-antitrypsin deficiency associated with panniculitis. J Am Acad Dermatol 1988; 18: 684-692

151 O'Riordan K, Blei A, Rao MS et al. Alpha-1-antitrypsin deficiency-associated panniculitis: resolution with intravenous $\alpha-1$ antitrypsin administration and liver transplantation. Transplantation 1997; 63: 480-482

152 Fortin PR, Fraser RS, Watts CS et al. Alpha-1-antitrypsin deficiency and systemic necrotizing vasculitis. J Rheumatl 1991; 18: 1613-1616

153 Frederick WG, Enriquez R, Bookbinder MJ. Peripheral neuropathy associated with $\alpha-1$ antitrypsin deficiency. Arch Neurol 1990; 47: $233-235$

${ }^{154}$ Schievink WI, Puumala MR, Meyer FB et al. Giant intracranial aneurysm and fibromuscular dysplasia in an adolescent with $\alpha-1$ antitrypsin deficiency. J Neurosurg 1996; 85: 503-506

155 St Jean P, Hart B, Webster M et al. Alpha-1-antitrypsin deficiency in aneurysmal disease. Hum Hered 1996; 46: 92 - 97

${ }^{156}$ Dowd SK, Rodgers GC, Callen JP. Effective treatment with $\alpha-1$ protease inhibitor of chronic cutaneous vasculitis associated with $\alpha-1$ antitrypsin deficiency. J Am Acad Dermatol 1995; 33: 913 - 916

${ }^{157}$ Edmonds BK, Hodge JA, Rietschel RL. Alpha-1-antitrypsin deficiencyassociated panniculitis: case report and review of the literature. Pediatr Dermatol 1991; 8: 296-299

158 Irvine C, Neild V, Stephens C et al. Case reports: alpha-1-antitrypsin deficiency panniculitis. J R Soc Med 1990; 83: 743 -744

159 Kueppers F, Donhardt A. Obstructive lung disease in heterozygotes for $\alpha-1$ antitrypsin deficiency. Ann Intern Med 1974; 80: 209-212

160 Mittman C, Lieberman J, Rumsfeld J. Prevalence of abnormal protease inhibitor phenotypes in patients with chronic obstructive lung disease. Am Rev Respir Dis 1974; 109: 295-296
${ }^{161}$ Barnett TB, Gottovi D, Johnson AM. Protease inhibitors in chronic obstructive pulmonary disease. Am Rev Respir Dis 1975; 111: 587-593

162 Cox DW, Hoeppner VH, Levison H. Protease inhibitors in patients with chronic obstructive pulmonary disease: the $\alpha-1$ antitrypsin heterozygote controversy. Am Rev Respir Dis 1976; 113: 601 -606

163 Shigeoka JW, Hall WJ, Hyde RW et al. The prevalence of $\alpha-1$ antitrypsin heterozygotes (PiMZ) in patients with obstructive pulmonary disease. Am Rev Respir Dis 1976; 114: 1077 - 1084

${ }^{164}$ Lochon BDV, Lochon C, Fournier M et al. Pan-lobular emphysema: relationship with serum $\alpha-1$ antitrypsin levels, Pi phenotype and the HLA system [author's translation]. Nouv Presse Med 1978; 7: $1167-1170$

165 Stockley RA. Alpha-1-antitrypsin phenotypes in cor pulmonale due to chronic obstructive airways disease. QJ Med 1979; 48: 419-428

${ }^{166}$ Bartmann K, Fooke-Achterrath M, Koch G et al. Heterozygosity in the Pi-system as a pathogenetic cofactor in chronic obstructive pulmonary disease (COPD). Eur J Respir Dis 1985; 66: 284-296

${ }^{167}$ Klasen EC, Biemond I, Laros CD. $\alpha-1$ antitrypsin deficiency and the flaccid lung syndrome: the heterozygote controversy. Clin Genet 1986; 29: $211-215$

168 Lieberman J, Winter B, Sastre A. $\alpha-1$ antitrypsin Pi-types in 965 COPD patients. Chest 1986; 89: 370-373

169 Fagerhol MK, Hauge HE. Serum Pi types in patients with pulmonary disease. Acta Allergol 1969; 24: 107-109

170 Welch MH, Reinecke ME, Hammarsten JF et al. $\alpha-1$ antitrypsin deficiency in pulmonary disease; the significance of intermediate levels. Ann Intern Med 1969; 71: 533-537

171 Talamo RC, Langley CE, Levine BW et al. Genetic vs. quantitative analysis of serum $\alpha-1$ antitrypsin. N Engl J Med 1972; 287: 1067-1069

172 Gerblich AA, Kleinerman J, Rynbrandt DJ et al. Pi-Z phenotypes in a pulmonary clinic: their prevalence and physiologic state. Am J Clin Pathol 1978; 69: 509-513

173 Ostrow DW, Cherniak RM. The mechanical properties of the lungs in intermediate deficiency of $\alpha-1$ antitrypsin. Am Rev Respir Dis 1972; 106: $377-383$

174 Cooper DM, Hoeppner V, Cox D et al. Lung function in $\alpha-1$ antitrypsin heterozygotes (Pi type MZ). Am Rev Respir Dis 1974; 110: 708 - 715

175 Johnson TF, Reisman RE, Arbesman CE et al. Obstructive airway disease associated with heterozygous $\alpha-1$ antitrypsin deficiency. J Allergy Clin Immunol 1976; 58: 69-75

176 Madison R, Mittman C, Afifi AA et al. Risk factors for obstructive lung disease. Am Rev Respir Dis 1981; 124: 149-153

177 Seersholm N, Wilcke JT, Kok-Jensen A et al. Risk of hospital admission for obstructive pulmonary disease in $\alpha-1$ antitrypsin heterozygotes of phenotype PiMZ. Am J Respir Crit Care Med 2000; 161: 81 - 84

178 Webb DR, Hyde RW, Schwartz RH et al. Serum $\alpha-1$ antitrypsin variants: prevalence and clinical spirometry. Am Rev Respir Dis 1973; 108: 918 - 925

179 Gelb AF, Klein E, Lieberman J. Pulmonary function in nonsmoking subjects with $\alpha-1$ antitrypsin deficiency (MZ phenotype). Am J Med 1977; 62: $93-98$

${ }^{180}$ Morse JO, Lebowitz MD, Knudson RJ et al. Relation of protease inhibitor phenotypes to obstructive lung diseases in a community. N Engl J Med 1977; 296: $1190-1194$

181 Tattersall SF, Pereira RP, Hunter D et al. Lung distensibility and airway function in intermediate $\alpha-1$ antitrypsin deficiency (PiMZ). Thorax 1979; 34: $637-646$

182 Cole RB, Nevin NC, Blundell G et al. Relation of $\alpha$ - 1 antitrypsin phenotype to the performance of pulmonary function tests and to the prevalence of respiratory illness in a working population. Thorax 1976; 31: $149-157$

183 Buist AS, Sexton GJ, Azzam AM et al. Pulmonary function in heterozygotes for $\alpha-1$ antitrypsin deficiency: a case-control study. Am Rev Respir Dis 1979; 120: 759 - 766

${ }^{184}$ McDonagh DJ, Nathan SP, Knudsen RJ et al. Assessment of alpha1 -antitrypsin deficiency heterozygosity as a risk factor in the etiology of emphysema: physiological comparison of adult normal and heterozygous protease inhibitor phenotype subjects from a random population. J Clin Invest 1979; 63: 299-309

185 Horton FOD, Mackenthun AV, Anderson Jr PS et al. $\alpha-1$ antitrypsin heterozygotes (PI type MZ): a longitudinal study of the risk of development of chronic air flow limitation. Chest 1980; 77 (Suppl 2): $261-264$ 
186 Bruce RM, Cohen BH, Diamond EL et al. Collabortive study to assess risk of lung disease in PiMZ phenotype subjects. Am Rev Respir Dis 1984; 130: $386-390$

187 Klayton R, Fallat R, Cohen AB. Determinants of chronic obstructive pulmonary disease in patients with intermediate levels of $\alpha-1$ antitrypsin. Am Rev Respir Dis 1975; 112: 71 - 75

188 Tarjan E, Magyar P, Vaczi Z et al. Longitudinal lung function study in heterozygous PiMZ phenotype subjects. Eur Respir J 1994; 7: $2199-2204$

189 Sandford AJ, Weir TO, Spinell JJ et al. Z and S mutations of the $\alpha-1$ antitrypsin gene and the role of COPD. Am J Respir Cell Mol Biol 1999; 20: $287-291$

190 Larsson C, Eriksson S, Dirksen H. Smoking and intermediate $\alpha$ - 1 antitrypsin deficiency and lung function in middle-aged men. BMJ 1977; 2: $922-925$

191 Vance JC, Hall WJ, Schwartz RH et al. Heterozygous $\alpha-1$ antitrypsin deficiency and respiratory function in children. Pediatrics 1977; 60: $263-272$

192 Fallat RJ, Powell MR, Kueppers F et al. 133-Xe ventilatory studies in

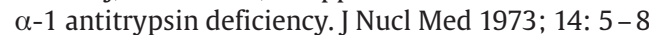

193 Eriksson S, Moestrup T, Hagerstrand I. Liver, lung and malignant disease in heterozygous (PiMZ) $\alpha-1$ antitrypsin deficiency. Acta Med Scand 1975; 198: $243-247$

194 Sutinen S, Koistinen J, Paakko P. A necropsy study of Pi phenotypes, emphysema and smoking. Acta Pathol Microbiol Immunol Scand (A) 1985; 93: $183-188$

195 Silverman EK, Province MA, Campbell EJ et al. Family study of $\alpha-1$ antitrypsin deficiency: effects of cigarette smoking, measured genotype, and their interaction on pulmonary function and biochemical traits. Genet Epidemiol 1992; 9: 317 - 331

196 Eriksson S, Lindell SE, Wiberg R. Effects of smoking and intermediate $\alpha-1$ antitrypsin deficiency (PiMZ) on lung function. Eur J Respir Dis 1985; 67: 279-285

197 Sandford AJ, Chagani T, Weir TD et al. Susceptibility genes for rapid decline of lung function in the Lung Health Study. Am J Respir Crit Care Med 2001; 163: 469-473

198 Morse JO, Lebowitz MD, Knudson RJ et al. A community study of the relation of $\alpha-1$ antitrypsin levels to obstructive lung disease. $\mathrm{N}$ Engl J Med 1975; 292: $278-281$

199 Hall WJ, Hyde RW, Schwartz RH et al. Pulmonary abnormalities in intermediate $\alpha-1$ antitrypsin deficiency. J Clin Invest 1976; 58: 1069 - 1077

200 Gulsvik A, Fagerhol MK. $\alpha-1$ antitrypsin phenotypes and obstructive lung disease in the city of Oslo. Scand J Respir Dis 1979; 60: 267 - 274

201 Cole RB, Nevin NC, Blundell G et al. Relation of alpha-1-antitrypsin phenotype to the performance of pulmonary function tests and to the prevalence of respiratory illness in a working population. Thorax 1976; 31: 149- 157

202 Brandslund I, Lund ED, Sigsgaard T. Is a low serum concentration of $\alpha-1$ antitrypsin associated with an increased susceptibility for byssinosis in cotton mill workers? Considerations regarding analytical quality requirements and economical consequences. Ups J Med Sci 1993; 98: 299-310

203 Sigsgaard T, Brandslund I, Rasmussen JB et al. Low normal $\alpha-1$ antitrypsin serum concentrations and MZ-phenotype are associated with byssinosis and familial allergy in cotton mill workers. Pharmacogenetics 1994; 4: 135-141

${ }^{204}$ Chan-Yeung M, Ashley MJ, Corey P et al. Pi phenotypes and the prevalence of chest symptoms and lung function abnormalities in workers employed in dusty industries. Am Rev Respir Dis 1978; 117: 239- 245

205 Stjernberg N, Beckman G, Beckman L et al. Alpha-1-antitrypsin types and pulmonary disease among employees at a sulphite pulp factory in northern Sweden. Hum Hered 1984; 34: 337 - 342

206 Horne SL, Tennent RK, Cockcroft DW et al. Pulmonary function in PiM and MZ grainworkers. Chest 1986; 89: 795 - 799

207 Pierre F, Pham QT, Mur JM et al. Respiratory symptoms and pulmonary function in 871 miners according to Pi phenotype: a longitudinal study. Eur J Epidemiol 1988; 4: 39-44

208 Hyde JS, Werner P, Kumar CM et al. Protease inhibitor variants in children and young adults with chronic asthma. Ann Allergy 1979; 43: $8-13$

209 Townley RG, Southard JG, Radford P et al. Association of MS Pi phenotype with airway hyperresponsiveness. Chest 1990; 98: 594 - 599

210 Schwartz RH, Van Ess JD, Johnstone DE et al. Alpha-1 antitrypsin in childhood asthma. J Allergy Clin Immunol 1977; 59: 31 - 34
211 Kabiraj MU, Simonsson BG, Groth S et al. Bronchial reactivity, smoking and $\alpha-1$ antitrypsin: a population-based study of middle-aged men. Am Rev Respir Dis 1982; 126: 864-869

212 Lindmark B, Svenonius E, Eriksson S. Heterozygous alpha-1-antichymotrypsin and PiZ $\alpha-1$ antitrypsin deficiency: prevalence and clinical spectrum in asthmatic children. Allergy 1990; 45: 197-203

213 Prados M, Monteseirin FJ, Carranco MI et al. Phenotypes of $\alpha-1$ antitrypsin in intrinsic asthma and ASA-triad patients. Allergol Immunopathol Madr 1995; 23: 24-28

214 Maune S, Rath NF, Gorogh T et al. Genetic disposition to chronic polypoid sinusitis and alpha-1-proteinase inhibitor deficiency types. HNO 1995; 43: $537-539$

215 Portenko GM. Alpha-1-antitrypsin phenotypes in healthy persons and patients with polypous rhinosinusitis. Vestn Otorinolaringol 1989; $3: 24-27$

216 Horne SL, Tennent R, Lovegrove A et al. Pi type MZ and an increased risk of pneumonia. Clin Invest Med 1984; 7: 85-88

217 Geddes DM, Webley M, Brewerton DA et al. Alpha-1-antitrypsin phenotypes in fibrosing alveolitis and rheumatoid arthritis. Lancet 1977; 2: $1049-1051$

218 Turino GM, Barker AF, Brantly ML et al. Clinical features of individuals with the Pi*SZ phenotype of $\alpha-1$ antitrypsin deficiency. Am J Respir Crit Care Med 1996; 154: 1718 - 1725

${ }^{219}$ Hutchinson DCS, Tobin MJ, Cook PLJ. Alpha-1 antitrypsin deficiency: clinical and physiologic features in heterozygotes of Pi-type SZ. A survey by the British Thoracic Association. Br J Dis Chest 1983; 77: $28-34$

${ }^{220}$ Larsson C, Dirksen H, Sundstrom G et al. Lung function studies in asymptomatic individuals with moderately ( $\mathrm{Pi}^{*} \mathrm{SZ}$ ) and severely ( $\mathrm{Pi}^{*} \mathrm{Z}$ ) reduced levels of $\alpha-1$ antitrypsin. Scand J Respir Dis 1976; 57 : $267-280$

221 Seersholm N, Dirksen A, Kok-Jensen A. Airways obstruction and twoyear survival in patients with severe $\alpha-1$ antitrypsin deficiency. Eur Respir J 1994; 7: 1985-1987

222 Wu MC, Eriksson S. Lung function, smoking and survival in severe $\alpha-1$ antitrypsin deficiency, Pi*ZZ. J Clin Epidemiol 1988; 41: 1157 - 1165

${ }^{223}$ Hutchison DCS. Epidemiology of alpha-1-protease inhibitor deficiency. Eur Respir J 1990; 9: 29S - 34S

224 Evald T, Dirksen A, Keittelmann S et al. Decline in pulmonary function in patients with $\alpha-1$ antitrypsin deficiency. Lung 1990; 168: 579 - 585

225 Lung Health Study. Effects of smoking intervention and the use of an inhaled anticholinergic bronchodilator on the rate of decline of $\mathrm{FEV}_{1}$. JAMA 1994; 272: 1497 - 1505

226 Wilcke JT, Dirksen A. The effect of inhaled glucocorticosteroids in emphysema due to $\alpha-1$ antitrypsin deficiency. Respir Med 1997; 9: $275-279$

227 Kojalima H, Geddes DM. Erythromycin in diffuse panbronchiolitis. Thorax 1997; 52: 915 - 918

228 McDonald CF, Blyth CM, Lazarus MD et al. Exertional oxygen of limited benefit in patients with chronic obstructive pulmonary disease and mild hypoxemia. Am J Respir Crit Care Med 1995; 152: $1616-1619$

${ }^{229}$ Rooyackers JM, Dekhuijzen PN, van Herwaarden CL et al. Training with supplemental oxygen in patients with COPD and hypoxaemia at peak exercise. Eur Respir J 1997; 10: 1276-1284

230 McEvoy CE, Ensrud KE, Bender E et al. Association between corticosteroid use and vertebral fractures in older men with chronic obstructive pulmonary disease. Am J Respir Crit Care Med 1998; 157: 704-709

231 Renfroe KL. Effect of progressive relaxation on dyspnea and state of anxiety in patients with chronic obstructive pulmonary disease. Heart Lung 1988; 17: 408-413

232 Karajgi B, Rifkin A, Doddi S et al. The prevalence of anxiety disorders in patients with chronic obstructive pulmonary disease. Am J Psychiatry 1990; 148: 1583 - 1585

233 Kent JM, Coplan JD, Gorman JM. Clinical utility of the selective serotonin reuptake inhibitors in the spectrum of anxiety. Biol Psychiatry 1998; 44: $812-814$

${ }^{234}$ American Thoracic Society (Medical Section of the American Lung Association). Pulmonary rehabilitation - 1999. Am J Respir Crit Care Med 1999; 159: 1666-1682

${ }^{235}$ Hunter AB, Carey MA, Larsh HW. The nutritional status of patients with chronic obstructive pulmonary disease. Am Rev Respir Dis 1981; 124: $376-378$ 
${ }^{236}$ Donohue M, Rogers RM, Wilson DO. Oxygen consumption of the respiratory muscles in normal and malnourished patients with chronic obstructive pulmonary disease. Am Rev Respir Dis 1989; 140: $385-391$

237 Schwaiblmaier M, Vogelmeier C. Alpha-1-antitrypsin: hope on the horizon for emphysema sufferers. Drug Ther (NY) 1998; 12: 429-440

${ }^{238}$ Gadek JE, Zimmermann RL, Fells GA et al. Antielastases of the human alveolar structures: implications for the protease-antiprotease theory of emphysema. J Clin Invest 1981; 68: 889-898

${ }^{239}$ Wewers MD, Casolaro MA, Sellers SE et al. Replacement therapy for $\alpha-1$ antitrypsin deficiency associated with emphysema. N Engl J Med 1987; 316: 1055 - 1062

${ }^{240}$ Hubbard RC, Sellers SE, Caerski DB et al. Biochemical efficacy and safety of monthly augmentation therapy for $\alpha-1$ antitrypsin deficiency. JAMA 1988; 260: 651 - 652

${ }^{241}$ Stoller JK, Rouhani F, Brantly M et al. Biochemical efficacy and safety of a new pooled human plasma alpha 1-antitrypsin, Respitin. Chest 2002; 122: 66-74

${ }^{242}$ Schmidt EW, Rasche B, Ulmer WT et al. Replacement therapy for alpha-1-protease inhibitor deficiency in PiZ subjects with chronic obstructive lung disease. Am J Med 1988; 84: 63-69

${ }^{243}$ American Thoracic Society. Guidelines for the approach to the patient with severe hereditary alpha1-antitrypsin deficiency. Am Rev Respir Dis 1989; 140: $1494-1497$

${ }^{244}$ Ad Hoc Committee on Alpha1-Antitrypsin Replacement Therapy of the Standards Committee, Canadian Thoracic Society. Current status of alpha1-antitrypsin replacement therapy: recommendations for the management of patients with severe hereditary deficiency. CMAJ 1992; 146: 841 - 844

245 Abboud RT, Ford GT, Chapman KR et al. Alpha1-antitrypsin deficiency: a position statement of the Canadian Thoracic Society. Can Respir J 2001; 8: $81-88$

${ }^{246}$ Seersholm N, Wencker M, Banik N et al. Does $\alpha-1$ antitrypsin augmentation therapy slow the annual decline in $\mathrm{FEV}_{1}$ in patients with severe hereditary $\alpha-1$ antitrypsin deficiency? Eur Respir J 1997; 10: 2260-2263

247 Wencker M, Banik N, Buhl R et al. Long-term treatment of $\alpha-1$ antitrypsin deficiency-related pulmonary emphysema with human $\alpha-1$ antitrypsin. Eur Respir J 1998; 11: 428 -433

248 Meyer FJ, Wencker M, Teschler $\mathrm{H}$ et al. Acute allergic reaction and demonstration of specific IgE antibodies against alpha-1-protease inhibitor. Eur Respir J 1998; 12: 996-997

${ }^{249}$ Hubbard RC, McElvaney NG, Sellers SE et al. Recombinant DNA-produced $\alpha-1$ antitrypsin inhibitor administered to dogs and sheep. J Clin Invest 1989; 84: 1349-1354

250 Wencker M, Banik N, Hotze LA et al. Relationship of pulmonary deposition of $\alpha-1-\mathrm{Pi}$ aerosol and lung function in patients with $\alpha-1$-Pi deficiency [abstract]. Am J Respir Crit Care Med 1998; 154: A400

251 Birrer P, McElvaney NG, Gillissen A et al. Intravenous administration of recombinant secretory leukoprotease inhibitor as strategy to augment antineutrophil elastase protective screen of the lung. J Appl Physiol 1992; 73: 317-323

${ }^{252}$ Cherfas J. Sheep to produce $\alpha-1$ antitrypsin. BMJ 1992; 304: 527

${ }^{253}$ Hosenpud JD, Novick RJ, Breen TJ et al. The Registry of the International Society for Heart and Lung Transplantation: twelfth official report. J Heart Lung Transplant 1995; 14: $805-815$

254 Levine SM, Anzueto A, Peters JI et al. Medium term functional results of single-lung transplantation for end stage obstructive lung disease. Am J Respir Crit Care Med 1994; 150: 398-402

${ }^{255}$ King MB, Campbell EJ, Gray BH et al. The proteinase-antiproteinase balance in alpha-1-proteinase inhibitor-deficient lung transplant recipients. Am J Respir Crit Care Med 1994; 149: 966 - 971

256 Trulock E. Lung transplantation for $\alpha-1$ antitrypsin deficiency emphysema. Chest 1996; 110: 248-294

257 Gaissert HA, Trulock EP, Cooper JD et al. Comparison of early functional results after volume reduction or lung transplantation for chronic obstructive pulmonary disease. J Thorac Cardiovasc Surg 1996; 111: 296-306

258 Cassina PC, Teschler H, Konietzko $\mathrm{N}$ et al. Two-year results after lung volume reduction surgery in $\alpha-1$ antitrypsin deficiency versus smoker's emphysema. Eur Respir J 1998; 12: 1028 - 1032

259 Russi EW, Stammberger U, Weder W. Lung volume reduction surgery for emphysema. Eur Respir J 1997; 10: 208-218
${ }^{260}$ Gelb AF, McKenna RJ, Brenner M et al. Lung function after bilateral lower lobe lung volume reduction surgery for 1 antitrypsin emphysema. Eur Respir J 1999; 14: 92 - 933

${ }^{261}$ Teschler H, Stamatis G, el-Raouf Farhat AA et al. Effect of surgical lung volume reduction on respiratory muscle function in pulmonary emphysema. Eur Respir J 1995; 9: 1779-1784

262 Cooper JD, Patterson GA, Sundaresan RS et al. Results of 150 consecutive bilateral lung volume reduction procedures in patients with severe emphysema. J Thorac Cardiovasc Surg 1996; 112: 1319-1329

263 Brenner M, Gonzalez X, Jones B et al. Effects of a novel implantable elastomer device for lung volume reduction surgery in a rabbit model of elastase-induced emphysema. Chest 2002; 121: 201 - 209

${ }^{264}$ National Emphysema Treatment Trial Research Group. Patients at high risk of death after lung-volume reduction surgery. N Engl J Med 2001; 345: 1075-1083

${ }^{265}$ Kuller JA, Katz VL, McCoy MC et al. Alpha-1-antitrypsin deficiency and pregnancy. Am J Perinatol 1995; 12: 303 - 305

${ }^{266}$ Atkinson AR. Pregnancy and $\alpha-1$ antitrypsin deficiency. Postgrad Med J 1987; 63: 817-820

267 Geisler CF, Buehler JH, Depp R. $\alpha-1$ antitrypsin deficiency: severe obstructive lung disease and pregnancy. Obstet Gynecol 1977; 49: $31-34$

${ }^{268}$ Schwartz JS, Bencowitz HZ, Moser KM. Air travel hypoxaemia with chronic obstructive pulmonary disease. Ann Intern Med 1984; 100: $473-477$

${ }^{269}$ Berg BW, Dillard TA, Rajagopal KR et al. Oxygen supplementation during air travel in patients with chronic obstructive pulmonary disease. Chest 1992; 101: 638-641

${ }^{270}$ Hall JC, Tarala RA, Hall JL et al. A multivariate analysis of the risk of pulmonary complications after laparotomy. Chest 1991; 99: 923-927

${ }^{271}$ Boris-Lawrie KA, Temin HM. Recent advances in retrovirus technology. Curr Opin Genet Dev 1993; 301: 353-362

272 Garver RI, Chytil A, Courtney M et al. Clonal gene therapy: transplanted mouse fibroblast clones express human $\alpha-1$ antitrypsin gene in vivo. Science 1987; 237: 762 - 764

273 Kolodka TM, Finehold M, Woo SLC. Hepatic gene therapy: efficient retroviral-mediated gene transfer into rat hepatocytes in vivo. Somat Cell Mol Genet 1993; 19: 491 - 497

${ }^{274}$ Curiel D, Stier L, Crystal RG. Gene therapy for $\alpha-1$ antitrypsin deficiency using lymphocytes as vehicles for $\alpha-1$ antitrypsin delivery. Clin Res 1989; 37: 578A

275 Straus SE. Adenovirus infections in humans. In: Ginsberg HS (eds.). The adenoviruses. New York: Plenum Press, 1984: 451-496

${ }^{276}$ Rosenfeld MA, Siegfried N, Yoshimura K et al. Adenovirus-mediated transfer of a recombinant $\alpha-1$ antitrypsin gene to the lung epithelium in vivo. Science 1991; 252: $431-434$

277 Jaffe HA, Danel C, Longenecker G et al. Adenovirus-mediated in vivo gene transfer and expression in normal rat liver. Nat Genet 1992; 1: $368-371$

${ }^{278}$ Setoguchi Y, Jaffe HA, Chu CS et al. Intraperitoneal in vivo gene therapy to deliver alpha- 1 antitrypsin to the systemic circulation. Am J Respir Cell Mol Biol 1994; 10: 369-377

${ }^{279}$ Song SH, Embury J, Laipais PJ et al. Stable therapeutic serum levels of human alpha-1-antitrypsin (AT) after portal vein injection of recombinant adeno-associated virus (rAAV) vectors. Gene Ther 2001; 8 : $1299-1306$

280 Song S, Morgan M, Ellis T et al. Sustained secretion of human alpha-1 antitrypsin from murine muscle transduced with adeno-associated virus vectors. Proc Natl Acad Sci USA 1998; 95: 14384-14388

281 Canonico AE, Conary JT, Meyrick BO et al. Aerosol and intravenous transfection of human $\alpha-1$ antitrypsin gene to lungs of rabbits. Am J Respir Cell Mol Biol 1984; 10: 24-29

282 Michael SI, Curiel DT. Strategies to achieve targeted gene delivery via the receptor-mediated endocytosis pathway. Gene Ther 1994; 1: $223-232$

283 Kren BT, Metz R, Kumar R et al. Gene repair using chimeric RNA/DNA oligonucleotides. Semin Liver Dis 1999; 19: 93 - 104

${ }^{284}$ Cantor JO, Shteyngart B, Cerreta JM et al. The effect of hyaluronan on elastic fiber injury in vitro and elastase-induced airspace enlargement in vivo. Proc Soc Exp Biol Med 2000; 225: 65 - 71

${ }^{285}$ Cantor JO, Cerreta JM, Armand G et al. Aerosolized hyaluronic acid decreased alveolar injury induced by human neutrophil elastase. Proc Soc Exp Biol Med 1998; 217: 471 - 475 
${ }^{286}$ Massaro GD, Massaro D. Retinoic acid treatment partially rescues failed septation in rats and in mice. Am J Physiol Lung Cell Mol Physiol 2000; 278: L955 - L960

${ }^{287}$ Massaro GD, Massaro D. Retinoic acid treatment abrogates elastaseinduced pulmonary emphysema in rats. Nat Med 1997; 3: 675-677

288 McElvaney NG, Hubbard RC, Birrer P et al. Aerosol $\alpha-1$ antitrypsin treatment for cystic fibrosis. Lancet 1991; 337: 392 - 394

289 Sallenave JM, Shulmann J, Crossley J et al. Regulation of secretory leukocyte proteinase inhibitor (SLPI) and elastase-specific inhibitor (ESI/ Elafin) in human airway epithelial cells by cytokines and neutrophilic enzymes. Am J Respir Cell Mol Biol 1994; 11: 733 - 741

290 Stockley RA. The pathogenesis of chronic obstructive lung diseases: implications for therapy. QJ Med 1995; 88: 141-146

${ }^{291}$ Stockley RA, Hill SL, Morrison HM et al. Elastinolytic activity in sputum and its relation to purulence and lung function in patients with bronchiectasis. Thorax 1984; 39: 408-413

292 Sandhaus RA. Elastase may play a central role in the neutrophil migration through connective tissue. In: Taylor JC, Mittman C (eds.). Pulmonary emphysema and proteolysis. Orlando FL: Academic Press, 1997: $227-233$

293 Lomas DA, Stone SR, Llewellyn-Jones C et al. The control of neutrophil chemotaxis of inhibitors of cathepsin-G in chymotrypsin. J Biol Chem 1995; 270: $23437-23443$

${ }^{294}$ Burrows JAJ, Willis LK, Perlmutter DH. Chemical chaperones mediate increased secretion of mutant 1 antitrypsin (1-AT) Z: a potential pharmacological strategy for prevention of liver injury and emphysema in 1-AT. Proc Natl Acad Sci USA 2000; 97: 1796-1801

295 Carrell RW, Lomas DA. Alpha-1 antitrypsin deficiency: a model for conformational diseases. N Engl J Med 2002; 346: 45 -53

${ }^{296}$ Spence WC, Pass K, Murphy PD. A rapid fluorometric assay for newborn screening of $\alpha-1$ antitrypsin followed by phenotyping of deficient specimens by isoelectric focusing. Screening 1994; 3: $23-31$

${ }^{297}$ Morse J, Lebowitz M, Knudson R et al. Relationship of protease inhibitor phenotypes to obstructive lung diseases in a community. N Engl J Med 1977; 196: 1190-1194

${ }^{298}$ Fagerhol MK, Cox DW. The Pi polymorphism: genetic, biochemical and clinical aspects of alpha-1-antitrypsin deficiency. Adv Hum Genet $1981 ; 11: 1-62$

${ }^{299}$ Dati LF, Schumann G, Thomas L et al. Consensus of a group of professional societies and diagnostic companies on guidelines for interim reference ranges for 14 proteins in serum based on the standardization against the IFCC/BCR/CAP reference material (CRM 470). International Federation of Clinical Chemistry, Community Bureau of Reference of the Commission of the European Communities, College of American Pathologists. Eur J Clin Chem Clin Biochem 1996; 34: $517-520$

${ }^{300}$ Horne SL, Chen Y, Cockcroft DW et al. Risk factors for reduced pulmonary function in women: a possible relationship between Pi phenotype, number of children and pulmonary function. Chest 1992; 102: $158-163$

${ }^{301}$ Buist AS, Adams BE, Azzam AH et al. Pulmonary function in young children with alpha-1-antitrypsin deficiency: comparison with matched control subjects. Am Rev Respir Dis 1980; 122: 817-822

302 Sveger T, Mazodier P. Alpha-1-antitrypsin screening of 18-year old men. Thorax 1979; 34: 397-400

${ }^{303}$ Sveger T. Prospective study of children with alpha-1-antitrypsin deficiency: eight-year old follow-up. J Pediatr 1984; 104: 91 - 104
${ }^{304}$ Browne RJ, Mannino DM, Khoury MJ. Alpha-1-antitrypsin deficiency deaths in the United States from 1979-1991: an analysis using multiple-cause mortality data. Chest 1996; 110: 78 - 83

${ }^{305}$ Sveger T, Thelin T, McNeil TF. Young adults with alpha-1-antitrypsin deficiency identified neonatally: their health, knowledge about and adaptation to the high-risk condition. Acta Paediatr 1997; 86: 37-40

${ }^{306}$ Fagerhol MK, Hauge HE. Serum Pi types in patients with pulmonary diseases. Acta Allergol 1969; 24: 107-114

${ }^{307}$ Lieberman J. Heterozygous and homozygous alpha-1-antitrypsin deficiency in patients with pulmonary emphysema. N Engl J Med 1969; 281: $279-284$

${ }^{308}$ Hepper NG, Black LF, Gleich GJ et al. The prevalence of alpha-1-antitrypsin deficiency in selected groups of patients with chronic obstructive lung disease. Mayo Clin Proc 1969; 44: 697-710

${ }^{309}$ Kueppers F, Fallat R, Larson RK. Obstructive lung disease and alpha1 -antitrypsin deficiency gene heterozygosity. Science 1969; 165: 899-901

310 Kueppers F, Miller RD, Gordon $\mathrm{H}$ et al. Familial prevalence of chronic obstructive pulmonary disease in a matched pair study. Am J Med 1977; 63: 336-342

${ }^{311}$ Kueppers F, Black LF. Alpha-1-antitrypsin and its deficiency. Am Rev Respir Dis 1974; 110: 176-194

312 Black L, Kueppers F. Alpha-1-antitrypsin deficiency in nonsmokers. Am Rev Respir Dis 1978; 117: 421 - 428

${ }^{313}$ Eriksson S, Wu MC. Aspects of treatment in alpha- 1 antitrypsin deficiency: insights derived from a Swedish PiZZ series. Eur Respir J 1990; 9: $39 \mathrm{~s}-43 \mathrm{~s}$

314 Miravitlles M, Vidal R, Barros-Tizon JC et al. Usefulness of a national registry of alpha-1-antitrypsin deficiency: the Spanish experience. Respir Med 1998; 92: 1181 - 1187

315 Larson RK, Barman ML, Kueppers F et al. Genetic and environmental determinants of chronic obstructive pulmonary disease. Ann Intern Med 1970; 72: 627-632

${ }^{316}$ Lam S, Abboud RT, Chan-Yeung M et al. Neutrophil elastase and pulmonary function in subjects with intermediate alpha-1-antitrypsin deficiency (MZ phenotype). Am Rev Respir Dis 1979; 119: 941 - 951

317 Khoury MJ, Beaty TH, Newill CA et al. Genetic-environmental interactions in chronic airways obstruction. Int J Epidemiol 1986; 15: $65-72$

318 Mittman C, Barbela T, Lieberman J. Antitrypsin deficiency and abnormal protease inhibitor phenotypes. Arch Environ Health 1973; 27: $201-206$

319 Cooper DM, Hoeppner V, Cox D et al. Lung function in alpha-1-antitrypsin heterozygotes (Pi type MZ). Am Rev Respir Dis 1974; 110: $708-715$

320 de Hamel FA, Carrell RW. Heterozygous alpha-1-antitrypsin deficiency: a longitudinal lung function study. N Z Med J 1981; 94: 407-410

${ }^{321}$ Laros KD, Biemond I, Klasen EC. The flaccid lung syndrome and alpha1-protease inhibitor deficiency. Chest 1988; 93: $831-835$

${ }^{322}$ Hoffmann JJ, Kramps JA, Dijkman JH. Intermediate alpha-1-antitrypsin deficiency in atopic allergy. Clin Allergy 1981; 11: 555-560

${ }^{323}$ Monteseirin MFJ, Hernandez JC, Castano MP et al. Differentiating atopic patients by means of alpha-1-antitrypsin phenotypes. Allergol Immunopathol Madr 1984; 12: 111 - 114

${ }^{324}$ Seersholm H, Kok-Jensen A. Intermediate $\alpha-1$ antitrypsin deficiency PiSZ: a risk factor for emphysema? Respir Med 1998; 92: 241 -245 